Aus aktuellem Anlass

Martin Hellwig*

\title{
Target-Falle oder Empörungsfalle?
}

\author{
Zur deutschen Diskussion über die Europäische Währungsunion
}

https://doi.org/10.1515/pwp-2019-0002

Zusammenfassung: Die deutsche Diskussion über die Europäische Währungsunion steckt in einer Empörungsfalle. Rechtsnormen und Zahlen werden ungenau und missverständlich wiedergegeben, Kausalzusammenhänge werden nicht belegt. Der Begriff des „Target-Kredits“ vermengt volkswirtschaftliche und einzelwirtschaftliche Vorstellungen auf unzulässige Weise und ist analytisch unbrauchbar. Dass die Deutsche Bundesbank in ihrem operativen Geschäft nicht selbständig agiert, wird verdrängt. Eine inhaltliche Auseinandersetzung mit den Aufgaben der Zentralbank fehlt weitgehend. Die Besonderheiten eines deckungslosen Papiergelds werden nicht angemessen berücksichtigt. Die in wiederholten Verlustwarnungen enthaltene Priorisierung fiskalischer Belange ist sachlich verfehlt und ordnungspolitisch gefährlich.

JEL-Klassifikation: E44, E52, E58, F45

Schlüsselwörter: Papiergeld, Vermögenseffekte, Geldpolitik, Friedman-Schwartz-Paradox, Lender of last resort, Europäische Währungsunion, Target-Salden, Finanzkrise, Eurokrise, Vollzuteilung, Notkredite, ANFA, Quantitative easing

\section{Einführung}

Im Juli 2018 schlugen die Wellen der deutschen Empörung über die Europäische Währungsunion wieder hoch. Die so genannte Target-Forderung der Deutschen Bundesbank näherte sich der magischen Zahl von einer Billion Euro. Was für eine Katastrophe, wenn diese Forderung ausfallen würde! Und was für ein „Wahnsinn“, dass man es dazu kommen ließ!' Wieder einmal wurde die Vorstellung be-

1 So zum Beispiel Mayer 2018, Sinn 2018a,b. Dagegen Bofinger 2018, Fratzscher 2018, Hellwig 2018c, Krahnen 2018. Winkler (2018b) gibt einen kritischen Überblick über die Argumente.

*Kontaktperson: Martin Hellwig, Max-Planck-Institut zur Erforschung von Gemeinschaftsgütern, Bonn, E-Mail: hellwig@coll.mpg.de stärkt, die Europäische Währungsunion sei eine Veranstaltung zur Ausbeutung Deutschlands und die Europäische Zentralbank (EZB) sei maßgeblich daran beteiligt. Dass die EZB in Irland und Griechenland aufgrund der dortigen Erfahrungen als Handlanger deutscher Interessen gesehen wird, nehmen wir nicht wahr. ${ }^{2}$ Wir nehmen auch nicht wahr, dass die Target-Diskussion in anderen Ländern vielfach als abwegig angesehen wird. ${ }^{3}$

Die deutsche Diskussion ist maßgeblich geprägt worden durch die Arbeiten von Hans-Werner Sinn, vor allem die Bücher „Die Target-Falle“ (Sinn 2012), „The Euro Trap“ (Sinn 2014) und das ifo-Schnelldienst-Sonderheft „Die griechische Tragödie“ (Sinn 2015d). Bei näherer Betrachtung erweisen sich diese Schriften als problematisch. ${ }^{4}$ Ihre Sprache und Begrifflichkeit stehen einer genauen Analyse entgegen.

So werden Äpfel und Birnen zusammengezählt, wenn es heißt, dass „die Griechenland zur Verfügung gestellten Kredite der Staatengemeinschaft“ die 201 Milliarden Euro an offiziellen Krediten der anderen Eurostaaten und des Internationalen Währungsfonds an den griechischen Staat um mehr als die Hälfte übersteigen (Sinn 2015d, S. 5). Da erscheinen die „Target-Kredite“ und die Bargeldausgabe der griechischen Notenbank ebenso wie die von der EZB auf dem offenen Markt den Geschäftsbanken abgekauften Staatsanleihen, obwohl bei keiner dieser Transaktionen Mittel an den griechischen Staat geflossen sind. ${ }^{5} \mathrm{Da}$ ist die

2 Hellwig 2015f, Whelan 2016. Savona (2012) beschreibt die Währungsunion gar als Umsetzung eines Plans des Reichsbankpräsidenten Funk von 1940, wonach eine Währungsvereinheitlichung dafür sorgen wollte, dass Südeuropa auf Landwirtschaft und Tourismus reduziert würde.

3 Siehe zum Beispiel Whelan 2014, 2017. Tooze (2018, S. 380) schreibt: „This alarmist interpretation of the accounting data should be seen less as a piece of economic analysis than as a symptom of the increasing loss of legitimacy on the part of the euro system."

4 Diese Kritik betrifft auch Fuest und Sinn (2018). Diese Arbeit kam heraus, als dieser Aufsatz in den Druck gegangen war, und wird daher nur am Rande behandelt.

5 Sinn steht mit dieser Vermengung nicht allein. Auch Heinemann (2017) spricht von einer „Begünstigung der südeuropäischen Länder“ durch die Wertpapierkäufe des Eurosystems, obwohl viele der durch 
Rede von Krediten und Zinsvorteilen „für Griechenland“, ohne dass unterschieden wird, ob diese Vorteile der griechischen Regierung, der griechischen Zentralbank, oder griechischen Geschäftsbanken, Unternehmen und Privatpersonen zugutekommen. Die Vorteile, die die deutsche Regierung und die deutsche Wirtschaft aus der Politik der EZB gezogen haben, kommen nicht vor.

Die Geschichten, die Sinn erzählt, sind geprägt von Empörung und sollen Empörung schüren. Empörung aber kann das Denken in eine Falle führen und den rationalen Diskurs unmöglich machen. ${ }^{6}$ Das Auseinanderfallen der Diskurse in Europa ist gefährlich - gerade auch für Deutschland. Im Folgenden erläutere und begründe ich meine Kritik im Einzelnen. In Teil 2 erörtere ich Funktionsweise, Aufgaben und Governance von Zentralbanken im Allgemeinen, in Teil 3 die Regeln der Europäischen Währungsunion einschließlich der rechtlichen und betriebswirtschaftlichen Einordnung der Target-Salden. Teil 4 behandelt die Entwicklung der Target-Salden in den Krisen des vergangenen Jahrzehnts und ihre volkswirtschaftliche Bedeutung. Die Folgen des Austritts eines Landes werden in Teil 6 behandelt. Im einzelnen werde ich folgende Punkte kritisieren.

- Die Besonderheiten eines deckungslosen Papiergelds werden nicht richtig berücksichtigt.

- Eine inhaltliche Auseinandersetzung mit den Aufgaben der Zentralbank als Institution der Geld- und Währungspolitik fehlt weitgehend.

- Die unausgesprochen geforderte Priorisierung fiskalischer Belange ist ordnungspolitisch gefährlich.

- Die Tatsache, dass die Deutsche Bundesbank in ihrem operativen Geschäft nicht selbständig agiert, sondern als Teil des Europäischen Systems der Zentralbanken (ESZB), wird verdrängt.

- Der Begriff des „Target-Kredits“ vermengt volkswirtschaftliche und einzelwirtschaftliche Vorstellungen auf unzulässige Weise und ist analytisch unbrauchbar.

- Rechtsnormen und Zahlen werden ungenau und missverständlich wiedergegeben, Kausalzusammenhänge werden nicht belegt.

Um kein Missverständnis aufkommen zu lassen: Ich selbst stehe der Geldpolitik der EZB seit 2015 kritisch gegenüber und habe dies bei mehreren Gelegenheiten auch schriftlich

diese Käufe unmittelbar Begünstigten, d.h. der Verkäufer, ihren Sitz in Deutschland hatten.

6 Jensen 2017. und mündlich geäußert. ${ }^{7}$ Ich halte es für problematisch, dass die EZB durch den massiven Aufkauf börsengängiger Titel in Konkurrenz zu den Geschäftsbanken tritt, die Prämien für Risiko- und Fristentransformation senkt und die Gewinnmöglichkeiten der Geschäftsbanken schmälert. Die Instrumentalisierung der Geschäftsbanken zur Belebung der Konjunktur durch stärkere Kreditvergabe birgt erhebliche Risiken, zumal die Geschäftsbanken die Folgen der Finanzkrisen seit 2007 noch nicht voll bewältigt haben. Sollte ein Anziehen der Inflation einen Ausstieg aus dieser Geldpolitik erforderlich machen, so ist eine erneute Finanzkrise zu befürchten.

Jedoch ist der Dissens für mich kein Grund für Empörung und Agitation. Meinungsverschiedenheiten gehören zum Alltag. Und wenn die von Seiten der EZB vorgetragenen geldpolitischen Argumente für mich nicht stichhaltig sind, so ist das noch kein Grund, diese Argumente als vorgeschoben $\mathrm{zu}$ betrachten und den Verantwortlichen andere als geldpolitische Zielsetzungen zu unterstellen. ${ }^{8}$

\section{Funktionsweise, Aufgaben und Governance der Zentralbank ${ }^{9}$}

\subsection{Verteilungseffekte, Anreizverzerrungen und Verlustrisiken sind unvermeidlich}

In der Diskussion über die EZB wird regelmäßig kritisiert, dass eine Gruppe von demokratisch nicht legitimierten Experten Entscheidungen treffe, die große Verteilungswirkungen haben und die die Steuerzahler erheblichen Risiken aussetzen können. Jedoch ist beides unvermeidlich.

7 Schriftlich zuerst in Hellwig 2015d, zuletzt in Wissenschaftlicher Beirat 2017, mündlich in der Sitzung des General Board des European Systemic Risk Board (ESRB) im März 2015, dem ich als Vorsitzender (2011-12) bzw. Stellvertretender Vorsitzender (2012-15) des Advisory Scientific Committe (ASC) des ESRB angehörte. Sinn (2018c) unterstellt, dass meine Kritik an seinen Vorstellungen dieser früheren Zuständigkeit „für die Beobachtung der makroökonomischen Risiken“ „bei der EZB“ geschuldet sei. Er verwechselt das ESRB mit der EZB und übersieht, dass das ASC des ESRB ein unabhängiges Beratungsgremium ist, ähnlich dem Wissenschaftlichen Beirat beim Bundesministerium für Wirtschaft und Energie, dem wir beide angehören.

8 Die Argumente wurden dem ASC des ESRB im November 2014 vorgetragen und ausführlich erörtert. Aufgrund meiner damals geäußerten Kritik hatte ich im Januar 2015 weitere Diskussionen mit Vertretern der EZB.Die Gesprächspartner haben mich nicht überzeugt, aber ich sah keinen Grund, ihre Lauterkeit anzuzweifeln. 9 Die Ausführungen dieses Teils beruhen auf Hellwig 2015a, 2015d, 2015e, 2018 a. 
Die Zentralbank operiert überwiegend als Bank, das heißt durch Transaktionen mit Marktteilnehmern: Annahme von Einlagen der Geschäftsbanken, Vergabe von Krediten an Geschäftsbanken, Ankauf und Verkauf von Wertpapieren. Da die Betroffenen nicht gezwungen sind, die Angebote der Zentralbank anzunehmen, ist davon auszugehen, dass sie aus der Annahme einen Vorteil ziehen. Dass Zentralbankaktivitäten den Beteiligten nützen, ist kein Skandal, sondern eine unvermeidliche Folge der Tatsache, dass die Zentralbank nicht mit Verwaltungsoktrois, sondern mit freiwillig abgeschlossenen Verträgen arbeitet. $^{10}$

Auch eine gewisse Selektivität ist unvermeidlich. Man mag kritisieren, dass eine Offen-Markt-Politik, die sich auf Staatsanleihen konzentriert, den Staat gegenüber privaten Emittenten bevorzugt und dass eine Kreditvergabe an Geschäftsbanken diese gegenüber anderen Finanzinstituten bevorzugt, zum Beispiel gegenüber Geldmarktfonds, Hedge Funds oder Private-Equity-Firmen. Jedoch kann die Zentralbank nicht allen für Geschäfte zur Verfügung stehen. Die Selektivität, die wir haben, ist historisch bedingt, denn die Zentralbanken sind als Banken ihrer Staaten entstanden und haben sich alsbald zu Banken der Geschäftsbanken entwickelt. ${ }^{11}$ Inhaltlich ist diese Selektivität insofern sinnvoll, als alle anderen Zinssätze sich am Zinssatz für Staatsanleihen orientieren, dieser also eine zentrale Rolle im Finanzsystem spielt, und insofern, als die Kundeneinlagen der Geschäftsbanken als Grundlage für bargeldlose Zahlungen ein wesentlicher Teil des Geldsystems sind.

Gewiss setzt die Privilegierung bestimmter Anlagen und bestimmter Partner durch die Zentralbank schlechte Verhaltensanreize und verzerrt den Wettbewerb. Regierungen, die erwarten, dass die Zentralbank Staatsanleihen kauft, haben weniger Anlass, Haushaltsdisziplin zu üben. Banken, die auf Liquiditätshilfen der Zentralbank zählen können, können größere Risiken eingehen. ${ }^{12}$ Sie haben

10 Eine Ausnahme sind die Mindestreservevorschriften. Bei einem Mindestreservesatz von 1 Prozent sind diese jedoch kaum von Bedeutung.

11 Goodhart 1988.

12 Tilly (1989) sieht einen Zusammenhang zwischen der Verfügbarkeit des Wechseldiskonts bei der Reichsbank (im Unterschied zur Bank of England) und der Bereitschaft der deutschen Großbanken, große, riskante und langlebige Industrieinvestitionen zu finanzieren. Schnabel (2004, 2009) zeigt, dass die Gewohnheit, sich Liquidität über den Wechseldiskont der Reichsbank zu beschaffen, die Großbanken zu einer leichtsinnigen Liquiditätspolitik veranlasste. In der Krise im Sommer 1931 erwies sich das als fatal, denn im „ZwillingsRun“, auf Währung und Banken gleichzeitig, musste die Reichsbank den Wechseldiskont aussetzen, als sie an die gesetzliche Grenze für auch einen Wettbewerbsvorteil gegenüber anderen, so etwa nach der Aufhebung des Glass-Stegall-Gesetzes die Commercial Banks gegenüber den Investment Banks in den Vereinigten Staaten. Das Risikoverhalten der Investment Banks im Vorfeld der Finanzkrise war auch durch den Druck der Commercial Banks bedingt. ${ }^{13}$

Jedoch ergeben sich die Anreizwirkungen der Zentralbanktätigkeit schon daraus, dass sie überhaupt geldpolitisch aktiv ist. Bei einer Ausweitung der Offen-Markt-Politik auf Anleihen und Aktien privater Emittenten oder bei einer Ausweitung der Zentralbankkredite auf weitere Kreditnehmer dürften die Anreizverzerrungen eher noch zunehmen. Die Ausweitung der Zentralbankinterventionen des vergangenen Jahrzehnts in verschiedenen Ländern, in der Eurozone ebenso wie in den Vereinigten Staaten, sind daher oft nicht als Aufhebung von Diskriminierung begrüßt, sondern als Quelle neuer Fehlanreize kritisiert worden.

Der Aktionismus der Zentralbanken im vergangenen Jahrzehnt ist auch wegen der damit verbundenen Verlustrisiken kritisiert worden. Jedoch sind Verlustrisiken unvermeidlich. Wenn die Zentralbank Wertpapiere kauft oder Kredite vergibt, steht sie im Risiko. Die Kurse der Wertpapiere können sinken, und die Kredite können notleidend werden. Das gilt nicht erst seit der Finanzkrise, als die amerikanische Federal Reserve „toxische Papiere“ kaufte, und nicht erst seit der Euro-Krise, als die EZB anfing, Staatsanleihen von Krisenländern zu kaufen.

In der Vergangenheit verbuchte die Bundesbank regelmäßig hohe Verluste, wenn die D-Mark aufgewertet wurde und der in D-Mark ausgewiesene Wert ihrer Devisenbestände sank. Im Frühjahr 1973 erschien sie deshalb sogar als überschuldet: Der „Ausgleichsposten wegen Verlust aus Neubewertung der US-Dollar-Position“ betrug 7,2 Milliarden D-Mark, die ausgewiesenen eigenen Mittel nur 1,2 Milliarden D-Mark, und in den Folgemonaten verdoppelten sich die Verluste noch einmal. Auf die Frage: „Ist die Bundesbank pleite?“ war damals die selbstverständliche Antwort: „Heute ist die Zentralbank [...] eine Einrichtung zur Regulierung der Währung, die nicht nach dem Ertragsprinzip zu arbeiten braucht. ${ }^{\text {"14 }}$ In der heutigen Dis-

die Deckung der Geldausgabe durch Gold oder Devisen kam, und danach brach das Banksystem zusammen.

13 Hakenes und Schnabel (2010) entwickeln ein theoretisches Modell für die These, dass die Privilegierung eines Teils des Finanzsystems die nicht privilegierten Institute aufgrund des höheren Wettbewerbsdrucks zum Eingehen größerer Risiken veranlassen kann.

14 Siehe Herlt 1973. Ich danke Adalbert Winkler für den Hinweis auf diese Episode. Auch die Goldbestände waren keine gute Anlage. In den Jahren 1980-2001 fiel der Preis für eine Unze Gold von 885 auf 253 Dollar. Beim heutigen Preis von ca. 1.200 Dollar ergibt sich eine 
kussion über mögliche Verluste der Zentralbanken des Eurosystems wird diese Erfahrung zumeist verdrängt.

\subsection{Banknoten sind keine Schuldtitel}

Im Unterschied zu einer Geschäftsbank muss eine moderne Zentralbank nicht befürchten, dass etwaige Verluste sie zahlungsunfähig werden lassen, zumindest in ihrer eigenen Währung, denn diese Währung kann sie selbst produzieren und das praktisch ohne Kosten. ${ }^{15}$ Das von ihr ausgegebene Zentralbankgeld (Einlagen der Geschäftsbanken und Banknoten) erscheint zwar in ihrer Bilanz als Verbindlichkeit, aber dies ist eine Verbindlichkeit, die sie praktisch zu nichts verpflichtet. Es gibt keine Einlösepflicht mehr für Banknoten, allenfalls die Pflicht, eingereichte Banknoten in andere Banknoten umzutauschen. Und die Einlagen der Geschäftsbanken verpflichten die Zentralbank auch nur zur Auszahlung der entsprechenden Beträge in Banknoten.

In der Vergangenheit war das anders. Unter dem Goldstandard beinhalteten die Banknoten eine Verpflichtung zum Eintausch in Gold. Da die Zentralbanken Gold nicht selbst herstellen konnten, mussten sie immer darauf achten, dass sie zahlungsfähig blieben. Später, im BrettonWoods-System der festen Wechselkurse war die Zentralbank verpflichtet, den Kurs der eigenen Währung gegenüber dem Dollar zu stützen. Seit dem Ende des Systems von Bretton Woods ist jegliche Verpflichtung dieser Art entfallen.

Die Bilanzierung des ausstehenden Zentralbankgeldes als Verbindlichkeit ist ein Relikt aus der Vergangenheit und entspricht nicht mehr den tatsächlichen wirtschaftlichen Zusammenhängen. Bei der für andere Unternehmen üblichen Bilanzierung nach dem Zeitwert („Fair value“) würden die Werte dieser „Verbindlichkeiten“ auf Null gesetzt, das heißt auf den abdiskontierten Gegenwartswert der Kosten der mit der Ausgabe von Zentralbankgeld eingegangenen Verpflichtungen. ${ }^{16}$

Wenn die Zentralbank Wertpapiere kauft oder einer Geschäftsbank einen Kredit gibt und zu diesem Zweck neues Zentralbankgeld schafft, so kommen auf der Aktiv-

Dollar-Ertragsrate seit 1980 von weniger als 1 Prozent; die DM/EuroErtragsrate ist noch einmal niedriger.

15 Andere Währungen kann sie nicht selbst produzieren; deshalb konnte die isländische Zentralbank 2008 die isländischen Banken, die sich in Dollars und Euros hoch verschuldet hatten, nicht über Wasser halten.

16 Nach dem Zeitwertprinzip wären allenfalls die erwarteten Kosten eines späteren Umtauschs der Banknoten in neue Banknoten $\mathrm{zu}$ passivieren. Diese machen allerdings nur einen Bruchteil des Nennwerts aus. seite ihrer Bilanz die neuen Vermögenswerte hinzu, auf der Passivseite der Wert des zusätzlich geschaffenen Geldes. Ginge man nach Zeitwertprinzip vor, so würden in unserem Papiergeldsystem allerdings nicht die Verbindlichkeiten, sondern das Eigenkapital der Zentralbank erhöht. Die Praxis, die Notenausgabe als Verbindlichkeit zu passivieren, verschleiert diesen Zusammenhang.

Politisch ist diese Verschleierung sinnvoll. Würde man die Eigenkapitalerhöhung offen ausweisen, so wäre der ausgewiesene Gewinn entsprechend größer - und damit auch die Begehrlichkeit der Politik. Dann wäre auch zu erwarten, dass kontraktive Maßnahmen wie Offen-MarktVerkäufe von Wertpapieren, die die Menge des ausstehenden Zentralbankgeldes senken, auf großen Widerstand der Politik stoßen, denn die Vernichtung von Zentralbankgeld geht - wiederum bei Rechnungslegung nach Zeitwertprinzip - mit einem Verlust einher.

Diese Überlegungen zur Besonderheit von Papiergeld sind nicht neu. In den fünfziger und sechziger Jahren gab es eine intensive Debatte zur Frage, wann die Ausgabe von Geld eine Schuld des Emittenten begründet, bzw. wann dem positiven Beitrag eines Besitzes von Geld zum Vermögen einer Person ein negativer Beitrag zum Vermögen des Emittenten gegenüber steht. Patinkin (1956/1965) hatte die Diskussion angestoßen mit der These, dass die üblichen Vorstellungen vom Zusammenhang zwischen Geldmenge und Güterpreisen einen „Realkasseneffekt“" voraussetzen, der bewirkt, dass die Privaten ihre Geldbestände entsprechend ihrer Kaufkraft als Teil ihres Vermögens ansehen und bei einem höheren Realwert dieser Geldbestände mehr Güter nachfragen; sofern sich auf der Angebotsseite nichts ändere, bedeute dies, dass eine Erhöhung der nominalen Geldmenge im Gleichgewicht durch eine entsprechende Erhöhung der Güterpreise ausgeglichen werden müsse. Patinkin setzte dabei voraus, dass der Realkasseneffekt auf Seiten der Privaten nicht durch einen negativen Realkasseneffekt auf Seiten der Emittenten von Geld neutralisiert wird, das heißt, dass der Emittent dieses Geld nicht als echte Schuld behandelt. ${ }^{17}$

Gurley und Shaw (1960) führten dazu die Unterscheidung zwischen „Innengeld“ (echte Schuld des Emittenten)

17 Siehe Patinkin 1956/1965, vor allem Kap. 12. Man beachte die Unterscheidung zwischen der Analyse von Verhaltensfunktionen und der Analyse von Gleichgewichten. Die Vorstellung, dass Geldbestände einen positiven Vermögenseffekt auf das Verhalten der Besitzer ausüben, nicht aber einen negativen Vermögenseffekt auf das Verhalten der Emittenten, bedeutet nicht, dass die Zentralbank mit Gelddrucken das „Realvermögen der Volkswirtschaft“ erhöhen kann, denn die aufgrund der Realkasseneffekte induzierten Preisänderungen neutralisieren die Vermögenswirkungen der nominalen Geldmengenerhöhungen. 
und „Außengeld“ (keine echte Schuld des Emittenten) ein und identifizierten ersteres mit dem von Geschäftsbanken geschaffenen Giralgeld, letzteres mit Zentralbankgeld. ${ }^{18}$ Auch Tobin (1967) betonte den Unterschied zwischen Giralgeld und Zentralbankgeld, wies aber darauf hin, dass auch Giralgeldschöpfung das Vermögen des Emittenten steigern kann - dann nämlich, wenn staatliche Regulierung oder eine Kartellvereinbarung bewirken, dass Einlagen bei Geschäftsbanken, das heißt Giralgeld, keine Erträge in Form von Zinsen oder realen Dienstleistungen erbringen. Bei unreguliertem Wettbewerb müssten die Banken die Erträge, die sie auf ihre Aktiva verdienen, in Form von Zinsen auf Bankeinlagen an ihre eigenen Geldgeber weitergeben; dies schmälere den Vermögenszuwachs der Geschäftsbanken aus Giralgeldschöpfung.

Pesek und Saving (1967) weiteten diese Analyse auf die Verzinsung von Zentralbankgeld aus. Wenn die Zentralbank das von ihr ausgegebene Geld verzinst und dabei die inflationären Wirkungen einer Finanzierung der Zinsen durch Drucken von neuem Geld vermeiden will, so muss sie die Erträge auf die mit der Geldausgabe finanzierten Vermögenswerte zum Bedienen der Zinsverpflichtung einsetzen. Dementsprechend ist der Gegenwartswert dieser Verpflichtung als echte Schuld der Zentralbank zu verbuchen. ${ }^{19}$

Die geldtheoretische und geldpolitische Diskussion hat sich seither anderen Fragen zugewandt. Die hier skizzierte Diskussion der fünfziger und sechziger Jahre ist daher etwas in Vergessenheit geraten. Die damaligen Überlegungen sind aber nach wie vor relevant. ${ }^{20}$

18 Siehe auch die Diskussion dieser Unterscheidung in der 1965 erschienenen zweiten Auflage von Patinkin 1956/1965. Sinn (2014, S. 190) gebraucht die Ausdrücke „Binnengeld“ und „Außengeld“, um zu unterscheiden, ob das betreffende Zentralbankgeld in Deutschland selbst oder in einem anderen Mitgliedstaat entstanden ist. Er bezieht sich dabei auf Gurley und Shaw (1960). Ein inhaltlicher Zusammenhang ist aber nicht erkennbar.

19 Der daraus von Pesek und Saving (1967) gezogene Schluss, dass das Zahlen von Zinsen auf Geld den Charakter des Geldes verändert, so dass es seine Funktionen nicht mehr in gleicher Weise erfüllt, wurde allerdings von Johnson (1969) widerlegt. Für eine neuere Diskussion der Implikationen von Zinszahlungen auf Zentralbankgeld siehe Hall und Reis 2015 sowie Reis 2015.

20 Hahns (1965) Kritik an Patinkin (1956/1965) hatte eine Spaltung der Literatur in eine grundlagenorientierte Richtung und eine politikorientierte Richtung zur Folge. Die Grundlagenforschung befasste sich mit der von Hahn gestellten Frage, unter welchen Bedingungen es ein allgemeines Gleichgewicht gibt, in dem Papiergeld, das kein Schuldtitel ist, überhaupt einen positiven Realwert hat. In Modellen, in denen Papiergeld das einzige Wertaufbewahrungsmittel ist, lautet die Antwort: wann immer die reale Nachfrage nach einem Wertaufbewahrungsmittel hinreichend groß ist. In Modellen, in denen es neben Papiergeld auch andere Wertaufbewahrungsmittel gibt, lautet

\subsection{Zur Diskussion um die Risiken expansiver Geldpolitik}

Die vorstehenden Überlegungen sind unmittelbar von Bedeutung für die deutsche Diskussion um die seit 2015 betriebene Politik des „Quantitative easing“, der massiven Offen-Markt-Käufe von Wertpapieren durch die Zentralbanken des Eurosystems. Am Anfang dieser Diskussion stand ein Interview von Bundesbankpräsident Jens Weidmann unter der Überschrift „Für die Verluste haften die Steuerzahler" (Frankfurter Allgemeine Sonntagszeitung vom 28. Dezember 2014). Wenn das Eurosystem Wertpapiere ankauft und hinterher Verluste erleidet, so die Warnung, wird der Steuerzahler dafür büßen müssen. Diese Befürchtung spielt auch eine Rolle im Verfahren vor dem Bundesverfassungsgericht zu dieser Politik und in dem Beschluss, mit dem das Bundesverfassungsgericht 2017 dem Europäischen Gerichtshof die Frage nach der Zulässigkeit dieser Politik vorgelegt hat. ${ }^{21}$

Die Warnungen und Befürchtungen sind ein Artefakt einer Rechnungslegung, die, wie erklärt, die wirtschaftlichen Realitäten nicht angemessen widerspiegelt. Jeder Geldfälscher weiß, dass, wenn er „Blüten“ produziert und zum Kauf von Aktien verwendet, er einen Gewinn macht; sollten die Aktienkurse danach einbrechen, so ist der Gewinn zwar kleiner, aber er wird nicht negativ. Ähnliches gilt für die Zentralbank, nur dass diese im Unterschied zum Geldfälscher keine Angst vor der Polizei haben muss. Wenn sie mit neu geschaffenem Geld Wertpapiere kauft, so macht sie, wie oben erläutert, bei Rechnungslegung nach Zeitwertprinzip einen Geldschöpfungsgewinn. Wenn diese Wertpapiere hinterher an Wert verlieren, so verringert sich der Gewinn, wird aber nicht negativ. Ein echter Verlust tritt nur auf, wenn die Zentralbank aufgrund einer Veränderung der geldpolitischen Lage zu einem späteren Zeitpunkt die Wertpapiere wieder verkaufen will und der Verkaufskurs unter dem ursprünglichen Ankaufskurs liegt.

Die eigentlichen sozialen Kosten der Geldschöpfung liegen an anderer Stelle. Unter normalen Bedingungen steht dem Geldschöpfungsgewinn der Zentralbank ein Ver-

die Antwort: dann und nur dann, wenn es hinreichend starke Friktionen gibt, die dafür sorgen, dass Papiergeld für bestimmte Zwecke als Wertaufbewahrungsmittel bzw. Zahlungsmittel besser geeignet ist; siehe Hellwig 1993. Für die wirtschaftspolitische Analyse sind solche Modelle zumeist zu komplex. Die geldpolitische Forschung hat sich daher von diesen Überlegungen gelöst und einfachere Formulierungen verwandt - bis hin zu Woodfords (2004) neukeynesianischem Ansatz, bei dem Geld nur die Funktion einer Rechnungseinheit hat und als physisches Objekt gar nicht vorkommt.

21 BVerfG, Beschluss des Zweiten Senats vom 18. Juli 2017 - 2 BvR $859 / 15$. 
mögensverlust der privaten Haushalte und der Unternehmen gegenüber, weil die Erhöhung der Geldmenge eine Erhöhung der Güterpreise nach sich zieht. Diese mindert den Realwert, die Kaufkraft des ausstehenden Zentralbankgelds und aller anderen in Geldeinheiten denominierten Titel und bewirkt eine Umverteilung von Realvermögen weg von den Inhabern und hin zu den Emittenten der auf Geldeinheiten lautenden Titel. Aus volkswirtschaftlicher Sicht machen diese externen Effekte die eigentlichen Kosten der Geldschöpfung aus. Soweit die Erwartungen sich entsprechend anpassen und die Betroffenen ihr Verhalten ändern, kommt es über die Verteilungseffekte hinaus auch zu Anreizverzerrungen und einer Senkung der allokativen Effizienz des Geldwesens.

In der Diskussion 2015 konnte man aber kaum mit diesen externen Kosten der Geldschöpfung argumentieren. Zum einen hatte sich der aus normalen Zeiten bekannte Zusammenhang von Zentralbankgeldmenge und Güterpreisen seit 2008 nicht mehr beobachten lassen. Zum anderen berief sich EZB-Präsident Draghi gerade auf das Preisstabilitätsmandat der Zentralbank und argumentierte, es gelte, einer Deflation vorzubeugen..$^{22}$ Eine inhaltliche Diskussion zur Frage, ob wirklich eine Deflation drohte, wäre vermutlich in Details versandet. Die Warnung vor den Risiken der vorgeschlagenen Politik für den deutschen Steuerzahler war da wirkungsvoller. Dass diese Warnung inhaltlich problematisch war und ist, wurde kaum wahrgenommen. ${ }^{23}$

Nun könnte man einwenden, die tatsächlich von den Zentralbanken geübte Rechnungslegung entfalte recht-

22 Die Warnung von einer möglichen Deflation findet sich schon bei Sinn in einer Diskussion über die Geldpolitik nach der Lehman-Krise (Sinn 2009). Später dagegen befürwortet Sinn eine Deflation als Mittel zur Wiederherstellung der Wettbewerbsfähigkeit der Krisenländer (Sinn 2014). Allerdings erklärt er nicht wie dieses Ziel zum Mandat der EZB passt.

23 Als ich im März 2015 darauf hinwies, dass die Warnungen vor etwaigen Verlusten aus Offen-Markt-Käufen von Wertpapieren an der wirtschaftlichen Realität vorbeigingen (Hellwig 2015d), antwortete Sinn (2015c), im Fall des (nie umgesetzten) OMT-Programms treffe mein Argument nicht zu, denn bei diesem Programm sei vorgesehen gewesen, die monetären Wirkungen der Staatsanleihenkäufe durch Verkäufe anderer Vermögenswerte zu neutralisieren; siehe auch Sinn 2013. Jedoch ging es 2015 gerade nicht um Ankäufe von Wertpapieren bei gleichzeitiger Veräußerung anderer Vermögenswerte. Bei Sinn findet sich dazu die Aussage, Offen-Markt-Ankäufe von Wertpapieren ohne gleichzeitige Neutralisierung der monetären Wirkungen seien inflationär und daher nicht mit dem Preisstabilitätsmandat der EZB vereinbar (Sinn 2014, S. 166). Die Ausführungen weiter unten in Abschnitt 2.5 zeigen, dass diese Aussage in dieser Allgemeinheit falsch ist. Noch 2009 hatte Sinn eine ähnliche Auffassung vertreten, siehe Sinn 2009. liche und wirtschaftliche Wirkungen, denen man Rechnung tragen müsse, auch wenn diese Rechnungslegung den wirtschaftlichen Zusammenhängen nicht gerecht werde. Konkret: Die Gewinnausschüttung im Eurosystem ist daran gebunden, dass Gewinne ausgewiesen werden. Wenn Erträge ausfallen, sinkt die Gewinnausschüttung, das schädigt die Eigentümer der Zentralbanken, das heißt die Regierungen und letztlich die Steuerzahler. ${ }^{24}$ Bei größeren Verlusten sieht das Bundesverfassungsgericht sogar das Risiko, dass eine Rekapitalisierung der Zentralbanken notwendig werden könnte, auch dies wäre eine Belastung der Staatshaushalte. ${ }^{25}$

In dieser Argumentation fehlen allerdings zwei wichtige Punkte: Erstens, wenn ein Verlust nur die laufenden Erträge der Wertpapiere betrifft, sind die Gewinnausschüttungen nicht kleiner als wenn die Offen-Markt-Maßnahme nicht stattgefunden hätte. Zweitens, wenn der Verlust die laufenden Erträge übersteigt und die Gewinnausschüttung entsprechend verringert wird oder sogar neues Eigenkapital zugeschossen wird, so erhöhen die Einbehaltungen oder Kapitalzuschüsse die Vermögenswerte der Zentralbank - und damit auch die Aussichten auf zukünftige Gewinnausschüttungen an den Fiskus.

Nehmen wir zum Beispiel an, dass die Zentralbank in einem Jahr mit neu geschaffenem Geld festverzinsliche Papiere mit ewiger Laufzeit im Wert von X kauft, für die eine Zinszahlung R pro Jahr vorgesehen ist. Die Bilanz der Zentralbank verlängert sich auf beiden Seiten um X, der Gewinn und die Gewinnausschüttung erhöhen sich in jedem Jahr um R. Fällt die Zinszahlung in einem Jahr aus, so sinkt die Gewinnausschüttung in dem betreffenden Jahr um R, ist aber nicht niedriger, als sie ohne den Wertpapierkauf gewesen wäre. Ergibt sich in einem Jahr, dass die Zinszahlungen für immer ausfallen werden, so ist eine Abschreibung in Höhe von X vorzunehmen. ${ }^{26}$ Diese Abschreibung reduziert die Gewinnausschüttung an den Fiskus um X, wenn nicht gar eine Rekapitalisierung durch den Fiskus erforderlich wird. Aufgrund der zusätzlichen Gewinneinbehaltung bzw. der Rekapitalisierung stehen der Zentralbank dann zusätzliche Mittel in Höhe von X zur Verfügung. Verwendet sie diese zum Kauf neuer Wertpapiere, so erhöhen sich die für die Zukunft zu erwartenden Erträge entsprechend. Der Kapitalwert des Zuwachses ist X. Für den Fiskus bedingt die Verringerung der Gewinn-

24 Sinn 2015a; dagegen Hellwig 2015b.

25 BVerfG, Beschluss des Zweiten Senats vom 18. Juli 2017 - 2 BvR $859 / 15$.

26 Der Einfachheit halber nehme ich an, dass die sonstigen Faktoren, die die Bewertung eines Versprechens auf Zahlen von $\mathrm{R}$ pro Jahr beeinflussen, sich nicht geändert haben. 
ausschüttung bzw. die Rekapitalisierung nur insofern eine Belastung, als die zeitliche Inzidenz der anfallenden Geldströme sich ändert; ein Nettovermögensverlust entsteht dadurch nicht. ${ }^{27}$

Diese Überlegungen sind nicht als Plädoyer für eine Vernachlässigung der Verlustrisiken der Zentralbankpolitik zu verstehen. Für die Steuerzahler ist es allemal besser, wenn die im Zuge der Geldschöpfung akquirierten Vermögenswerte Erträge abwerfen, als wenn sie das nicht tun. Jedoch taugt diese Erwägung nicht für eine Diskussion über die Ausweitung der Zentralbankgeldmenge, denn die Ausweitung der Zentralbankgeldmenge ist für sich schon eine Quelle von Gewinnen, auch wenn diese nicht ausgewiesen werden. Die Diskussion über die Ausweitung der Zentralbankgeldmenge sollte sich auf die rechtlich vorrangige und volkswirtschaftlich maßgebliche Frage nach den Auswirkungen der ins Auge gefassten Maßnahmen auf die Preisstabilität konzentrieren.

\subsection{Die fiskalischen Wirkungen der Geldpolitik und die Unabhängigkeit der Zentralbank}

Vor dem Hintergrund unserer Geschichte mutet es merkwürdig an, dass die Auswirkungen der Politik der EZB auf die Zentralbankgewinne und auf die Staatsfinanzen im Zentrum der deutschen Diskussion stehen. Wenn das Bundesverfassungsgericht argumentiert, es sei demokratiepolitisch und verfassungsrechtlich problematisch, wenn die Politik der unabhängigen (Europäischen) Zentralbank Risiken für den Staatshaushalt mit sich bringe, so zeigt es eine bemerkenswerte Nonchalance gegenüber der geschichtlichen Erfahrung. ${ }^{28}$ Es ignoriert, dass jegliche Zentralbankaktivität notwendigerweise Budgetwirkungen hat und dass gerade die Budgetwirkungen der Geldschöpfung

27 Die hier skizzierte Überlegung ist ein Spezialfall des Theorems von Modigliani und Miller (1961) zur Irrelevanz der Dividendenpolitik eines Unternehmens, wenn es keine Friktionen in den Märkten für Schuldtitel des Unternehmens oder seiner Eigentümer gibt.

28 Die Fokussierung auf die Risiken der Zentralbankpolitik für den Staatshaushalt ist um so bemerkenswerter, als es um die entsprechenden Risiken bei den deutschen öffentlichen Banken bzw. die tatsächlich angefallenen Kosten für die Steuerzahler aus der Stützung von Banken kaum öffentliche, parlamentarische oder gerichtliche Auseinandersetzungen gegeben hat. Allein im Fall der WestLB hat 2012 der damalige nordrhein-westfälische Finanzminister die Kosten für die Steuerzahler auf 18 Milliarden Euro beziffert („WestLB kostet Steuerzahler 18 Milliarden Euro“, Handelsblatt vom 20. Juni 2012). Die Kosten der Finanzkrise für die Steuerzahler dürften deutlich über 70 Milliarden Euro liegen; siehe Hellwig 2018b. der Grund dafür waren, dass man die Zentralbank unabhängig machte.

Die Geschichte der staatlichen Prärogative im Geldwesen ist auch eine Geschichte der Inflationen, verursacht durch die Nutzung der Notenpresse zur Deckung staatlichen Budgetbedarfs. Diese Erfahrung gab es nicht nur in Diktaturen und nicht nur in Kriegszeiten, sondern auch in Demokratien, so in den westlichen Parteiendemokratien in den siebziger Jahren. Deutschland und die Schweiz waren damals die großen Ausnahmen - aufgrund der Unabhängigkeit ihrer Zentralbanken. ${ }^{29}$

Die Forderung nach Unabhängigkeit der Zentralbank gründet sich letztlich auf die Einsicht, dass eine Unterwerfung des Geldwesens unter den Primat der Politik auch in der Demokratie schwerwiegende Probleme aufwirft, nicht nur für die Funktionsfähigkeit des Geldwesens, sondern auch für die Vertrauenswürdigkeit des Staates. Eine Politik, die auf die Budgetwirkungen der Geldschöpfung abstellt, unterliegt einem Zeitinkonsistenzproblem: Im Interesse eines möglichst hohen Erlöses aus der Geldschöpfung muss man den Abnehmern das Vertrauen vermitteln, dass die Kaufkraft des Geldes stabil ist. Ist das Geld dann einmal im Umlauf, so kommt man alsbald in die Versuchung, noch mehr Geld zu schaffen, um noch mehr Ausgaben zu finanzieren. Unter normalen Umständen sinkt die Kaufkraft des Geldes durch diese zusätzliche Geldschöpfung, das heißt, das im Vorhinein aufgebaute Vertrauen wird enttäuscht. Beschönigende Gründe für den Vertrauensbruch lassen sich immer finden. ${ }^{30}$

Die Unabhängigkeit der Zentralbank als einer der demokratischen Willensbildung gerade auch in Haushaltsangelegenheiten entzogenen Institution bietet die Möglichkeit, das Zeitinkonsistenzproblem zu lösen. Der Politik wird die Möglichkeit genommen, immer wieder neu auf die Geldschöpfung Einfluss zu nehmen. Die Unabhängigkeit der Zentralbank mit einem Mandat für Preisstabilität bietet einen gewissen Ersatz dafür, dass die Inhaber von Bargeld keinen Rechtsanspruch auf Geldwertstabilität haben.

Man mag an dieser Stelle einwenden, es sei doch etwas anderes, ob man über die Möglichkeit von Verlusten und deren Auswirkungen auf die Gewinnausschüttungen oder über die Verwendung der Notenpresse zur Finanzierung von Staatsausgaben rede. Jedoch ist dies nur eine

29 Die amerikanische Federal Reserve ist zwar auch rechtlich unabhängig, aber das Gesetz kann jederzeit geändert werden. Die Inflation der siebziger Jahre ging unter anderem darauf zurück, dass die Federal Reserve unter Arthur Burns mit einer expansiven Politik 1972 die Wiederwahlchancen von Präsident Nixon steigern wollte.

30 Für eine ausführliche Analyse unter Rückgriff auf Coase 1972 siehe Hellwig 1985. 
Frage der Größenordnungen. Die Priorisierung der budgetären Wirkungen im deutschen Diskurs und die öffentlichrechtliche Dogmatik des Bundesverfassungsgerichts lassen sich ebenso gut für eine Unterwerfung der Bundesbank unter das Diktat des Finanzministers wie für die Auseinandersetzung mit der EZB einsetzen. ${ }^{31}$

\subsection{Preisstabilität und Geldpolitik}

Vorrangiges Ziel der Geldpolitik in der Europäischen Währungsunion ist, wie schon vorher in der Bundesrepublik, die Wahrung der Preisstabilität. Was genau dieses Ziel von der Geldpolitik verlangt, ist umstritten. Dabei überlagern sich verschiedene Fragen:

- Wie beeinflusst die Geldpolitik die Preisstabilität?

- Wie interventionistisch darf bzw. sollte die Zentralbank agieren?

- Inwiefern spielt (auch) Finanzstabilität eine Rolle?

- Inwiefern sind betriebswirtschaftliche/fiskalische Belange zu berücksichtigen?

Die Antworten auf diese Fragen hängen oft stark von Werturteilen, Denkweisen und Traditionen ab. ${ }^{32}$ Um so wichtiger ist es, dass man sich als Wissenschaftler bewusst ist, wo die Grenze liegt zwischen dem, was man zwingend begründen kann, und dem, was man aus den eigenen Wertvorstellungen ableitet. Eine unabhängige Zentralbank ist nicht verpflichtet, sich so zu verhalten, wie ich das wünsche, und nicht einmal so, wie man vermutet, dass die Bundesbank sich früher verhalten hätte.

In den einfachsten geldtheoretischen Modellen ergibt sich ein proportionaler Zusammenhang zwischen der Zentralbankgeldmenge und dem nominalen Bruttoinlandsprodukt. Wenn ein solcher Zusammenhang wirklich besteht, dann kann man hoffen, das Ziel der Preisstabilität zu erreichen, indem man das Wachstum der Zentralbankgeldmenge am erwarteten realen Wachstum der Wirtschaft ausrichtet. ${ }^{33}$ Für einen Gegner staatlicher Interventionen in der Wirtschaft hat dies den Vorteil, dass die Markteingriffe

31 Der Umstand, dass in der Folge des Maastricht-Vertrags die Unabhängigkeit der Bundesbank im Grundgesetz festgeschrieben wurde, bietet hier keinen verlässlichen Schutz, denn die Ausführungen des Bundesverfassungsgerichts betreffen das Demokratieprinzip nach Art. 20 GG und damit den nach Art. 79 Abs. 3 GG unveränderlichen Kern der Verfassung.

32 Zum Einfluss von Denkweisen und Traditionen siehe Brunnermeier et al. 2016.

33 Identifiziert man „Preisstabilität“ mit 2 Prozent Inflation, so muss das Geldmengenwachstum entsprechend höher ausfallen. der staatlichen Institution Zentralbank sich auf ein Minimum beschränken und regelbasiert erfolgen.

Der postulierte proportionale Zusammenhang zwischen der Zentralbankgeldmenge und dem nominalen Bruttoinlandsprodukt liegt aber in der Realität nicht immer vor. So kam es in der Schweiz 1988 zu einem deutlichen Anstieg der Inflationsrate, obwohl die Zentralbank das Wachstum der Zentralbankgeldmenge nicht erhöht hatte. Eine Änderung der Liquiditätsvorschriften für die Geschäftsbanken und die Einführung eines neuen InterBanken-Zahlungssystems hatten die Giralgeldschöpfung der Geschäftsbanken stark ansteigen lassen, mit entsprechenden Wirkungen auf die Inflation. Die Zentralbank hätte der Entwicklung vorbeugen können, wenn sie den institutionellen Änderungen Rechnung getragen hätte, vielleicht auch, wenn sie aus der Entwicklung der Geldmarktzinssätze erschlossen hätte, was vor sich ging. ${ }^{34}$

In den Vereinigten Staaten veranlassten die hohen Nominalzinssätze, das heißt die hohen Opportunitätskosten der Geldhaltung, in den siebziger Jahren die Marktteilnehmer, nach Alternativen für "Geld“ im Sinne von Bargeld und Bankeinlagen (, $\mathrm{M}_{1}$ “) $\mathrm{zu}$ suchen sowie nach Techniken der Organisation von Zahlungsströmen, die die durchschnittlich erforderliche Geldhaltung reduzierten. Die Nachfrage nach „Geld“ im Sinne von $\mathrm{M}_{1}$ ging dementsprechend zurück, und die Inflationsraten lagen über den Wachstumsraten dieses Geldaggregats. ${ }^{35}$ Auch hier wäre die Inflation vermutlich weniger hoch gewesen, wenn die Zentralbank die Entwicklungen früher wahrgenommen und reagiert hätte.

Ein Gegenstück zu diesen Beispielen findet sich in der Analyse der Großen Depression der dreißiger Jahre durch Friedman und Schwartz (1963). Für die Periode 1929-33 beobachten diese Autoren ein Wachstum der Zentralbankgeldmenge von 15 Prozent, ein Schrumpfen des Geldaggregats $\mathrm{M}_{1}$ von 33 Prozent und einen Rückgang des nominalen Nettosozialprodukts von mehr als 50 Prozent, wobei das reale Nettosozialprodukt um mehr als 33 Prozent zurückging und die Güterpreise um 25-33 Prozent. ${ }^{36}$ Nach Friedman und Schwartz (1963) war die Geldpolitik dieser Jahre trotz der 15 Prozent Wachstum der Zentralbankgeldmenge kontraktiv, denn dieses Wachstum reichte nicht aus, um den Rückgang der Giralgeldschöpfung der Geschäftsbanken zu kompensieren, der durch deren vermehrte Reservehaltung und durch die vermehrte Bargeldhaltung der Nichtbanken verursacht wurde.

$34 \mathrm{Zu}$ dieser Episode siehe Capitelli und Buomberger 1990 sowie Rich 1990.

35 Goldfeld (1976) weist als erster auf diese Entwicklung hin. 36 Friedman und Schwartz 1963, S. 299. 
Hinter dieser merkwürdigen Semantik verbirgt sich ein Paradox. Friedman und Schwartz, die Hohen Priester des Laissez-Faire, plädierten gleichzeitig für eine Regelbindung und einen aktiven Interventionismus der Geldpolitik. Für die Regelbindung sollte die Vorgabe einer Zielgröße für die Geldmenge dienen. Als relevante Geldmenge nannten sie aber nicht die Zentralbankgeldmenge, sondern das für die Wirtschaft relevante monetäre Aggregat $M_{1}$, die Summe aus Bargeld der Nichtbanken und Sichteinlagen der Nichtbanken bei Geschäftsbanken (Giralgeld). Eine Zielvorgabe für $\mathrm{M}_{1}$ enthält implizit die Aufforderung zu aktivem Interventionismus, um Änderungen bei der Bargeldhaltung des Publikums oder der Reservehaltung der Banken zu kompensieren.

In den Jahrzehnten vor der Finanzkrise gab es keinen Anlass, sich weiter mit diesem Paradox zu befassen, und so ist es in Vergessenheit geraten. Vielleicht hat man es auch verdrängt, denn der geforderte Interventionismus passt nicht zur Doktrin des Laissez-Faire.

\subsection{Finanzsystem und Geldpolitik}

Seit 2008 ist das Friedman-Schwartz-Paradox wieder relevant, denn der in normalen Zeiten zu erwartende Zusammenhang zwischen dem Wachstum der Zentralbankgeldmenge und der Inflation ist nicht mehr zu beobachten. So ist die Zentralbankgeldmenge zwischen 2008 und 2013 um ca. 100 Prozent angestiegen, die Güterpreise aber nur um ca. 10 Prozent, das heißt 2 Prozent pro Jahr. Das von der EZB (wie früher schon von der Bundesbank) als maßgeblich betrachtete Geldmengenaggregat $M_{3}\left(M_{1}\right.$ plus Spareinlagen) ist in dieser Periode ebenfalls um ca. 10 Prozent angestiegen. Man könnte meinen, die EZB sei genau den Vorgaben von Friedman und Schwartz gefolgt.

Gleichwohl ist die aktive Politik der EZB seit 2008 viel kritisiert worden, vor allem von Ökonomen, die jeglichen Aktionismus der Zentralbank ablehnen. Dazu gehören neben Monetaristen, die das Friedman-Schwartz-Paradox verdrängt haben und jegliches Wachstum der Zentralbankgeldmenge als inflationär ansehen, auch Anhänger der auf Mises (1912/1924) und Hayek (1931) zurückgehenden österreichischen Tradition, die eine Politik des leichten Geldes, exzessive Schöpfung von Zentralbankgeld sowie leichtsinnige Kreditvergabe und Giralgeldschöpfung der Geschäftsbanken, als Ursache der wichtigsten konjunkturellen und realwirtschaftlichen Fehlentwicklungen ansieht. ${ }^{37}$

37 Zum Beispiel Hoffmann und Schnabl 2016, Freytag und Schnabl 2017. Für manchen Anhänger dieser Denkrichtung ist schon die Exis-
In Anbetracht des Umstands, dass die EZB das gesetzte Inflationsziel von 2 Prozent pro Jahr in der angegebenen Periode genau erreicht hat, könnte man fragen, ob das Mandat der EZB den Kritikern egal ist. Die Kritiker könnten antworten, es gebe eben große Verzögerungen, die Inflationswirkungen dieser Politik würden aber noch kommen. Jedoch ist dieser Einwand zehn Jahre nach Beginn der Expansionsstrategie wenig überzeugend..$^{38}$

Dies gilt um so mehr, als der mit der Long Term Refinancing Operation (LTRO) von 2011/12 verbundene besonders drastische Anstieg der Zentralbankgeldmenge um eine Billion Euro bis 2014 wieder zurückgenommen wurde und weder die Erhöhung 2011/12 noch die Senkung 2013/ 14 sich in den Inflationsraten spiegelten. Auch die massiven Erhöhungen seit 2015 haben bislang keine kommensurablen Auswirkungen auf die Inflation gehabt.

Die Long Term Refinancing Operation sollte einer Liquiditätsklemme im Finanzsektor entgegenwirken, die begonnen hatte, als die Geldmarktinvestoren erkannten, wie hoch der griechische Schuldenschnitt sein würde und wie sehr bestimmte Banken in Europa betroffen sein würden. Der Rückzug der Geldmarktinvestoren veranlasste die Geschäftsbanken, Wertpapiere zu verkaufen, um an Liquidität zu kommen, wie schon im September 2008. Die darauf einsetzenden Kursverluste erhöhten das Misstrauen und beschleunigten die Mittelabzüge. Die beim Oktober-Gipfel der Euro-Staaten beschlossene Erhöhung der Eigenkapitalanforderungen für große Institute veranlasste diese wiederum zu weiteren Wertpapierverkäufen, und es kam zu erheblichen weiteren Kursverlusten. Das im Dezember 2011 initiierte LTRO-Programm setzte diesem Prozess ein Ende.

Mit diesem Programm und schon vorher mit ihren Interventionen ab 2007 knüpfte die EZB an die uralte Vorstellung an, dass die Zentralbank in einer Krise als Geldverleiher der letzten Instanz („Lender of last resort“) auftreten soll. Bagehot (1873) formulierte dazu die klassische Forderung: „lend freely to solvent banks, at high rates and against good collateral, valued at normal prices“ - verleihe Geld großzügig an solvente Banken, zu hohen Zinssätzen und gegen gute Sicherheiten bei Bewertung dieser

tenz einer staatlichen Zentralbank, die ungedecktes Papiergeld ausgibt, ein Problem. Siehe zum Beispiel Hayek 1976 oder Vaubel 1985. Winkler (2015) sieht in der Opposition der Bundesbank gegen die Politik des Quantitative easing das Wirken Hayekscher Vorstellungen. Siehe auch Hellwig 2015e.

38 Winkler (2018a) kritisiert das Argument, die behaupteten negativen Wirkungen der Politik würden sich eben erst langfristig zeigen und man sei noch nicht am Ende der langen Frist angelangt, als Immunisierungsstrategie, die letztlich jegliche empirische Überprüfung ausschließt. 
Sicherheiten $\mathrm{zu}$ den für normale Zeiten $\mathrm{zu}$ erwartenden Preisen. Diese Strategie sei nicht nur wünschenswert, um Finanzkrisen $\mathrm{zu}$ mildern, sondern sie könnte auch ein gutes Geschäft sein, aufgrund der Zinsen, die die Geschäftsbanken in der Krise zahlten, und weil die Zentralbank selbst davon profitiere, wenn sie einen Kollaps der Wertpapierpreise verhindere.

Der Maastricht-Vertrag und das Bundesbankgesetz enthalten kein Mandat für Finanzstabilität, nur ein Mandat für Preisstabilität. ${ }^{39}$ Der Aktionismus seit 2008 ist mit dem Argument begründet worden, es gelte dem von der Finanzkrise ausgehenden Risiko einer Deflation vorzubeugen. ${ }^{40}$

In der Weltwirtschaftskrise wurde Bagehots Regel nicht befolgt. Unter dem Goldstandard waren die Zentralbanken zur Einlösung des von ihnen ausgegebenen Geldes in Gold verpflichtet und mussten um ihre eigene Zahlungsfähigkeit fürchten. Aus Furcht vor Goldabflüssen sahen sie von expansiven Maßnahmen ab und setzten stattdessen die Zinssätze hoch..$^{41}$ Dieses Verhalten, das unter den Regeln des Goldstandards durchaus geboten sein mochte, gilt heute als maßgeblicher Grund für die Schwere der Weltwirtschaftskrise. ${ }^{42}$

39 Auch die amerikanische Federal Reserve hat kein Mandat für Finanzstabilität, nur ein Mandat, für Preisstabilität, Vollbeschäftigung und niedrige Zinssätze zu sorgen. Das hinderte den Präsidenten Alan Greenspan nicht, im Interesse der Finanzstabilität immer wieder sehr aktiv einzugreifen, so 1987, um durch massive Liquiditätshilfen die Folgen des Kurssturzes an der Börse zu mildern, und 1990, um durch eine Senkung der kurzfristigen Zinssätze den großen amerikanischen Banken die Möglichkeit zu geben, bei niedrigen kurzfristigen und hohen langfristigen Zinssätzen durch Fristentransformation hohe Gewinne zu erzielen, um ihr Eigenkapital wieder aufzubauen; bei etlichen dieser Banken war die Solvenz zweifelhaft.

40 Eine solche Subsumption von Finanzstabilität unter Preisstabilität setzt allerdings voraus, dass beide Ziele parallel laufen. Diese Bedingung ist nicht erfüllt, wenn sowohl die Wirtschaft als auch das Banksystem marode sind und man zu wählen hat zwischen einer Strategie, die den Finanzsektor instrumentalisiert, um die Konjunktur zu beleben, und einer Strategie, die vorab eine Sanierung des Finanzsektors anstrebt in der Hoffnung, dass die Konjunkturbelebung alsbald folgt. Letzteres entspricht der Strategie von Greenspan 1990, ersteres der Strategie der EZB seit 2015. Bei dieser Strategie wird ein immer noch maroder Finanzsektor neuen Risiken ausgesetzt; daher besteht die Gefahr, dass die Konjunkturbelebung nicht nachhaltig wirkt und eine spätere Bereinigung der Probleme des Finanzsektors um vieles teurer wird. Siehe zum Beispiel Caprio und Klingebiel 1996, 1997. Daher meine eingangs erwähnte Opposition gegen diese Politik. 41 Die Ausnahme, die die Regel bestätigt, sind die Offen-Markt-Operationen der Federal Reserve in den Vereinigten Staaten 1932, die positiv wirkten, aber alsbald wieder gestoppt wurden, als es zu Goldabflüssen kam. Siehe Friedman und Schwartz 1963.

42 Siehe Eichengreen 1992. In der Krise von 1931 machte die Reichsbank die Erfahrung, dass ihre Liquiditätshilfe an die Geschäftsbanken ihre Währungsreserven aufzehrten. Von 68 Prozent des ausgegebe-
Zwischen der damaligen Sorge um die Zahlungsfähigkeit der Zentralbank unter dem Goldstandard und den heutigen Warnungen vor möglichen Verlusten auf die im Zuge expansiver Geldpolitik erworbenen Vermögenswerte besteht eine Parallele: In beiden Fällen werden betriebswirtschaftliche Erwägungen ins Spiel gebracht und das mit Priorität gegenüber volkswirtschaftlichen Erwägungen und gegenüber dem Mandat der Zentralbank.

In der Weltwirtschaftskrise war die betriebswirtschaftliche Prioritätensetzung der Einlösungspflicht der Zentralbanken unter dem Goldstandard geschuldet. ${ }^{43}$ Heute gibt es dafür keine Berechtigung mehr, denn die Ausgabe von Zentralbankgeld bringt keine betriebswirtschaftlich relevante Verpflichtung mehr mit sich. Insofern kann man heute auch fragen, ob die von Bagehot für den Lender of last resort genannten Bedingungen, Solvenz der Banken, gute Sicherheiten, hohe Zinssätze, unbedingt erforderlich sind, denn diese Bedingungen waren damals durch die betriebswirtschaftliche Erwägung motiviert, dass die Zentralbank selbst keinen Anlass zu Zweifeln an ihrer Solvenz geben dürfe. ${ }^{44}$ Muss das in den Rechtsnormen vorgegebene Ziel der Preisstabilität nicht Vorrang haben? Warum konzentriert die deutsche Kritik an der EZB sich auf betriebswirtschaftliche und fiskalische Belange und nicht auf die eigentliche Aufgabe der Geldpolitik?

nen Bargelds sanken diese in kurzer Zeit auf 40 Prozent, die vom Gesetz vorgegebene Untergrenze. Siehe Born 1967, Schnabel 2004.

43 Die Alternative einer Aufgabe des Goldstandards galt bis zu den Krisen von 1931 und der Abkehr des Vereinigten Königreichs vom Goldstandard als undenkbar.

44 Sinn (2015a,b) begründete seine Kritik an den damaligen Notkrediten für die griechischen Banken mit deren Insolvenz. Dem hielt ich die Erfahrung von 1931 entgegen, als die Beendigung der Unterstützung der insolventen Danatbank durch die Reichsbank eine allgemeine Bankenkrise auslöste, die eine nochmalige dramatische Vertiefung der Wirtschaftskrise nach sich zog (Hellwig 2015b). Sinns negative Einschätzung der Solvenz der griechischen Banken beruhte auf einer fehlerhaften Analogie mit den zypriotischen Banken, die aufgrund ihrer Käufe griechischer Staatsanleihen nach dem Schuldenschnitt insolvent waren (Hellwig 2015c). Die griechischen Banken waren rekapitalisiert worden und hielten nicht mehr viele Staatsanleihen. Siehe auch Hellwig 2015g. 


\section{Die Zentralbanken in der Europäischen Währungsunion}

\subsection{Föderale Struktur und Vergemeinschaftung der Einkünfte}

Im Unterschied zu früheren Währungsunionen, etwa der lateinischen Münzunion des ausgehenden 19. Jahrhunderts, hat die Europäische Währungsunion mit der EZB eine eigene Zentralbank. Die nationalen Zentralbanken sind nicht verschwunden, sondern machen mit der EZB zusammen das ESZB aus. Das Nebeneinander und Miteinander der verschiedenen Zentralbanken macht das Eurosystem komplex und teilweise auch intransparent.

Komplexität und Intransparenz rühren auch daher, dass die nationalen Zentralbanken in verschiedenen Rollen auftreten:

- Als Eigentümer der EZB haben sie nach Maßgabe ihrer Kapitalanteile Anspruch auf eine Beteiligung an den Gewinnen des Eurosystems.

- Ihre Präsidenten sind Mitglieder des EZB-Rats, des obersten Beschlussgremiums des ESZB. ${ }^{45}$

- Als ausführende Organe des Eurosystems sind die nationalen Zentralbanken maßgeblich an der operativen Umsetzung der Politik des Eurosystems beteiligt.

- Nach Art. 14 Abs. 4 der Satzung des ESZB und der EZB (im folgenden kurz „Satzung“) haben sie außerdem das Recht, ,in eigener Verantwortung und auf eigene Rechnung“ weitere Aktivitäten durchzuführen; allerdings kann der EZB-Rat diese Aktivitäten mit ZweiDrittel-Mehrheit untersagen.

$\mathrm{Zu}$ den Aufgaben der EZB und des ESZB gehört es, „die Geldpolitik festzulegen und durchzuführen“ und „das reibungslose Funktionieren des Zahlungssystems zu fördern“. ${ }^{46}$ Dazu ermächtigt die Satzung die Mitglieder des ESZB zur Ausgabe von Banknoten, zur Hereinnahme von Einlagen auf Konten, zu Offen-Markt-Käufen und -Verkäufen von börsengängigen Wertpapieren, zur Kreditvergabe gegen Sicherheiten, zum Erlass von Mindestreservevorschriften und zur Schaffung von Einrichtungen, „um effi-

45 Es ist dies eine persönliche Mitgliedschaft. Eine Wahrnehmung der Mitwirkungsrechte durch einen anderen „Vertreter“ der nationalen Zentralbank ist ausgeschlossen, es sei denn, der Präsident sei „für längere Zeit an der Teilnahme an Sitzungen des EZB-Rats verhindert“. In diesem Fall kann er für die Zeit der Verhinderung einen Stellvertreter benennen. Siehe Art. 10 der Satzung.

46 Siehe Art. 127 des Vertrags über die Arbeitsweise der Europäischen Union (AEUV). ziente und zuverlässige Zahlungssysteme zu gewährleisten“.

Wir sind es gewohnt, die Deutsche Bundesbank als eine rein nationale Institution anzusehen. Jedoch ist sie in ihrer Funktion als ausführendes Organ des Eurosystems eine europäische Institution und als solche den durch EUVertrag und Satzung vorgegebenen Pflichten unterworfen. Auch die Mitwirkung des Präsidenten im EZB-Rat gilt der Erfüllung der vom EU-Vertrag und der Satzung vorgegebenen Aufgaben dieses Gremiums.

Dass die nationalen Zentralbanken als Organe des ESZB nicht unabhängig agieren, spiegelt sich in den Regeln für die Ermittlung und Verteilung der Einkünfte bzw. Gewinne des Eurosystems. Nach Art. 32 der Satzung werden die „Einkünfte, die den nationalen Zentralbanken aus der Erfüllung der währungspolitischen Aufgaben zufließen“ (Art. 32 Abs. 1) addiert und ,unter den nationalen Zentralbanken entsprechend ihren eingezahlten Anteilen am Kapital der EZB verteilt“" (Art. 32 Abs. 5). Bei jeder nationalen Zentralbank entspricht der Betrag dieser monetären Einkünfte ,ihren jährlichen Einkünften aus Vermögenswerten, die sie als Gegenposten zum Bargeldumlauf und zu ihren Verbindlichkeiten aus Einlagen der Kreditinstitute hält. Diese Vermögenswerte werden von den nationalen Zentralbanken gemäß den vom EZB-Rat zu erlassenden Richtlinien gesondert erfasst“ (Art. 32 Abs. 2). „Der Betrag der monetären Einkünfte einer jeden nationalen Zentralbank vermindert sich um den Betrag etwaiger Zinsen, die von dieser Zentralbank auf ihre Verbindlichkeiten auf Einlagen der Kreditinstitute ... gezahlt werden“(Art. 32 Abs. 4).

In der Erfüllung währungspolitischer Aufgaben behandelt der Vertrag die nationalen Zentralbanken wirtschaftlich als eine Einheit. Nur die Betriebskosten der nationalen Zentralbanken gehen auf deren eigene Rechnung, sodann auch die nach Art. 14 Abs. 4 der Satzung durchgeführten nicht monetären Aktivitäten „in eigener Verantwortung und auf eigenes Risiko“.

Für die EZB selbst bestimmt Art. 33 der Satzung, dass die Gewinne an die nationalen Zentralbanken entsprechend ihren eingezahlten Anteilen am Kapital ausgeschüttet werden, soweit sie nicht in einen allgemeinen Reservefonds gehen. Ein etwaiger Verlust der EZB kann nach Art. 33 Abs. 2 der Satzung aus den monetären Einkünften der nationalen Zentralbanken nach Art. 32 der Satzung ausgeglichen werden. 


\subsection{Aktivitäten ,in eigener Verantwortung und auf eigene Rechnung“: Notkredite}

In der Praxis ist die Bestimmung der monetären Einkünfte einer nationalen Zentralbank komplizierter, als man bei oberflächlicher Lektüre der Satzung erwarten würde. Die Vorgabe von Art. 32 Abs. 2 der Satzung ist in gewissem Sinn widersprüchlich. Da ist einerseits davon die Rede, dass die einzubeziehenden Vermögenswerte von der nationalen Zentralbank „als Gegenposten zum Bargeldumlauf und zu ihren Verbindlichkeiten aus Einlagen der Kreditinstitute“ gehalten werden, andererseits davon, dass diese Vermögenswerte ,gemäß den vom EZB-Rat zu erlassenden Richtlinien gesondert erfasst" werden. Es ist aber nicht auszuschließen, dass die Summe der gesondert erfassten Vermögenswerte nicht mit dem Wert der Bemessungsgrundlage, das heißt des Bargeldumlaufs und der Verbindlichkeiten aus Einlagen der Kreditinstitute übereinstimmt.

Ein Auseinanderfallen von gesondert erfassten Vermögenswerten und Bemessungsgrundlage ist sogar zu erwarten, wenn eine nationale Zentralbank ,in eigener Verantwortung und auf eigenes Risiko" entsprechend Art. 14 Abs. 4 der Satzung zusätzliche Vermögenswerte erwirbt und den entsprechenden Betrag einer Geschäftsbank gutschreibt. Die Gutschrift für die Geschäftsbank erhöht deren Einlage bei der betreffenden Zentralbank, die zusätzlichen Vermögenswerte dagegen sind von der Vergemeinschaftung der monetären Einkünfte im ESZB ausgenommen. Die Bemessungsgrundlage für die Ermittlung der monetären Einkünfte steigt, die „Gegenposten“ dazu steigen nicht.

Man könnte vermuten, ein solcher Vorgang verletze den Vertrag. Aus Art. 32 Abs. 2 der Satzung sei zu schließen, dass Aktivitäten nach Art. 14 Abs. 4 nicht durch Erhöhungen von Bargeldumlauf oder Geschäftsbankeneinlagen bei der Zentralbank finanziert werden dürfen. Der EZB-Rat hat diesen Schluss nicht gezogen, sondern in bestimmten Fällen eine monetäre Finanzierung von Aktivitäten nach Art. 14 Abs. 4 zugelassen oder sogar vorgesehen. $\mathrm{Zu}$ nennen sind insbesondere die Notkredite, die nationale Zentralbanken an Geschäftsbanken vergeben, die nicht mehr den Bedingungen des ESZB genügen, zum Beispiel weil es ihnen an Vermögenswerten fehlt, die nach den Regeln des ESZB als Sicherheiten akzeptiert werden.

Als die Währungsunion geschaffen wurde, blieben Bankenregulierung und Bankenaufsicht außen vor. Die Regierungen und die nationalen Zentralbanken wollten diese Kompetenz nicht auch abgeben. Solange die Bankenaufsicht in nationaler Kompetenz lag, erschien es auch allen als angemessen, die Zuständigkeit für etwaige Probleme bei Banken in nationaler Kompetenz zu belassen.
Nach Schaffung der Währungsunion regelte man die Arbeitsteilung für den Fall einer Krise in einer Vielzahl von Memoranda of understanding, Absichtserklärungen der beteiligten Finanzministerien und Zentralbanken. Danach sollten die Regierungen für Solvenzprobleme und Rekapitalisierungen von Banken zuständig sein, die nationalen Zentralbanken für Liquiditätsprobleme einzelner Banken und die EZB für Liquiditätsprobleme des Systems als Ganzem. ${ }^{47}$

In diesem Zusammenhang wurden Liquiditätshilfen (,Emergency liquidity assistance“, im Weiteren abgekürzt ELA) als Aktivitäten im Sinne von Art. 14 Abs. 4 der Satzung deklariert, die ,von den nationalen Zentralbanken in eigener Verantwortung und auf eigene Rechnung wahrgenommen" werden. Daraus ergibt sich der oben angesprochene Widerspruch in den Rechtsnormen. Bei einer Liquiditätshilfe vergibt die Zentralbank einen Kredit an eine Geschäftsbank („Notkredit“) und erhöht gleichzeitig die Einlage, auf die die Geschäftsbank bei der Zentralbank zugreifen kann. Die Einlagenerhöhung erhöht die Bemessungsgrundlage für die Ermittlung der monetären Einkünfte nach Art. 32 Abs. 2, aber der Kredit ist nach Art. 14 Abs. 4 von der Vergemeinschaftung der Einkünfte ausgenommen.

Das Eurosystem löst den Widerspruch auf folgende Weise: ${ }^{48}$ In den Beschlüssen des EZB-Rats über die Verteilung der monetären Einkünfte der nationalen Zentralbanken der Mitgliedstaaten, deren Währung der Euro ist, zuletzt Beschluss EZB/2016/36, ${ }^{49}$ werden jeweils in einem Anhang die Positionen der harmonisierten Zentralbankbilanzen aufgeführt, die als Teil der Bemessungsgrundlage nach Art. 32 Abs. 2 der Satzung angesehen werden, und in einem anderen Anhang die Positionen, die als „Gegenposten“ der Bemessungsgrundlage angesehen werden, die „gesondert erfassten Vermögenswerte“. Für den Fall, dass die so ermittelten Werte von Bemessungsgrundlege und „Gegenposten“ nicht übereinstimmen, wird der größere der beiden Werte genommen, und die Differenz wird der Gegenposition zugerechnet mit einer fiktiven Verzinsung zum Zinssatz für Hauptrefinanzierungsgeschäfte

47 Hellwig (2007) erörtert die Probleme dieses Arrangements. Siehe auch Hellwig 2014, 2015a.

48 Der EZB-Rat stützt sich dabei auf die in Art. 32 Abs. 6 und Abs. 7 der Satzung enthaltene Ermächtigung zum Erlass von Richtlinien für die Verrechnung und Ausgleich der Salden aus der Verteilung der monetären Einkünfte und zum Treffen "alle(r) weiteren Maßnahmen, die zur Anwendung dieses Artikels erforderlich sind.“

49 Der Beschluss EZB/2016/36 löste den früheren Beschluss EZB/2010/23 ab. Die Unterschiede fallen nicht ins Gewicht. Der Einfachheit halber beziehe ich mich im folgenden auf den späteren, heute geltenden Beschluss, auch wenn es um frühere Vorgänge geht. 
des ESZB mit Geschäftsbanken (Art. 3 Abs. 2 des Beschlusses EZB/2016/36).

Die mit dem Notkredit geschaffene zusätzliche Aktivposition einer nationalen Zentralbank geht als solche nicht in die Vergemeinschaftung der Gewinne ein. Jedoch geht die Einlagenerhöhung als zusätzliche Passivposition in die Vergemeinschaftung ein; sie ist Teil der Bemessungsgrundlage nach Art. 32 Abs. 2 der Satzung. Als „Gegenposten" fungiert ein fiktiver Refinanzierungskredit an eine Geschäftsbank zum Hauptrefinanzierungszinssatz des Eurosystems. Das Zinseinkommen auf diesen fiktiven Kredit wird den monetären Einkünften der betreffenden Zentralbank zugerechnet. Eine etwaige Differenz zwischen dem tatsächlich erzielten Zinseinkommen aus dem Notkredit und dem veranschlagten Zinseinkommen auf den fiktiven Kredit verbleibt bei der nationalen Zentralbank, die auch das Risiko des Notkredits trägt.

Sinn $(2014$, S. 170 ff.) sowie Fuest und Sinn $(2015,2016)$ haben gewarnt, dass die Zentralbanken und Steuerzahler anderer Länder nicht wirklich gegenüber den Risiken der Vermögenswerte abgeschottet sind, die eine Zentralbank „in eigener Verantwortung und auf eigene Rechnung“ nach Art. 14 Abs. 4 der Satzung vornimmt. In der Diskussion zu den Notkrediten der griechischen Zentralbank für griechische Geschäftsbanken 2015 behaupteten sie, die griechischen Geschäftsbanken seien überschuldet, daher seien die Notkredite mit erheblichen Risiken für den deutschen Steuerzahler verbunden. ${ }^{50}$ Es sei ja nicht auszuschließen, dass das Zinseinkommen auf den fiktiven Kredit den Anteil der nationalen Zentralbank am Gewinn des ESZB übersteige, die nationale Zentralbank aber aufgrund von Ausfällen nicht in der Lage sei, die dann anfallende Verpflichtung zur Zahlung der Differenz zu erfüllen.

Diese Warnung ist aus zwei Gründen problematisch. Zum einen wird nicht begründet, warum die Vergabe von Notkrediten durch die griechische Zentralbank dem deutschen Steuerzahler schaden könnte. Wenn der Schöpfung von Zentralbankgeld, die mit der Vergabe von Notkrediten verbunden ist, ein fiktives Zinseinkommen auf fiktive Refinanzierungskredite zugerechnet wird, so erhalten die übrigen Zentralbanken einen Anspruch, durch den sie und damit auch die Steuerzahler ihrer Staaten besser gestellt werden. Sollte dieser Anspruch ausfallen, so entfällt die Besserstellung, aber das Ergebnis ist für den deutschen

50 Hellwig 2015g, Fuest und Sinn 2015, 2016. Die Argumentation findet sich unverändert bei Fuest und Sinn (2018) und bildet dort die Grundlage für alle weiteren Überlegungen.
Steuerzahler nicht schlechter als wenn die Notkredite nicht vergeben worden wären..$^{51}$

Zum andern sind nach Art. 32 Abs. 4 der Satzung des ESZB und der EZB die Finanzierungskosten der Zentralbank von dem fiktiven Zinseinkommen abzuziehen. Tatsächlich bestand die Gegenposition zu den Notkrediten nicht in Geschäftsbankeneinlagen, sondern in Verbindlichkeiten gegenüber der EZB, denn in der Krise 2015 brauchten die griechischen Geschäftsbanken die Notkredite, um den Abfluss von Mitteln ins Ausland zu kompensieren. Durch die Auslandsüberweisungen wurden die mit den Notkrediten geschaffenen Einlagen der Geschäftsbanken bei der griechischen Zentralbank in Verbindlichkeiten der Zentralbank gegenüber der EZB umgewandelt. Die Verbindlichkeiten gegenüber der EZB werden ebenfalls zum Hauptrefinanzierungszinssatz verzinst (siehe unten $\mathrm{Ab}$ schnitt 3.4). Der Nettobetrag, mit dem die Notkredite in die Vergemeinschaftung der Gewinne eingingen, war daher Null..$^{52}$ Da hatte der deutsche Steuerzahler zwar nichts zu gewinnen, aber auch nichts zu verlieren $!^{53}$

51 Ohnehin ist unklar, wann genau ein Zahlungsausfall einer nationalen Zentralbank eintritt. Sinn (2014, S. 172) identifiziert Zahlungsunfähigkeit und Überschuldung, ohne zu berücksichtigen, dass, wie die erwähnte Erfahrung der Bundesbank von 1973 gezeigt hat, die Überschuldung einer Zentralbank nicht notwendigerweise eine Zahlungsunfähigkeit zur Folge hat. Er bemängelt, dass die Satzung des ESZB und der EZB nichts zur Eigenkapitalausstattung der nationalen Zentralbanken enthält, ohne zu sehen, dass dieses Thema der nationalen Gesetzgebung vorbehalten ist.

52 Bei Fuest und Sinn (2018) geht es genau um den hier besprochenen Fall, wo die Gegenposition zu den Notkrediten in Verbindlichkeiten gegenüber der EZB besteht. Bei Berücksichtigung der Finanzierungskosten für diese Gegenposition gemäß Art. 32 Abs. 4 der Satzung wird ihre Analyse hinfällig, denn der aufgrund der Notkredite erforderliche Beitrag zu den monetären Einkünften des ESZB saldiert sich dadurch zu Null.

53 Zur Einordnung dieser Diskussion sind auch die Zahlen hilfreich: Die griechischen Notkredite lagen in ihrem Maximum im Sommer 2015 bei 90 Milliarden Euro. Der Hauptrefinanzierungszinssatz betrug 0,05 Prozent, der Zinssatz für die Einlagen der Geschäftsbanken -0,20 Prozent. Aufs Jahr bezogen käme das auf eine fiktive Verzinsung von 45 Millionen Euro für die Notkredite, ferner auf negative Kosten von -180 Millionen Euro bei den Geschäftsbankeneinlagen, zusammen also 225 Millionen Euro. Tatsächlich bestand die Gegenposition zu den Notkrediten nicht in Geschäftsbankeneinlagen, sondern in Verbindlichkeiten gegenüber der EZB in Höhe von über 100 Milliarden Euro, mit kalkulatorischen Zinskosten von aufs Jahr bezogen 50 Millionen Euro. Zur Einordnung der Warnung vor einem Zahlungsausfall sei darauf hingewiesen, dass der für 2015 insgesamt ausgewiesene (und ausgeschüttete) Gewinn der griechischen Zentralbank mehr als 1,1 Milliarden Euro betrug, dies vor allem, weil die griechischen Geschäftsbanken hohe Zinsen auf die Notkredite zahlten. Von denen hatte der deutsche Steuerzahler allerdings nichts. 


\subsection{Aktivitäten „in eigener Verantwortung und auf eigene Rechnung“: Netto- Finanzaktiva}

Die Warnung von Fuest und Sinn betrifft auch die anderen sogenannten Finanzaktiva, die die nationalen Zentralbanken aufgrund von Aktivitäten ,in eigener Verantwortung und auf eigene Rechnung“ halten und mit der Schöpfung von Zentralbankgeld finanzieren. Das Wort „Finanzaktiva" (Financial assets) steht hier im Gegensatz zu den Aktiva, die aufgrund von geldpolitischen Maßnahmen gehalten werden (relating to monetary policy operations); entsprechend bezeichnen „Finanzpassiva“ (Financial liabilities) alle Passiva, die nicht als monetäre Verbindlichkeiten anzusehen sind, einschließlich des Eigenkapitals. Als „Netto-Finanzaktiva“ (Net financial assets) bezeichnet man den Saldo zwischen Finanzaktiva und Finanzpassiva, das heißt den Betrag, zu dem Finanzaktiva nicht durch Finanzpassiva, sondern durch Geldschöpfung finanziert werden. Das sogenannte Agreement on net financial assets (ANFA) lässt eine solche Finanzierung $\mathrm{zu}$, begrenzt aber den zulässigen Betrag (außer für Notkredite). ${ }^{54}$

Auch hier könnte man vermuten, die monetäre Finanzierung von Aktivitäten, die die nationalen Zentralbanken nach Art. 14 Abs. 4 der Satzung ,in eigener Verantwortung und auf eigene Rechnung" durchführen, stehe im Widerspruch zu der Formulierung von Art. 32 Abs. 2 der Satzung, wonach Einkünfte aus Vermögenswerten, die „als Gegenposten zum Bargeldumlauf und zu ... Verbindlichkeiten aus Einlagen der Kreditinstitute“ gehalten werden, als monetäre Einkünfte anzusehen sind. Auch hier behilft man sich mit dem im vorstehenden Abschnitt erläuterten Verfahren, dass der Saldo zwischen monetären Passiva und monetären Aktiva mit einer Verzinsung zum Hauptrefinanzierungszinssatz in die Berechnung der monetären Einkünfte einbezogen wird.

Dieses Vorgehen des EZB-Rats ist historisch zu erklären. $\mathrm{Zu}$ den Finanzaktiva gehören viele Dinge, die die nationalen Zentralbanken von alters her in ihren Bilanzen hatten, die sie nicht an das Eurosystem übertragen wollten, die zum Teil auch nichts mit Geldpolitik zu tun hatten..$^{55}$ Darunter finden sich Währungsreserven, Einlagen beim Internationalen Währungsfonds und andere Fremdwährungspositionen, ferner auch zweckgebundene Vermögenswerte, mit denen die nationalen Zentralbanken Finanzdienstleistungen für Dritte erbringen. Ein Beispiel

54 Für Einzelheiten zu ANFA und zur Rolle von ANFA im vergangenen Jahrzehnt siehe die Diskussion in Teil 4.

55 Zum folgenden siehe Deutsche Bundesbank 2016. sind Fonds zur Erbringung von Pensionsleistungen für Mitarbeiter, ein anderes die Verwaltung von Währungsreserven der Zentralbanken von Drittländern; so verwaltet die Banque de France die Währungsreserven der afrikanischen Länder der früheren Franc-Zone, deren Währung heute an den Euro gebunden ist.

Schließlich finden sich hier auch bestimmte im $\mathrm{Zu}$ sammenhang mit geldpolitischen Operationen entstandene Kredit- und Wertpapierportefeuilles aus der Vergangenheit, darunter in größerem Umfang staatliche Schuldtitel. Als der EZB-Rat zu Anfang seiner Tätigkeit beschloss, seine Geldpolitik nur über die Bereitstellung von Liquidität für Kreditinstitute zu betreiben, wurde den nationalen Zentralbanken, die bis dahin den Erwerb staatlicher Schuldtitel als Hauptinstrument der Geldpolitik eingesetzt hatten, gestattet, diese Titel weiter zu halten - und sogar zu erneuern - als „nicht-geldpolitische“ Aktivitäten „in eigener Verantwortung und auf eigene Rechnung“. Auf diese Weise vermied man es, Staaten und Märkte mit den Folgen einer Liquidation oder eines Auslaufens dieser Titel zu belasten.

Aus heutiger Sicht erscheint dieses Vorgehen als Anachronismus, denn spätestens seit 2015 verwendet das ESZB selbst die Offen-Markt-Politik als maßgebliches Instrument der Geldpolitik. Jedoch hat man den Übergang von einer Geldpolitik vermittels der Bereitstellung von Liquidität für Kreditinstitute zu einer Geldpolitik durch Offen-Markt-Operationen nicht zum Anlass genommen, die Verwendung von Geldschöpfung zum Kauf von Finanzaktiva zu beenden, sondern stattdessen das für die Netto-Finanzaktiva angewandte Verfahren der Ermittlung der monetären Einkünfte auf die im Rahmen des seit 2015 verfolgten „Public Sector Purchase Programme“ gekauften Wertpapiere ausgeweitet. Diese fallen zwar in den Bereich der Geldpolitik, aber sie werden von den nationalen Zentralbanken in eigener Verantwortung und auf eigenes Risiko im Sinne von Art. 14 Abs. 4 der Satzung vorgenommen; jede Zentralbank kauft Anleihen des eigenen Staates, die Deutsche Bundesbank Anleihen der Bundesrepublik Deutschland, die Banca d'Italia Anleihen der Italienischen Republik usw.

Diese auf eine Anregung des Präsidenten der Deutschen Bundesbank zurückgehende Regelung schützt den deutschen Steuerzahler vor den Ausfallrisiken der Anleihen anderer Mitgliedstaaten. Sie hat aber auch dazu beigetragen, dass der Gewinn der Bundesbank 2017 bei einer Bilanzsumme von 1,7 Billionen Euro nur 2 Milliarden Euro ausmachte, der Gewinn der Banca d'Italia dagegen bei einer Bilanzsumme von 0,9 Billionen Euro auf 3,8 Milliarden Euro kam. Die vergleichsweise hohen Zinsen auf italienische Staatsanleihen gingen nicht in die Vergemeinschaftung der monetären Einkünfte des ESZB ein, nur die 
Zinsen auf die fingierten Refinanzierungskredite, die als Gegenposten zu der mit den Wertpapierkäufen verbundenen Schöpfung von Zentralbankgeld angesetzt wurden.

\subsection{Forderungen und Verbindlichkeiten innerhalb des ESZB}

Die Satzung des ESZB und der EZB sagt nichts über die Einkünfte, die eine nationale Zentralbank aus Vermögenswerten erzielt, die sie mit Mitteln einer anderen Zentralbank finanziert. Ein Beispiel dafür liefern die Dollar-Kredite, die die nationalen Zentralbanken ihren Geschäftsbanken in der Lehman-Krise 2008 in Form von Reverse repos zur Verfügung stellten. ${ }^{56}$ Die nationalen Zentralbanken hatten die Dollars über eine Swap-Vereinbarung mit der EZB erhalten, diese wiederum über eine Swap-Vereinbarung mit der amerikanischen Federal Reserve. Die Federal Reserve selbst hatte die Swap-Vereinbarung 2008 vorgeschlagen, um die Liquiditätsprobleme europäischer Banken zu beheben, die gewohnt waren, ihre Dollargeschäfte über den Geldmarkt zu refinanzieren und in Schwierigkeiten kamen, als nach dem Lehman-Konkurs die Geldmärkte zusammenbrachen. ${ }^{57}$ In diesem Fall erzielt die nationale Zentralbank Zinseinkommen auf die DollarKredite an die Geschäftsbanken, diese werden aber nicht aus der Bargeldausgabe oder den Einlagen der Kreditinstitute finanziert, sondern über die Swap-Vereinbarungen der nationalen Zentralbank mit der EZB und der EZB mit der Federal Reserve.

Nach den Beschlüssen des EZB-Rats werden diese Zinsen gleichwohl als Teil der monetären Einkünfte der Mitglieder des ESZB behandelt. In dem erwähnten Beschluss EZB/2016/36 über die monetären Einkünfte im Eurosystem werden die Zinseinkünfte der nationalen Zentralbanken aus den durch Swap-Vereinbarungen ermöglichten Fremdwährungskrediten an Geschäftsbanken explizit aufgeführt. Die Euro-Komponente der Swap-Vereinbarung zwischen EZB und nationaler Zentralbank wird als Verbindlichkeit der nationalen Zentralbank gegenüber der EZB ausgewiesen und der Bemessungsgrundlage für die Ermittlung der monetären Einkünfte der nationalen Zentralbank zugerechnet.

Der Beschluss EZB/2016/36 bezieht auch die sogenannten Target-Salden in die Ermittlung und Verteilung der

56 Rechtlich waren dies Verträge, bei denen die Geschäftsbanken den Zentralbanken zu einem vereinbarten Preis Sicherheiten gegen Dollars verkauften und $\mathrm{zu}$ einem ebenfalls vereinbarten Preis für einen späteren Termin zurückkauften.

57 Tooze 2018, S. 204f. und S. $212 \mathrm{ff}$ monetären Einkünfte ein. Das Akronym Target steht für „Trans-European Automated Real-time Gross settlement Express Transfer system" und bezeichnet ein elektronisches System zur augenblicklichen Abwicklung von Zahlungen innerhalb des Eurosystems. Nach Art. 127 Abs. 2 des Vertrags über die Arbeitsweise der Europäischen Union gehört es zu den Aufgaben des ESZB, „das reibungslose Funktionieren des Zahlungssystems zu fördern“. Nach Art. 22 der Satzung können die EZB und die nationalen Zentralbanken „Einrichtungen zur Verfügung stellen..., um effiziente und zuverlässige Verrechnungs- und Zahlungssysteme innerhalb der Union und im Verkehr mit dritten Ländern zu gewährleisten“. Dazu dient das Target-System.

Als Banken der Geschäftsbanken stehen moderne Zentralbanken im Zentrum der Zahlungssysteme ihrer Jurisdiktionen. Überweisungen von einer Bank an eine andere erfolgen durch Übertragungen von dem Zentralbankkonto der einen Bank auf das Zentralbankkonto der anderen Bank. Im Eurosystem ist der Vorgang komplizierter, da die Geschäftsbanken ihre Konten bei den nationalen Zentralbanken und nicht bei der EZB haben. Die nationalen Zentralbanken ihrerseits haben Konten bei der EZB.

Wenn eine deutsche Geschäftsbank Geld an eine französische Bank überweisen will, so gibt sie den Auftrag an die Bundesbank; diese beauftragt die EZB, den Betrag der Überweisung von ihrem Konto bei der EZB auf das Konto der Banque de France bei der EZB zu übertragen; die Banque de France wiederum schreibt den Betrag der französischen Geschäftsbank gut. Am Ende des Gesamtvorgangs sind die Kontostände der deutschen Geschäftsbank bei der Bundesbank und der Bundesbank bei der EZB um den Betrag der Überweisung niedriger; die Kontostände der Banque de France bei der EZB und der französischen Geschäftsbank bei der Banque de France sind entsprechend höher.

Wie beeinflussen die Senkung der Einlagen der deutschen Geschäftsbank bei der Bundesbank und die Erhöhung der Einlagen der französischen Geschäftsbank bei der Banque de France die monetären Einkünfte, den zu vergemeinschaftenden Teil der Gewinne, von Bundesbank und Banque de France? Nähme man Art. 32 Abs. 2 der Satzung des ESZB und der EZB wörtlich, so würde die Bemessungsgrundlage für die Ermittlung der monetären Einkünfte bei der Bundesbank verringert und die Bemessungsgrundlage bei der Banque de France vergrößert, und die „Gegenposten“ müssten entsprechend angepasst werden. Diese Wirkung wird vermieden, indem man die „TargetKonten" in die Bestimmung der monetären Einkünfte einbezieht. Bei der Bundesbank wird die Verringerung der Einlage der deutschen Geschäftsbank aufgrund der Überweisung durch eine Verringerung von „Target-Forderun- 
gen“ oder Erhöhung von „Target-Verbindlichkeiten“ neutralisiert; für die Erhöhung der Einlage der französischen Geschäftsbank bei der Banque de France gilt Entsprechendes. Die Target-Verbindlichkeiten werden als Teil der Bemessungsgrundlage behandelt, die Target-Forderungen zählen zu den als Gegenposten der Bemessungsgrundlage gesondert erfassten Vermögenswerten.

Da es um die Ermittlung der Einkünfte geht, muss man diesen Positionen auch einen Zinssatz zuordnen. Dazu dient jeweils der Halbsatz ,die zum Referenzzinssatz verzinst werden“. Target-Forderungen werden für die Ermittlung der monetären Einkünfte so behandelt, als wären sie Kredite an Geschäftsbanken zum Hauptrefinanzierungszinssatz, Target-Verbindlichkeiten so behandelt als wären sie Einlagen von Geschäftsbanken zu eben diesem Zinssatz. Die Verwendung desselben Zinssatzes für Target-Forderungen und Target-Verbindlichkeiten bewirkt, dass die Summe der den verschiedenen Zentralbanken zurechenbaren vom Eurosystem insgesamt erzielten monetären Einkünfte durch die Überweisung von einer deutschen Geschäftsbank an eine französische Geschäftsbank nicht verändert wird.

Als letzter Punkt in diesem Abschnitt ist zu erwähnen, dass nach den zitierten Beschlüssen des EZB-Rats auch der Bargeldumlauf in das System der Forderungen und Verbindlichkeiten zwischen den beteiligten Zentralbanken eingebaut wird. Für die Bargeldausgabe jeder Zentralbank wird ein Normwert festgesetzt. ${ }^{58}$ Übersteigt die tatsächliche Bargeldausgabe den Normwert, so wird der Überschuss als Intra-Eurosystem-Verbindlichkeit verbucht; ist die tatsächliche Bargeldausgabe niedriger als der Normwert, so wird die Differenz als Intra-Eurosystem-Forderung verbucht. Beides geht mit einer Verzinsung zum Hauptrefinanzierungszinssatz in die Berechnung der monetären Einkünfte der nationalen Zentralbanken ein (Art. 2, Abs. 2 und Anhänge zu Beschluss EZB/2016/36).

\subsection{Die Irrelevanz der Target-Salden für die Gewinnverteilung unter den Zentral- banken}

Aus dem Umstand, dass bestimmte Größen in einer Bilanz als Forderungen oder Verbindlichkeiten aufgeführt werden, kann man nicht ohne weiteres ersehen, welche Ansprüche die Inhaber der Forderungen haben und welche Pflichten die Emittenten der Verbindlichkeiten. Im ersten

58 Die Normwerte sind als Anteile am Gesamtbargeldumlauf des Eurosystems definiert. Für die EZB liegt der Normanteil bei 0,08, für die nationalen Zentralbanken jeweils bei 0,92 mal ihrem Kapitalanteil an der EZB.
Teil dieses Aufsatzes hatte ich bereits erläutert, dass die Aufführung der ausgegebenen Banknoten unter den Verbindlichkeiten einer Zentralbank nicht so zu interpretieren ist, dass die Inhaber dieser Banknoten einen Anspruch und die Zentralbank selbst eine Verpflichtung hätte. Bei Bargeld bestehen solche Ansprüche und Verpflichtungen nicht, und die Passivierung der Bargeldausgabe steht im Widerspruch zum Zeitwertprinzip für die Rechnungslegung.

Für die Target-Salden gilt Ähnliches. Auch sie stellen keine Forderungen und Verbindlichkeiten in dem Sinn dar, dass sich für die betreffende nationale Zentralbank daraus ein Anspruch oder eine Verpflichtung auf Zahlung der angegebenen Beträge ergibt. Nach derzeit geltendem Recht gibt es Rechtswirkungen der Target-Salden nur bei der Ermittlung des Teils der Gewinne der nationalen Zentralbanken, der dem Eurosystem zuzurechnen ist.

Bei näherer Betrachtung zeigt sich allerdings, dass die Gewinnansprüche der einzelnen Zentralbanken gar nicht von den Target-Salden abhängen und auch nicht von den Bargeld-Salden. Im Folgenden betrachte ich die monetären Einkünfte einer Zentralbank i. Es seien $B_{i}$ die Bargeldausgabe dieser Zentralbank, $\mathrm{B}^{\star}{ }_{\mathrm{i}}$ die Norm für ihre Bargeldausgabe, $D_{i}$ die Geschäftsbankeneinlagen und anderen zur Bemessungsgrundlage gehörenden Verbindlichkeiten außer den Target-Salden und dem Bargeld. Es seien ferner $A_{i}$ die als Gegenposten zur Bemessungsgrundlage gesondert erfassten Vermögenswerte außer den Target- und BargeldSalden und $\mathrm{T}_{\mathrm{i}}$ die Target-Forderung dieser Zentralbank $\left(\mathrm{T}_{\mathrm{i}}<\right.$ 0 entspricht einer Target-Verbindlichkeit). Schließlich seien $R_{i}$ die Einkünfte auf die in $A_{i}$ enthaltenen Vermögenswerte, $K_{i}$ die Zinskosten auf die in $D_{i}$ enthaltenen Verbindlichkeiten und $\mathrm{r}_{\mathrm{M}}$ der Hauptrefinanzierungszinssatz.

Gemäß Art. 32 Abs. 2 der Satzung und EZB-Rats-Beschluss EZB/2016/36 kommt dann die Bemessungsgrundlage für die Bestimmung der monetären Einkünfte der Zentralbank i auf den Betrag

$$
B^{\star}{ }_{i}+D_{i}-\min \left(0, T_{i}\right)+\max \left(0, B_{i}-B^{\star}{ }_{i}\right) .
$$

Die gesondert erfassten Vermögenswerte kommen auf

$$
A_{i}+\max \left(0, T_{i}\right)+\max \left(0, B^{\star}{ }_{i}-B_{i}\right) .
$$

Die Differenz zwischen der Bemessungsgrundlage und den gesondert erfassten Vermögenswerten beträgt

$\mathrm{B}^{\star}{ }_{\mathrm{i}}+\mathrm{D}_{\mathrm{i}}-\min \left(0, \mathrm{~T}_{\mathrm{i}}\right)+\max \left(0, \mathrm{~B}_{\mathrm{i}}-\mathrm{B}^{\star}{ }_{\mathrm{i}}\right)$

$-\left[A_{i}+\max \left(0, T_{i}\right)+\max \left(0, B^{\star}{ }_{i}-B_{i}\right)\right]$

$=B_{i}+D_{i}-A_{i}-T_{i}$.

Die monetären Einkünfte der Zentralbank i ergeben sich als Summe

$$
R_{i}-K_{i}+r_{M}\left(T_{i}+B^{\star}{ }_{i}-B_{i}\right)+r_{M}\left(B_{i}+D_{i}-A_{i}-T_{i}\right),
$$
aus der Differenz $R_{i}-K_{i}$, der Verzinsung der Target- und Bargeld-Salden und der Verzinsung der Differenz zwischen Bemessungsgrundlage und gesondert erfassten Ver- 
mögenswerten. Dieser Ausdruck vereinfacht sich zu $R_{i}-K_{i}$ $+r_{M}\left(B^{\star}{ }_{i}+D_{i}-A_{i}\right)$. Sowohl die Target-Salden als auch die Bargeld-Salden fallen heraus. Die monetären Einkünfte des ESZB insgesamt (einschließlich der EZB) ergeben sich durch Summierung:

$\left.A_{i}\right)$,

$\Sigma_{\mathrm{i}}\left[\mathrm{R}_{\mathrm{i}}-\mathrm{K}_{\mathrm{i}}+\mathrm{r}_{\mathrm{M}}\left(\mathrm{B}^{\star}{ }_{\mathrm{i}}+\mathrm{D}_{\mathrm{i}}-\mathrm{A}_{\mathrm{i}}\right)\right]=\Sigma_{\mathrm{i}}\left[\mathrm{R}_{\mathrm{i}}-\mathrm{K}_{\mathrm{i}}+\mathrm{r}_{\mathrm{M}}\left(\mathrm{B}_{\mathrm{i}}+\mathrm{D}_{\mathrm{i}}-\right.\right.$ wobei ich den Umstand benutzt habe, dass die Summe der Normwerte für den Bargeldumlauf gleich dem tatsächlichen Bargeldumlauf ist.

Da die monetären Einkünfte des ESZB insgesamt unabhängig von den Target-Salden sind, sind auch die anteiligen Gewinnausschüttungen an die nationalen Zentralbanken unabhängig davon. Die hohe Target-Forderung der Deutschen Bundesbank an die EZB hat keinen Einfluss auf die Einkünfte, die die Bundesbank aus ihrer Tätigkeit als Mitglied des ESZB erzielt.

Zur „Verzinsung“ der Target-Salden schreibt Sinn (2012, S. 179): „Die Zinsen werden jährlich den Beständen zugeschlagen und werden in das kommende Jahr übertragen.“59 Er erklärt ferner, es sei „nicht einsichtig, dass sie (die Target-Salden) nur zum jeweiligen Hauptrefinanzierungszinssatz verzinst werden“, und spekuliert, die Verzinsung müsse als Vorkehrung für den Fall eines Austritts eines Landes aus der Währungsunion oder für den Fall einer Insolvenz einer Zentralbank gedacht sein: „Without this possibility in the background, the interest on Target debt is meaningless. “60

Diese Interpretation der „Verzinsung“ der Target-Salden ist falsch. Für eine Übertragung in das kommende Jahr gibt es keine Rechtsgrundlage, und eine solche Übertragung findet auch nicht statt. Sinn übersieht die oben beschriebene spezifische Funktion der „Verzinsung“ der Target-Salden in dem Kontext, in dem sie in den Rechtsnormen vorkommt. Der Halbsatz „die zum Referenzzinssatz verzinst werden“ steht im Kontext der Ermittlung der monetären Einkünfte der nationalen Zentralbanken und entfaltet keine darüber hinausgehende Rechtswirkung. Dass die „Verzinsung“ zum jeweiligen Hauptrefinanzierungszinssatz erfolgt, erklärt sich aus diesem Kontext, denn dies ist auch der Zinssatz, mit dem andere Salden in die Ermittlung der monetären Einkünfte der nationalen Zentralbanken eingehen. ${ }^{61}$ Eine darüber hinausgehende Spekulation über die Motivation für die „Verzinsung“ erübrigt sich.

59 Gleichlautend Sinn 2014, S. 195.

60 Siehe Sinn 2014, S. 196.

61 Die Unabhängigkeit des Aggregats von den Target-Salden wäre übrigens auch gegeben, wenn die Zinssätze für Target-Salden und für die Differenz zwischen Bemessungsgrundlage und gesondert erfassten Vermögenswerten nicht gleich wären. In diesem Fall enthielte das
Zur betriebswirtschaftlichen Einordnung mag eine Analogie hilfreich sein. Wenn ein in München ansässiger Kunde der Deutschen Bank Geld an einen in Köln ansässigen Kunden der Deutschen Bank überweist, so bewirkt diese Überweisung nicht nur eine Erhöhung des Kontostands bei dem Kölner Kunden und eine Senkung bei dem Münchner Kunden, sondern auch eine Erhöhung des Kontostands der Kölner Filiale der Deutschen Bank bei der Zentrale und eine Senkung des Kontostands der Münchner Filiale. Die Rechtswirkungen dieser Veränderungen hängen von den internen Reglementen der Organisation Deutsche Bank ab. Dass die Kontostände bilanziell als Forderungen und Verbindlichkeiten ausgewiesen sind, bedeutet nicht, dass die Filiale Köln eine schuldrechtlich relevante Forderung und die Filiale München eine schuldrechtlich relevante Verbindlichkeit gegenüber der Zentrale hätten.

Ähnliches gilt organisationsübergreifend, wenn im gegebenen Beispiel der Kölner Empfänger sein Konto nicht bei der Deutschen Bank, sondern bei der Sparkasse Köln hat. Dann dürfte die Überweisung über die Landeszentralbanken bzw. Hauptstellen München und Köln der Deutschen Bundesbank laufen, und über die Konten dieser Hauptstellen bei der Zentrale der Bundesbank. Die Bewegungen auf diesen Konten haben auch keine Rechtswirkungen im Verhältnis zwischen den Landeszentralbanken bzw. Hauptstellen und der Bundesbank, es sei denn die internen Reglemente der Organisation Deutsche Bundesbank sähen solche vor.

Nun mag man einwenden, die Bundesbank sei doch, anders als die Filialen der Deutschen Bank oder die Landeszentralbanken, rechtlich unabhängig. Insofern müsse ihr Status gegenüber der EZB und gegenüber den übrigen nationalen Zentralbanken doch ein anderer sein als der der Münchner Filiale der Deutschen Bank gegenüber der Zentrale und gegenüber den übrigen Filialen der Deutschen Bank. Dieser Einwand wäre richtig, wenn es um Aktivitäten der Bundesbank außerhalb der währungspolitischen Aufgaben des ESZB ginge. Der Zahlungsverkehr gehört aber zu den währungspolitischen Aktivitäten des ESZB. Bei diesen Aktivitäten ist die Bundesbank nicht selbständig, sondern nach Maßgabe von Vertrag und Satzung den Regeln des ESZB unterworfen. Zu diesen Regeln gehört der Umgang mit den Target-Salden und anderer Intra-Eurosystem-Salden bei der Ermittlung und Verteilung der monetären Einkünfte der nationalen Zentralbanken.

Aggregat die Target-Salden nur in der Summe $\Sigma_{\mathrm{i}} \mathrm{T}_{\mathrm{i}}$, deren Wert immer Null ist, da die Summe aller Target-Forderungen gleich der Summe aller Target-Verbindlichkeiten ist. 


\subsection{Sind Target-Salden ein Teil „unseres“ Vermögens?}

Zu den Regeln des ESZB gehört es auch, dass die betreffenden Salden keine Ansprüche auf oder Verpflichtungen zu Zahlungen begründen. Wenn Mayer (2018) schreibt, die EZB habe nicht das „nötige Geld ..., um ihre Verbindlichkeit an die Bundesbank begleichen zu können“, so unterstellt er eine Verpflichtung, die nicht besteht.

Aber die Target-Forderungen der Deutschen Bundesbank sind doch Teil des Auslandsvermögens der Bundesrepublik Deutschland!? Als solche werden sie in der offiziellen Statistik geführt! Sie machen sogar 51 Prozent des deutschen Nettoauslandsvermögens aus! Wenn diese Forderungen ausfallen sollten, ist das für uns ein Desaster! ${ }^{62}$

Solche Formulierungen schüren Angst und Empörung, sind aber in mehrfacher Hinsicht problematisch. Zum einen werden Brutto- und Nettogrößen verglichen. Die „Target-Forderung“ der Bundesbank gegenüber der EZB ist nur eine von mehreren Bilanzpositionen, die das Verhältnis Bundesbank-EZB betreffen. Ihr steht zum Beispiel auf der Passivseite der Bilanz eine „Verbindlichkeit“ aus einer relativ $\mathrm{zu}$ hohen Bargeldausgabe (siehe oben Abschnitt 3.3) gegenüber, im Juni 2018 waren das 378 Milliarden Euro. Die bilanzielle Nettoposition der Deutschen Bundesbank im Verhältnis zur EZB lag unter 600 Milliarden Euro, das sind ca. 31 Prozent des Nettoauslandsvermögens von 1,9 Billionen Euro. ${ }^{63}$ Relativ zum deutschen Bruttoauslandsvermögen von 8,3 Billionen Euro Ende 2017 kommen die „Target-Forderungen“ sogar nur auf 12 Prozent.

Zum anderen ist die Vorstellung, das sei „unser“ Vermögen, eine kollektivistische Fiktion. In der volkswirtschaftlichen Gesamtrechnung werden Einzelgrößen addiert, ohne dass notwendigerweise ein Zusammenhang zwischen ihnen besteht. Da steht mein Anteil an einem ausländischen Pensionsfonds neben dem Auslandsvermögen der Deutschen Bank aus ihrer New Yorker Tochter und neben den Target-Forderungen der Deutschen Bundesbank. Dass diese Größen und andere zusammengezählt das „Auslandsvermögen der Bundesrepublik Deutschland“ ergeben, sagt nichts über die Bedeutung dieser Größe. Auf einzelwirtschaftlicher Ebene bezeichnet das Wort „Vermögen“ ein Maß für Handlungsspielräume, für budgetäre Möglichkeiten, die einem Entscheidungsträger zur

62 Mayer 2018, Sinn 2018a,b,c.

63 In der Bilanz der Bundesbank steht der Target-Forderung gegenüber der EZB eine Verbindlichkeit aus Banknotenausgabe gegenüber. Diese belief sich im Juni 2018 auf 408 Milliarden Euro.
Verfügung stehen. Auf gesamtwirtschaftlicher Ebene gibt es keinen solchen Entscheidungsträger.

Das „Wir“, das hier suggeriert wird, ist eine gefährliche Fiktion. Ich betrachte weder die Auslandsposition der Deutschen Bank noch die Target-Forderungen der Bundesbank als Teil meines Vermögens. Ich würde mich auch gegen jeden wehren, der versucht, mein Auslandsvermögen als Teil seines Vermögens zu behandeln. ${ }^{64}$

Es ist auch problematisch, wenn man in diesem $\mathrm{Zu}$ sammenhang über „die Griechen“ oder „die Italiener“ als Kollektiv redete und sich vorstellt, der einzelne Grieche oder Italiener, der ein Konto bei einer Bank in Frankfurt hat, könnte oder sollte haftbar gemacht werden für die Target-Verbindlichkeiten „seiner“ Zentralbank. Der einzelne Grieche oder Italiener, der ein Konto in Frankfurt hat, nutzt die Möglichkeiten des EU-Binnenmarkts und hat als EU-Bürger denselben Anspruch auf Rechtsschutz wie ein Deutscher. Für eine Haftung einzelner Bürger für tatsächliche oder behauptete Verbindlichkeiten ihrer Staaten ist in der Europäischen Union kein Platz.

Zum Dritten schließlich ist zu hinterfragen, ob der Einbezug der Target-Salden in die Vermögensstatistik überhaupt angebracht ist. In der Übernahme der Zahlen aus der Bilanz der Deutschen Bundesbank wird übersehen, dass die Rechnungslegung der Bundesbank und der anderen nationalen Zentralbanken auf unklare Weise Positionen grundsätzlich verschiedener Art zusammenbringt, auch dass die Bundesbank nur noch in Teilen ihrer Tätigkeit eine rein deutsche Institution ist, in anderen Teilen dagegen eine supranationale Institution.

In ihrer Eigenschaft als Miteigentümer der EZB und in ihren eigenen nicht-monetären Geschäften ist die Bundesbank eine rein deutsche Institution. In ihrer Tätigkeit als Teil des ESZB jedoch ist die Bundesbank eine europäische Institution und arbeitet im Auftrag des ESZB, in Ausführung der Beschlüsse des EZB-Rats. Die rechtlichen und wirtschaftlichen Wirkungen von Forderungen und Verbindlichkeiten gegenüber anderen Mitgliedern des ESZB sind von grundsätzlich anderer Art als die rechtlichen und wirtschaftlichen Wirkungen von Forderungen und Verbindlichkeiten gegenüber Dritten oder auch die rechtlichen und wirtschaftlichen Wirkungen von Forderungen und Verbindlichkeiten in der Bilanz einer Geschäftsbank.

Gerade die Target-Salden machen den Unterschied deutlich: Nach geltendem Recht hat die Bundesbank kei-

64 Das schließt nicht aus, dass solche Auslandspositionen den nationalen Gesetzen unterworfen sind, zum Beispiel für die Besteuerung oder die Anrechnung bei der Rente. Jedoch unterliegen diese Gesetze der verfassungsrechtlichen Kontrolle, insbesondere im Hinblick auf den Schutz des Eigentums nach Art. 14 GG. 
nen Anspruch auf Auszahlung der Target-Forderungen. Die einzige Rechtsfolge dieser „Forderungen“ betrifft den oben erläuterten Einbezug in die Ermittlung der in die Vergemeinschaftung einzubringenden Einkünfte der nationalen Zentralbanken. Jedoch sind die Gewinnansprüche der Bundesbank, die sich am Ende ergeben, völlig unabhängig von der Höhe der Target-Salden. Insofern steht die Aufführung der Target-Salden in der Bilanz der Bundesbank im Widerspruch zu dem bei anderen Institutionen geforderten Prinzip der Bilanzierung nach dem Zeitwert („Fair value“). Der Zeitwert der Target-Forderungen ist, wenn man genau hinsieht, gleich Null.

Eine angemessene Rechnungslegung würde einen Strich ziehen zwischen den ESZB-internen und den ESZBexternen Aktivitäten der Bundesbank. Das könnte zum Beispiel dadurch geschehen, dass die nationalen Zentralbanken ihre Aktivitäten jeweils aufspalten in ein Institut, das ihre monetären Aktivitäten betreibt, und ein anderes Institut, das ihre anderen Aktivitäten betreibt, und dass sie jeweils das erste dieser beiden Institute in die EZB integrieren, wenn nicht de jure, so doch de facto. Dann würden die Target-Salden nur in der Bilanz der betreffenden Tochtergesellschaft auftauchen.

In der Bilanz der Bundesbank dagegen würde nur der Wert des Anteils an dieser Tochtergesellschaft auftauchen. Dieser Wert ergäbe sich aus dem mit der Tätigkeit der Tochtergesellschaft verbundenen Anspruch auf eine Beteiligung an den monetären Einkünften des ESZB; er entspräche dem Zeitwert der zu erwartenden Anteile an diesen monetären Einkünften. Da die monetären Einkünfte des ESZB unabhängig von den Target-Salden sind, wäre diese Bilanzposition ebenfalls unabhängig von den Target-Salden. Insoweit man die EZB als ausländische Institution ansieht, wäre für die Berichterstattung über das Auslandsvermögen der Bundesbank nur diese Bilanzposition heranzuziehen.

Auf die aus währungspolitischen Aktivitäten zu erwartenden Gewinnanteile der nationalen Zentralbanken hätte eine solche Reorganisation kaum einen Einfluss, ${ }^{65}$ aber sämtliche mit dem Zahlungssystem verbundenen Salden würden als Intra-Eurosystem-Salden ausgewiesen, nicht aber als Forderungen oder Verbindlichkeiten der nationalen Zentralbanken. Bei einer De-jure-Integration der Töchter in die EZB könnte diese auch ihre „Verbindlichkeiten“ gegenüber der Bundesbank „begleichen“, indem sie die „Verbindlichkeiten“ übernähme, die bei der Bundesbank selbst aus Einlagen der Geschäftsbanken und der Ausgabe von Banknoten in der Bilanz stehen. Nach der Logik der Ausführungen in Teil 2 dieses Aufsatzes wäre allerdings der Zeitwert all dieser Positionen Null - auf beiden Seiten der Bilanz!

\section{Zur volkswirtschaftlichen Bedeutung der Target-Salden}

\subsection{Die Target-Salden im Zeitverlauf}

Ich komme nunmehr zur volkswirtschaftlichen Bedeutung der Target-Salden. Zunächst gibt Abbildung 1 einen Überblick über die zeitliche Entwicklung der Bilanzpositionen „Sonstige Intra-Eurosystem Forderungen“ und „Sonstige Intra-Eurosystem-Verbindlichkeiten“, in denen (vor allem) die Target-Salden enthalten sind.

Die Abbildung macht deutlich, dass es in der Entwicklung der Target-Salden verschiedene Phasen gab. Bis 2007 waren die Target-Salden relativ klein. Im Zuge der Finanzkrise stiegen sie an und erreichten Ende 2008 einen ersten Höhepunkt. Nach einem Rückgang 2009 begann 2010 ein neuer Anstieg. Dieser beschleunigte sich 2011 und erreichte seinen Höhepunkt im Herbst 2012. Danach gab es bis Ende 2014 einen deutlichen Rückgang. Seit im Frühjahr 2015 die Wertpapierankäufe der EZB begannen, sind die Salden wieder gestiegen und liegen heute deutlich über dem Höhepunkt von 2012. So lag die Position der Bundesbank im Maximum 2012 bei 750 Milliarden Euro, im zwischenzeitlichen Minimum 2014/15 unter 500 Milliarden Euro und erreichte im Juni 2018 einen neuen Höhepunkt bei 976 Milliarden Euro.

Die verschiedenen Phasen entsprechen verschiedenen wirtschaftlichen Konstellationen. In den Jahren vor der Finanzkrise funktionierten die Geldmärkte des Euroraums annähernd wie ein integrierter Markt, und der private Kapitalverkehr sorgte unmittelbar für eine Anpassung der verfügbaren Liquidität an die Zahlungsbedürfnisse. Diese Mechanismen brachen in der Finanzkrise und in der EuroKrise zusammen. Die erste Spitze der Target-Salden fällt in die Zeit der Lehman-Krise, der spätere Anstieg von 2010 bis 2012 mit der heißen Phase der Euro-Krise. Der neuerliche Anstieg seit 2015 fällt mit der expansiven Offen-Markt-Politik der EZB zusammen.

\subsubsection{In der Lehman-Krise}

In der Lehman-Krise wies vor allem die EZB selbst hohe Target-Forderungen auf. Diese beruhten auf den oben er-
65 Das Wort „kaum“ steht hier, um den operativen Kosten der monetären Institute Rechnung zu tragen. Diese würden nicht mehr von den nationalen Zentralbanken getragen, sondern von der EZB. 


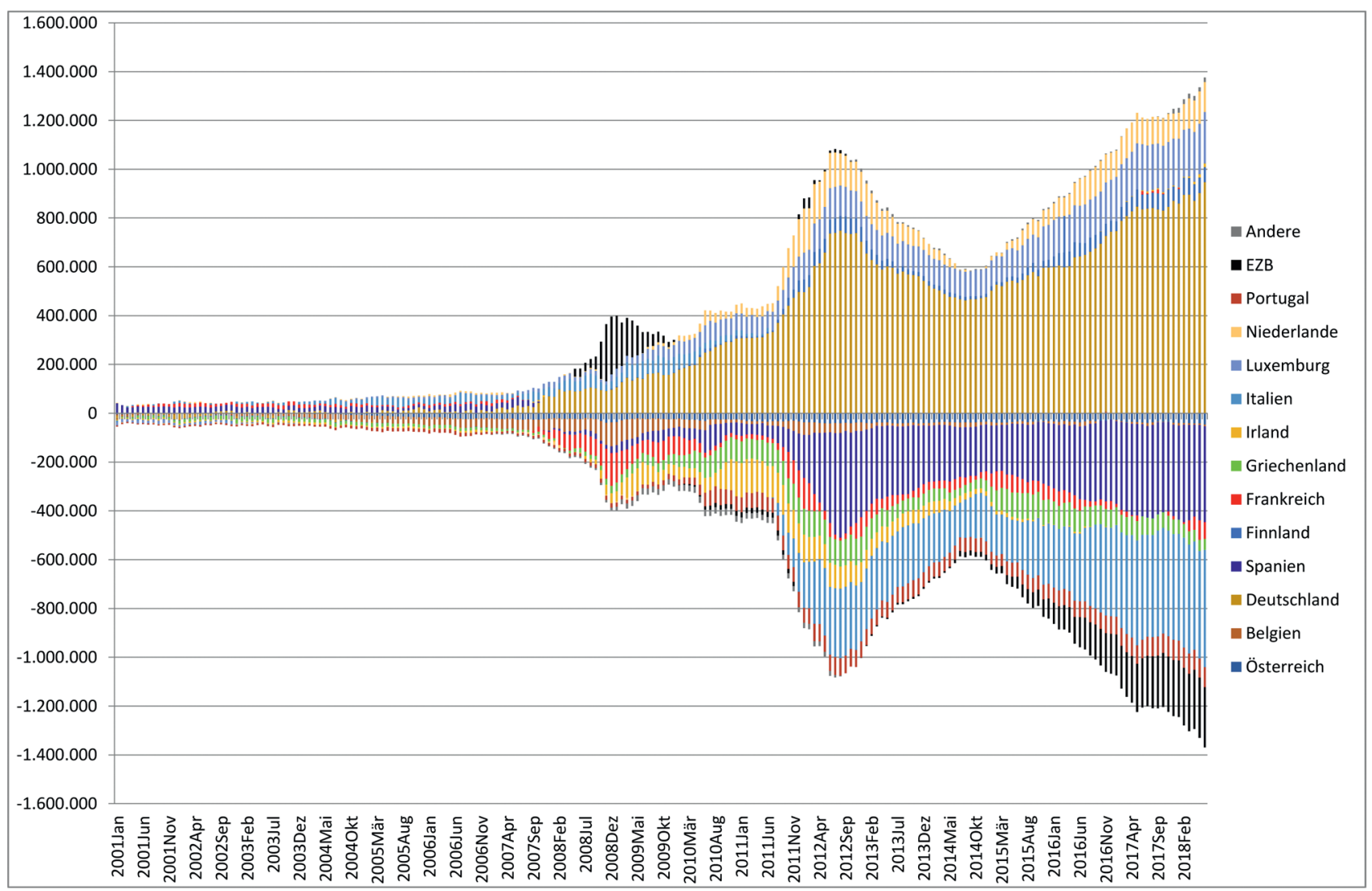

Abbildung 1: Target-Salden im Zeitverlauf

Quelle: Winkler 2018 auf der Grundlage von Daten der EZB

wähnten Swap-Vereinbarungen der EZB mit der Federal Reserve, die die Refinanzierung der Dollaraktivitäten europäischer Geschäftsbanken sicherstellte; die Bruttobeträge dieser Swaps lagen über 8 Billionen Dollar. ${ }^{66}$ Die Gegenposition zum Anstieg der Target-Forderungen der EZB in der Lehman-Krise zeigt sich in einem Anstieg der TargetVerbindlichkeiten der Zentralbanken von Belgien, Frankreich, Griechenland, Irland und Portugal und einem kurzfristigen Rückgang (!) der Target-Forderungen der Bundesbank. ${ }^{67}$

66 Siehe Tooze 2018, S. 210-19. In dieser Zeit hat die Federal Reserve auch den amerikanischen Töchtern mehrerer großer europäischer Banken unmittelbar Liquiditätshilfen gegeben, darunter Deutsche Bank, Dresdner Bank und Commerzbank jeweils mit dreistelligen Milliardenbeträgen.

67 Ein Blick in die griechische Bankenstatistik zeigt, dass auch für griechische Banken in der Lehman-Krise noch nicht die private Refinanzierung in Euro zusammenbrach, sondern die private Refinanzierung in anderen Währungen, vermutlich vor allem in Dollar.

\subsubsection{Entwicklung von 2010 bis Ende 2014}

Die Entwicklung von 2010 bis Ende 2014 spiegelt die Eurokrise wider, von ihrem Ausbruch 2010 bis zum Höhepunkt 2012 und ihrem Abflauen nach der Verkündung des OMTProgramms durch die EZB. Im Zuge dieser Krise kam es zu einer erneuten Fragmentierung des europäischen Finanzsystems. ${ }^{68}$ Die grenzüberschreitenden Finanzanlagen gingen zurück, und die Nominalzinssätze gingen auseinander. Die 2011 erfolgte Ankündigung eines Schuldenschnitts bei den von privaten Investoren gehaltenen griechischen Staatsschuldtiteln beschleunigte den Prozess dramatisch. Besonders hervorzuheben sind folgende Vorgänge:

- Die in den Jahren vor 2008 erfolgte Integration der Interbanken-Märkte des Euroraums wurde rückgängig gemacht. Geldmarktrefinanzierungen für Banken der Krisenländer wurden nicht erneuert. So verloren die griechischen Geschäftsbanken zwischen Januar und

68 Zum folgenden siehe ESRB 2015. Dieser Bericht ging auf eine Initiative des Advisory Scientific Committee beim ESRB vom Dezember 2011 zurück; ich war Co-Chair der Expertengruppe, die ihn verfasst hat. 
Juli 2010 bei einer aggregierten Bilanzsumme von knapp unter 500 Milliarden Euro Inter-Banken-Kredite im Umfang von über 20 Milliarden Euro, davon allein 13 Milliarden aus anderen Euroländern.

- Viele Anleger in den Krisenländern zogen ihre Mittel von den dortigen Finanzinstituten ab und legten sie in anderen Ländern an. So gingen in Griechenland die Kundeneinlagen bei den Geschäftsbanken von Januar bis Juli 2010 von 240 auf 222 Milliarden Euro zurück.

- Die in den Jahren vor 2008 erfolgte Integration der Anleihenmärkte, vor allem der Märkte für Staatsanleihen, wurde rückgängig gemacht. Staatsanleihen der Krisenländer wurden verkauft, oft an Käufer aus den betroffenen Staaten.

Alle diese Vorgänge waren mit Zahlungen aus den Krisenländern heraus verbunden. Die Zahlungsströme spiegeln sich in der Entwicklung der Target-Salden.

In den Jahren vor der Finanzkrise hatten die Banken in allen Ländern der Eurozone den Anteil der Schuldtitel des eigenen Staates an ihren Anlagen deutlich reduziert, so dass dieser 2008 nur in Belgien noch deutlich mehr als 5 Prozent ausmachte. Diese Entwicklung kehrte sich nunmehr um. In allen Ländern der Eurozone nahm ab Herbst 2008 der Anteil der Schuldtitel des eigenen Staates in den Bankbilanzen zu. Nach der ersten Griechenlandkrise 2010 verkauften deutsche, französische und niederländische Banken einen guten Teil ihrer griechischen Staatsanleihen. ${ }^{69}$ Als der griechische Schuldenschnitt angekündigt wurde, verkauften die Banken verstärkt auch Schuldtitel anderer Staaten. In den von der Eurokrise nicht betroffenen Ländern reduzierten die Banken ihre Bestände an Staatspapieren anderer Länder allein im Jahr 2011 um ca. 150 Milliarden Euro, mehr als ein Drittel dessen, was sie zu Anfang des Jahres gehalten hatten..$^{70}$ Die Verkaufswelle kam erst im Frühjahr 2012 zu einem Ende.

Käufer waren zum einen das ESZB unter dem „Securities Markets Programme“ von 2010, zum anderen nationale Zentralbanken mit Käufen „in eigener Verantwortung und auf eigene Rechnung " nach Art. 14 Abs. 4 der Satzung (siehe oben Abschnitt 3.3), zum dritten die Geschäftsbanken der betroffenen Länder, im Fall der griechischen Staatsanleihen auch zypriotische Banken. Die von der European Banking Authority (EBA) im Zusammenhang mit

69 Tooze 2018, S. 310 ff., Hellwig 2018b.

70 Aus deutscher Sicht von besonderem Interesse ist die im Juli 2011 erfolgte Ankündigung der Deutschen Bank, man habe 88 Prozent der zu Beginn des Jahres gehaltenen italienischen Staatsanleihen verkauft, im Wert von ca. 7 Milliarden Euro. Siehe Tooze 2018, S. 389 und 660, nn. 63, 64. dem Stress-Test von 2011 veröffentlichten Zahlen zeigen, dass die Sitzstaatpräferenz („Home bias“) der Geschäftsbanken zwischen 2008 und Mitte 2011 deutlich angestiegen ist. $^{71}$

Die Ankündigung und Konkretisierung des griechischen Schuldenschnitts und die Veröffentlichung von Informationen über die Staatsanleihenportefeuilles im $\mathrm{Zu}$ sammenhang mit dem Stress-Test von 2011 lösten die in Abschnitt 2.6 skizzierten Entwicklungen aus, mit einem erneuten Run der amerikanischen Geldmarktinvestoren und panischen Versuchen der Geschäftsbanken, durch Wertpapierverkäufe an Liquidität zu kommen bzw. die Basis für die Berechnung der Eigenkapitalanforderungen zu senken. Im Sommer 2011 reaktivierte die EZB das SwapAbkommen mit der Federal Reserve. Im Dezember 2011 und Januar 2012 brachte sie mit der Long-Term Refinancing Operation ca. eine Billion Euro an zusätzlicher Liquidität in das System. Die LTRO-Kredite wurden überproportional von den Banken der Peripherieländer nachgefragt. ${ }^{72}$ Sie wurden von schwächeren Banken überwiegend zum Kauf von - damals noch relativ hoch verzinsten - Staatsanleihen der Peripherieländer verwandt. ${ }^{73}$

\subsubsection{Die Entwicklung seit 2015}

Die Entwicklung seit 2015 schließlich spiegelt vor allem die Wertpapierankäufe des ESZB. Hier wirkt sich die auf die Initiative des Präsidenten der Deutschen Bundesbank getroffene Regelung aus, dass im Rahmen des seit 2015 verfolgten Public Sector Purchase Programme jede Zentralbank die Anleihen des eigenen Staates kauft, die Deutsche Bundesbank Anleihen der Bundesrepublik Deutschland, die Banca d'Italia Anleihen der Italienischen Republik usw. Wenn die Verkäufer dieser Anleihen ihren Sitz nicht in dem betreffenden Land selbst haben, erfordert der Kauf eine Überweisung in ein anderes Land; diese geht in die Target-Salden ein. Wenn etwa die Banca d'Italia eine italienische Staatsanleihe von einem Anleger in Frankfurt kauft, so bewirkt die Überweisung des Kaufpreises entsprechend den oben beschriebenen Regeln einen Anstieg der Target-Verbindlichkeiten der Banca d'Italia und einen Anstieg der Target-Forderungen der Deutschen Bundesbank bei der EZB. Würde stattdessen die Deutsche Bundesbank die Anleihen kaufen und bezahlen, so gäbe es keine Auswirkungen auf die Target-Konten.

71 ESRB 2015. Allerdings war die Sitzstaatpräferenz auch 2011 noch deutlich schwächer als vor der Währungsunion.

72 Tooze 2018, S. 421.

73 Acharya und Steffen 2015, ESRB 2015. 
Warum sollte dieser Mechanismus die Entwicklung der Target-Konten asymmetrisch beeinflussen? Schließlich kauft ja auch die Bundesbank Staatsanleihen. Wenn der Verkäufer in Rom oder Mailand sitzt, sollten die Target-Forderungen der Bundesbank und die Target-Verbindlichkeiten der Banca d'Italia beide abnehmen. Woher kommt die aus Abbildung 1 ersichtliche Asymmetrie der Entwicklung seit 2015?

Die Asymmetrie betrifft allerdings nicht nur Deutschland, sondern auch Finnland, Luxemburg und die Niederlande und spiegelt die besondere Rolle dieser Länder im Finanzanlagegeschäft. In Luxemburg sitzen viele Anlagefonds. Anlagefonds in London bevorzugen Frankfurt und Amsterdam als Standorte für ihre Aktivitäten im Euroraum, Anlagefonds in den skandinavischen Ländern betreiben solche Aktivitäten gern über Finnland. Viele der Staatsanleihen, die im Rahmen des Public Sector Purchase Programme gekauft wurden, kamen von solchen international tätigen institutionellen Anlegern. Die Asymmetrie, die wir in Abbildung 1 beobachten, beruht auf dieser Asymmetrie in den Standorten internationaler Anleger im Euroraum..$^{74}$

\subsection{Sind Target-Forderungen das Ergebnis einer Kreditvergabe?}

Sinn und andere Kritiker der Währungsunion sehen die Target-Salden als Indiz für die Ausbeutung Deutschlands durch andere Länder. Die Salden seien entstanden, weil die Zentralbanken bestimmter Länder, vor allem der Anrainerstaaten des Mittelmeers, unverhältnismäßig viel Geld geschöpft hätten. Dieses Geld habe dazu gedient, Güter und Dienstleistungen sowie Immobilien und andere Vermögenswerte in Deutschland zu kaufen. Deutschland sei „zu einem Selbstbedienungsladen geworden, in dem man nach Belieben anschreiben lassen kann, ohne dass der Ladeninhaber seine Forderungen fällig stellen kann. “75 Im Zentrum dieser Diskussion steht der Begriff des „Target-Kredits“. ${ }^{76}$ Die Target-Forderungen der Deutschen

74 Aufgrund einer detaillierten empirischen Analyse kommen Eisenschmidt et al. (2017) zu dem Schluss, dass die Asymmetrie in der Entwicklung der Target-Salden seit 2015 sogar weniger ausgeprägt ist, als zu erwarten wäre, wenn nur das Public Sector Purchase Programme des ESZB eine Rolle spielte. Die eigentliche Frage ist, warum diese Anleger nicht nach dem Verkauf z.B. von italienischen Staatsanleihen andere Anlagen in Italien getätigt haben, was die Auswirkungen des Verkaufs auf die Target-Salden neutralisiert hätte.

75 Sinn 2018a,b.

76 Siehe insbesondere Sinn und Wollmershäuser 2012, Sinn 2012, 2014.
Bundesbank, so wird behauptet, seien das Ergebnis einer Kreditvergabe „Deutschlands“ an andere Länder. Besonders fatal sei, dass diese Kredite nicht eingefordert werden könnten.

Jedoch verbindet der Begriff des „Target-Kredits“ auf unzulässige Weise volkswirtschaftliche und einzelwirtschaftliche Vorstellungen und ist analytisch unbrauchbar. Die Vorstellung von Deutschland als einem kreditvergebenden Kollektiv ist eine Fiktion. Diese Fiktion ist gefährlich, denn sie fördert nationalistische Hetze, zum Beispiel, wenn man ihr die Fiktion von Italien als einem schnorrenden Kollektiv gegenüberstellt. ${ }^{77}$

Sinn begründet seine Interpretation der Target-Salden als Kredite mit der Aussage, dass der Leistungsbilanzüberschuss eines Landes immer gleich der Summe aus privaten und öffentlichen Nettokapitalexporten ist, wobei er den Anstieg der Target-Salden als Teil der öffentlichen Kapitalexporte ansieht. Diese Gleichung dient als Beleg der These, dass „Deutschland“ mit den Target-Krediten die Leistungsbilanzdefizite der Krisenländer oder Kapitalflucht der Griechen oder der Italiener „finanziere“.

In dieser Darstellung erscheinen die Target-Salden als moderne Version der Dollarankäufe der Bundesbank unter dem Wechselkursregime von Bretton Woods. Ende der sechziger und Anfang der siebziger Jahre stand die D-Mark unter Aufwertungsdruck. Um zu verhindern, dass der Dollarkurs um mehr als die zulässige Marge vom amtlichen Festkurs abwich, musste die Bundesbank Dollar ankaufen. Mit diesen Dollarkäufen, so Sinn, gab Deutschland den Vereinigten Staaten einen Kredit und trug zur Finanzierung des Leistungsbilanzdefizits der Vereinigten Staaten und zur Finanzierung des Vietnamkriegs bei. ${ }^{78}$ Und so, wie damals die Bundesbank mit ihren Dollarankäufen den Vereinigten Staaten einen Kredit gegeben habe, so gebe sie heute mit jedem Anstieg der Target-Forderungen den Mittelmeerländern in der Eurozone einen Kredit.

Diese Interpretation der Dollarkäufe der Bundesbank unter dem System von Bretton Woods ist problematisch. Die Bezeichnung der Dollarkäufe als „Kredite“ ist eine Metapher. Diese Metapher war damals in der Debatte um

77 Der Spiegel-Artikel „Die Schnorrer von Rom“ vom 24. Mai 2018 sorgte nicht nur in Deutschland für Empörung, sondern auch in Italien, wo man darauf hinwies, dass der italienische Staat noch keinen Cent von Deutschland genommen habe, vielmehr selbst zur Finanzierung der Staatskredite für Griechenland und Spanien beigetragen habe, durch die es dem deutschen Fiskus erspart blieb, sich mit den Konsequenzen auseinandersetzen zu müssen, die ein Zahlungsausfall des griechischen Staates oder ein Bail-in der Gläubiger bei den spanischen Banken für die deutschen Banken gehabt hätte. Zum letzten Punkt siehe Fubini (2018).

78 Sinn 2012, S. $210 \mathrm{ff}$. 
die Aufwertung der D-Mark als rhetorisches Hilfsmittel sehr wirkungsvoll. Sie eignet sich aber nicht als Analyseinstrument.

Die damaligen Dollarkäufe der Bundesbank waren keine Kredite, sondern Interventionen im Devisenmarkt, die eine Aufwertung der D-Mark verhindern sollten. Dass die Dollarkäufe de facto einen Beitrag zur Finanzierung des Vietnamkriegs und der Great-Society-Programme der Vereinigten Staaten leisteten, betrifft die indirekten Wirkungen der Dollarkäufe, nicht aber die Dollarkäufe als solche. Die Papierzettel mit Bildern von George Washington und anderen amerikanischen Präsidenten bzw. die Ansprüche auf solche Zettel, die die Bundesbank damals erwarb, beinhalteten keine Leistungsansprüche gegen die Vereinigten Staaten, den Staat, seine Zentralbank oder seine Bewohner. Eine Kreditvergabe fand allenfalls statt, wenn die Bundesbank mit den gekauften Dollars Schuldtitel der amerikanischen Regierung kaufte, aber diese Schuldtitel waren auch nur Ansprüche auf Papierzettel mit Bildern von amerikanischen Präsidenten, die ihrerseits keine weiteren Ansprüche begründeten.

Eine Interpretation der Devisenmarktinterventionen als Kreditvergabe verwischt die Grenze zwischen Geldund Kreditmärkten. Das ist problematisch, denn die von Sinn ins Feld geführte Zahlungsbilanzgleichung ist genau genommen eine Geldmarktgleichung. ${ }^{79}$ Bei genauer Formulierung verlangt diese Gleichung, dass der Leistungsbilanzüberschuss eines Landes gleich der Summe aus Nettokapitalexporten und Devisenankäufen der Zentralbank sein muss. Diese Gleichung gilt als Identität ex post, weil die Summe aller Zahlungen in heimischer Währung gleich der Summe aller Einnahmen in heimischer Währung sein muss. Als Geldmarktgleichgewichtsbedingung ex ante besagt die Gleichung, dass für ein Gleichgewicht der Strömungsgrößen auf dem Geldmarkt entweder die Wechselkurse oder die Zentralbankintervention sich so anpassen müssen, dass die Devisenankäufe der Zentralbank gerade die Zuströme an Devisen aus einem Leistungsbilanzüberschuss und aus den Nettokapitalimporten aufnehmen.

Von einem Kredit der heimischen Zentralbank an „das andere Land" ist dabei nicht die Rede. Die von der Zentralbank des anderen Landes ausgegebenen Banknoten sind keine Schuldtitel. Der Besitzer hat keinen Rechtsanspruch gegen die ausgebende Zentralbank - diese Aussage gilt für die heimische Zentralbank, die Devisen gekauft hat, ebenso wie für die Unternehmen und Privatpersonen des anderen Landes. Der Devisenkauf der heimischen Zentralbank

79 Der sogenannte monetäre Ansatz der Zahlungsbilanztheorie setzt genau hier an. Siehe zum Beispiel Frenkel und Johnson 1976. dient der Stabilisierung des Wechselkurses, die von den Verantwortlichen gewünscht wird, zum Beispiel weil sie die Folgen einer Währungsaufwertung für die Wirtschaft fürchten. Das war beispielsweise 1968/69 in Deutschland der Fall, als Bundeskanzler Kiesinger auf Anraten der großen Wirtschaftsverbände eine D-Mark-Aufwertung ablehnte. ${ }^{80}$

Der Ausdruck „Leistungsbilanzfinanzierung“ findet sich in vielen Diskussionen über internationale Wirtschaftsbeziehungen. Diese Sprechweise ist bequem, aber auch irreführend. Da wird implizit unterstellt, man könne das Land wie eine Person behandeln, und die Leistungsbilanzgleichung wie die Budgetgleichung einer Person. Die Kollektivbetrachtung lenkt davon ab, dass die Interessen der Einwohner oder der Bürger des Landes nicht alle identisch sind, auch davon, dass Budgetgleichungen, Finanzierungsprobleme und Verträge sich jeweils auf einzelne natürliche oder juristische Personen beziehen, nicht aber auf ,das Land“ als Kollektiv. ${ }^{81}$

So ist auch das Bild von Deutschland als „einem Selbstbedienungsladen, ... in dem man nach Belieben anschreiben lassen kann“, schief. Die Verkäufer von Gütern und Dienstleistungen an Käufer in anderen Ländern der Eurozone haben ihre Bezahlung erhalten, es sei denn, sie hätten selbst Kredite gewährt. Und die deutschen Banken, bei denen griechische oder italienische Kunden Geld angelegt haben, haben von diesen Kunden Einzahlungen in Euro erhalten. Soweit Personen und Institutionen, die reale Leistungen für Personen oder Institutionen aus anderen Ländern der Eurozone erbringen, anschreiben lassen, geschieht dies durch explizite Kreditbewilligung.

Wenn Sinn (2018a und b, S. 30) dazu schreibt: „Zwar wurden die deutschen Verkäufer mit dem Geld der Bundesbank kompensiert, doch ist das eine Forderung gegen eine Einrichtung des deutschen Staates, die dafür nur eine

80 Aus eben diesem Grund hat die Schweizerische Nationalbank immer wieder in den Devisenmärkten interveniert, um Aufwertungen des Schweizer Franken zu verhindern oder wenigstens zu verlangsamen. Im vergangenen Jahrzehnt sind ihre Auslandsanlagen dadurch auf ca. 800 Milliarden Schweizer Franken angestiegen, fast 17 Prozent des Bruttoauslandsvermögens und ca. 100 Prozent des Nettoauslandsvermögens der Schweiz. Die Risiken dieser Fremdwährungsposition für die Bilanz der Schweiz sind den Verantwortlichen sehr wohl bewusst, aber sie wissen auch um die volkswirtschaftlichen Risiken einer Aufwertung. Die Folgen der abrupten Aufwertung von 2015 wurden als sehr problematisch empfunden.

81 Bereits Myrdal (1932) kritisiert die schon auf Ricardo zurückgehende Praxis des Redens über ein Land wie über eine Person als zutiefst ideologisch, denn diese Praxis bietet die Möglichkeit, normative Aussagen zu treffen, ohne sich um die Verteilungswirkungen der angesprochenen Maßnahmen zu kümmern. 
Target-Forderung gegen das Eurosystem erhielt“, so enthält diese Aussage drei grundlegende Fehler: Erstens ist das von den deutschen Verkäufern erworbene Geld keine Forderung, weder gegen die Bundesbank noch gegen eine andere Institution. Zweitens handelt es sich nicht um das „Geld der Bundesbank“, sondern um das Geld des ESZB, das überall in der Eurozone als Zahlungsmittel verwandt werden kann. Drittens arbeitet die Bundesbank innerhalb des ESZB nicht als „Einrichtung des deutschen Staates“, sondern als Teil des ESZB.

\subsection{Sind Änderungen der Target-Salden dasselbe wie Devisenmarktinterventionen?}

Ein weiteres Problem betrifft die Gleichsetzung der TargetSalden mit den Devisenmarktinterventionen in einem System fester Wechselkurse. Im Kontext der Zahlungsbilanzgleichung ist die Funktion dieselbe, ein Ausgleich der aus den Transaktionen von privaten Haushalten, Unternehmen und öffentlichen Institutionen herrührenden Geldströme. Der institutionelle Kontext ist aber ein anderer. Im System fester Wechselkurse agiert die Zentralbank in eigener Verantwortung und auf eigene Rechnung, unter dem Mandat der eigenen Regierung. In der Europäischen Währungsunion tut sie das nicht, sondern ist als unselbständiger Operateur eingebettet in das ESZB.Im System fester Wechselkurse besteht grundsätzlich die Option, vom vorgegebenen Wechselkurs abzugehen und die Devisenmarktinterventionen entsprechend einzuschränken. In der Währungsunion gibt es diese Option nicht, denn es gibt gar keinen Wechselkurs, von dem man abgehen könnte.

Stellen wir uns vor, es gäbe das Target-System nicht. Was würde dann passieren? Ein Zahlungsverkehr ohne Beteiligung des ESZB müsste privat organisiert werden. Eine Überweisung aus Italien nach Deutschland ginge einher mit einem Angebot zum Tausch von „italienischen Euros“ gegen „deutsche Euros“. Auf der Ebene der Banken lässt sich die Unterscheidung durchführen, und man kann sich vorstellen, dass zum Beispiel bei einer massiven Kapitalflucht aus Italien die „italienischen Euros“ nur mit einem Abschlag gegen „deutsche Euros“ verkauft werden können. Jedoch kann dieser Abschlag nicht sehr groß werden. Sonst würde es sich lohnen, in großem Umfang Banknoten in Bozen abzuheben, nach Innsbruck oder München zu fahren und dort wieder einzuzahlen; bei den Banknoten sind ,italienische Euros“ und „deutsche Euros“ ja nicht zu unterscheiden. Dasselbe Ergebnis könnte auch erreicht werden, indem zum Beispiel die Deutsche Bank eine italienische Tochtergesellschaft gründete, die als Dienstleistung Über- weisungen aus Italien nach Deutschland vornimmt, was sie kann, weil jeweils die Mutter in Frankfurt die von der Tochter in Italien angebotenen ,italienischen Euros“ abnimmt.

In beiden Fällen wiese die Bilanz der Bundesbank keine Target-Forderungen auf. Auf der Passivseite der Bilanz wären die Verbindlichkeiten aus Notenausgabe geringer, denn ein Teil der in Deutschland umlaufenden Banknoten käme aus Italien. ${ }^{82}$ Auch die Verbindlichkeiten gegenüber Kreditinstituten wären geringer, denn bei der Deutschen Bank würden Einlagen der Tochter bei der Banca d'Italia an die Stelle von Einlagen der Mutter bei der Bundesbank treten. Sieht man von den Wirkungen ab, die von den zusätzlichen Transaktionskosten der Privaten ausgehen, so würde die konsolidierte Bilanz des ESZB genauso aussehen wie bei Verwendung des Target-Systems. Die Bundesbank für sich genommen hätte weniger Aktiva und weniger Passiva, aber die Veränderung hätte keinen Einfluss auf die zu erwartenden Ausschüttungen von Seiten des ESZB.

Im System von Bretton Woods konnte man zwischen verschiedenen Währungen unterscheiden. Im Eurosystem kann man das nicht, wenigstens nicht auf der Ebene des Bargelds. Wenn es eine einheitliche Währung gibt, entfällt die Möglichkeit der Wechselkursanpassung, und „Ungleichgewichte“ der Zahlungsströme aus laufenden Leistungen und Kapitalverkehr gehen immer mit Geldströmen einher.

Eine bessere Analogie für das Eurosystem findet man in der Vergangenheit der Bundesrepublik. Wenn früher eine Person mit Wohnsitz in München einen Finanztitel auf dem Finanzplatz Frankfurt kaufte, ging die Bezahlung vom Konto der Person bei einer Bank in München über die Landeszentralbank Bayern und die Landeszentralbank Hessen an die Bank des Verkäufers in Frankfurt. Die dabei stattfindenden Bewegungen auf den Konten der Landeszentralbanken Bayern und Hessen bei der Zentrale der Bundesbank entsprachen den Bewegungen auf den heutigen Target-Konten der nationalen Zentralbanken im ESZB. In Anbetracht der großen Bedeutung des Finanzplatzes Frankfurt ist zu vermuten, dass damals mehr Geld von Bayern nach Hessen überwiesen wurde als umgekehrt, das heißt, dass es positive Salden bei der Landeszentralbank Hessen und negative Salden bei der Landeszentralbank Bayern gab. Aber es wäre niemand auf die

82 Es ist daher problematisch, die Target-Salden isoliert zu betrachten, ohne die anderen Intra-Eurosystem-Positionen einzubeziehen. „Fast 1 Billion Euro Target-Forderungen“ ist medial wirksamer als „fast 600 Milliarden Euro Saldo von Target-Forderungen und Bargeldausgabe-Verbindlichkeiten“, aber die Medienwirkung geht zu Lasten des Inhalts. 
Idee gekommen, diese Salden als Kredite zu interpretieren. Sie ergaben sich einfach aus der Wahrnehmung der Zentralbankaufgabe, ein Zahlungssystem bereitzustellen.

Aber die Landeszentralbanken Hessen und Bayern waren doch nicht unabhängig! Sie waren doch nur untergeordnete Teile der Gesamtinstitution Deutsche Bundesbank! Genau dies gilt heute für die nationalen Zentralbanken, auch wenn die Nostalgiker der alten Glorie der Bundesbank damit nicht zufrieden sind. Der einzige Unterschied liegt darin, dass die nationalen Zentralbanken rechtlich unabhängig sind und als solche gemeinsam Eigentümer der EZB.In der Wahrnehmung der geld- und währungspolitischen Aufgaben sind sie aber nicht unabhängig, sondern den Regeln des ESZB unterworfen, und es gibt auch keine separaten Gewinnzurechnungen. So wie früher die Gewinne der Bundesbank insgesamt ermittelt wurden und gemäß dem Bundesbankgesetz teils einbehalten, teils dem Bund überwiesen wurden, so werden heute die monetären Einkünfte des ESZB insgesamt ermittelt und gemäß der Satzung des ESZB und der EZB an die nationalen Zentralbanken verteilt.

\subsection{ANFA und ELA - „Selbstbedienung mit der Notenpresse"?}

Gegen den Vergleich mit der früheren innerdeutschen Situation wird eingewandt, die Landeszentralbanken hätten keine eigenständige Politik betrieben. Im ESZB dagegen agierten die nationalen Zentralbanken selbständig und betrieben „Selbstbedienung mit der Notenpresse“. ${ }^{83} \mathrm{Als}$ Beispiele werden die Vergabe von Notkrediten (ELA) und der Erwerb von Staatsanleihen ,in eigener Verantwortung und auf eigene Rechnung " nach Art. 14 Abs. 4 der Satzung genannt. Das Regime für die Vergabe von Notkrediten (ELA) erlaube es „einer jeden Notenbank [...], nach eigenem Gustus beliebig viel Geld zu drucken“; daher sei nicht $\mathrm{zu}$ verhindern gewesen, dass die „südeuropäischen Krisenländer und Irland [...] sich [...] für Hunderte von Milliarden Euro Ela-Kredite gewährten“. Und nach dem „sogenannten Anfa-Geheimabkommen [...] darf eine Notenbank mit selbst gedrucktem Geld Wertpapiere kaufen. So erwarb die Banca d'Italia [...] für 105 Milliarden Euro Staatspapiere.“

Die Aktivitäten der nationalen Zentralbanken ,in eigener Verantwortung und auf eigene Rechnung“ und die Zulassung der Finanzierung dieser Aktivitäten durch Geld-

83 So Sinn 2012, 2018a,b. Die folgenden Zitate sind alle Sinn (2018b, S. $28 \mathrm{ff}$.) entnommen. schöpfung sind in der Tat kritisch zu sehen, denn dadurch wird die Grenze zwischen selbständigen und unselbständigen Aktivitäten der nationalen Zentralbanken verwischt. Die oben angedachte Aufteilung der nationalen Zentralbanken in echt selbständige Institute und dem ESZB verpflichtete Institute würde dem entgegenwirken.

Jedoch haben die kritisierten Aktivitäten nicht den Umfang, den Sinn ihnen zuschreibt. Nach einem Bericht der Deutschen Bundesbank (2016) stiegen die Netto-Finanzaktiva des ESZB, das zur Finanzierung von ELA und ANFA dienende Zentralbankgeld in den Jahren 2007 bis 2011 von ca. 400 Milliarden Euro auf 600 Milliarden Euro. Danach gingen sie wieder zurück und lagen Ende 2015 wieder bei 490 Milliarden Euro. Seither sind sie weiter gefallen. Es gab also nicht nur die „Notenpresse“, sondern auch den „Notenshredder“. Die Bilanzpositionen im ESZB, die die durch Geldschöpfung finanzierten Wertpapiere und die Notkredite enthalten, weisen eine ähnliche Entwicklung auf. ${ }^{84}$

Der Rückgang dieser Positionen seit 2015 bedeutet, dass sie nichts mit dem Anstieg der Target-Salden seit 2015 zu tun haben. Auch ihr Anstieg in der vorangegangenen Phase machte nur einen sehr kleinen Teil der vom ESZB insgesamt vorgenommenen Zentralbankgeldschöpfung aus. Diese belief sich auf ca. 1.150 Milliarden Euro von Ende 2006 bis Ende 2012, ca. 2.500 Milliarden von Ende 2006 bis Ende 2017..$^{85}$ Insofern scheint die Bedingung des Art. 14 Abs. 4 der Satzung, dass diese Aktivitäten den geldpolitischen Zielen des EZB-Rats nicht zuwider laufen dürfen, erfüllt gewesen zu sein.

Die in der deutschen Presse kolportierten Zahlen zu ANFA, über 500 oder gar über 700 Milliarden Euro an Staatsanleihenkäufen, beruhen auf Missverständnissen. ${ }^{86}$ Hoffmann (2015), auf den die Zahlen zurückgehen, verwendet die Bezeichnung „Sonstige Wertpapiere“ in zwei verschiedenen Bedeutungen, zum einen für den Posten „Sonstige Wertpapiere“ in der konsolidierten Bilanz des ESZB, zum anderen für die Summe der Posten „Sonstige Wertpapiere“, „Sonstige Aktiva“ und „Sonstige Forderungen in Euro an Kreditinstitute im Euro-Währungsgebiet" in dieser Bilanz. Für diese Summe nennt er einen Zuwachs um über 500 Milliarden Euro auf über 700 Milliarden Euro

84 Jedoch war das Ausmaß der Geldschöpfung, im Maximum 200 Milliarden Euro, um mindestens 100 Milliarden Euro kleiner, als die Entwicklung dieser Bilanzposten vermuten ließe.

85 Die monetären Passiva (Banknoten, auf Euro lautende Verbindlichkeiten gegenüber Kreditinstituten und gegenüber Nicht-Kreditinstituten) beliefen sich 2006 auf 827 Milliarden Euro, 2012 auf 1.972 Milliarden Euro, 2017 auf 3.337 Milliarden Euro.

86 Siehe Hoffmann 2015, Plickert 2015 und Papadia 2015. 
von 2006 bis 2012. Jedoch enthält der Posten „Sonstige Forderungen..." nicht Wertpapiere, sondern Kredite, vor allem die Notkredite. Der Posten „Sonstige Aktiva“ enthält neben Dingen wie Scheidemünzen, Sachanlagen, Rechnungsabgrenzungsposten usw. vor allem die Position „Sonstige Finanzaktiva“, das sind Finanzaktiva, die bestimmten Finanzpassiva zweckgebunden zugeordnet sind, so der Anlage von Mitteln von Pensionsfonds, von Währungsreserven der Zentralbanken anderer Länder und nicht zuletzt von Eigenkapital und Rücklagen. Diese Finanzaktiva werden nicht durch Geldschöpfung finanziert.

Für den Posten „Sonstige Wertpapiere“ im eigentlichen Sinn ergibt sich von Anfang 2007 bis zum Höhepunkt 2015 ein Anstieg um 297 Milliarden Euro, von 81 Milliarden auf 378 Milliarden. Von diesem Anstieg gehen ca. 160 Milliarden Euro auf eine im Dezember 2008 aufgrund einer Änderung der Bilanzierungspraxis erfolgte Umbuchung zurück; damals wurde die oben genannte Präzisierung der Position „Sonstige Finanzaktiva“ vorgenommen, und die Vermögenswerte, die nicht mehr darunter fielen, in die Kategorie „Sonstige Wertpapiere“ übertragen. Nimmt man diese Umbuchung heraus, so ergibt sich für „Sonstige Wertpapiere“ ein Wachstum von 2007 bis 2015 von ca. 140 Milliarden Euro. Von 2015 bis jetzt ist diese Bilanzposition wieder gesunken und liegt mit ca. 250 Milliarden Euro nicht mehr weit über dem Wert von 2006 (unter Berücksichtigung der 2008 vorgenommenen Umbuchung).

Sinns $(2018 a, b)$ Aussage, die Banca d'Italia habe „nach dem sogenannten Anfa-Abkommen [...] mit selbst gedrucktem Geld [...] für 105 Milliarden Euro Staatsanleihen" gekauft, ist problematisch. Von den 111 Milliarden Euro an Staatspapieren, die die Banca d'Italia Ende 2017 in ANFA-Positionen hielt, entfielen 37 Milliarden auf die nicht durch Geldschöpfung finanzierte Kategorie „Sonstige Finanzanlagen" und nur 74 Milliarden auf die Kategorie „Sonstige Wertpapiere“. Dabei stammt ein Teil der Beträge aus grauer Vorzeit. Schon Anfang 2008, vor der Finanzkrise und lange vor dem Anstieg der italienischen TargetVerbindlichkeiten, hielt die Banca d'Italia Staatsschuldtitel im Wert von 23 Milliarden unter „Sonstige Finanzanlagen“ und 41 Milliarden unter „Sonstige Wertpapiere“. Die „mit selbstgedrucktem Geld“ finanzierten Käufe von Staatspapieren unter „Sonstige Wertpapiere“ kamen also in der Periode 01.01.2006-31.12.2017 auf 33 Milliarden Euro, weniger als ein Drittel der von Sinn behaupteten 105 Milliarden und weniger als ein Zehntel des Anstiegs der Target-Verbindlichkeiten der Banca d'Italia in diesen Jahren.

Auch die Behauptung, dass die „südeuropäischen Krisenländer und Irland [...] sich [...] für Hunderte von Milliarden Euro Ela-Kredite gewährten“, ist problematisch. Zum einen haben die Zentralbanken der „südeuropäischen Krisenländer“ Italien, Portugal und Spanien bisher kaum Notkredite vergeben. ${ }^{87}$ Zum anderen lag der Bilanzposten „Sonstige Forderungen in Euro an Kreditinstitute im EuroWährungsgebiet“, der die Notkredite enthält, in genau zwei Phasen über 100 Milliarden Euro, mit bis zu 250 Milliarden 2011/12 und bis zu 140 Milliarden 2015. ${ }^{88}$ Beide Spitzen wurden durch die Notkredite für griechische Banken verursacht, die an die Stelle normaler Refinanzierungskredite traten, weil das ESZB griechische Staatspapiere nicht mehr als Sicherheiten akzeptierte. ${ }^{89} \mathrm{Im}$ Höhepunkt 2011/12 waren sonst noch Frankreich und Irland mit jeweils über 40 Milliarden Euro dabei, Zypern mit 10 Milliarden, Belgien und die Niederlande mit 6 und 7 Milliarden. Bei Frankreich ging es um Dexia, bei Belgien und den Niederlanden um Fortis, bei Irland und Zypern jeweils um das gesamte Banksystem. ${ }^{90}$ Seit 2015 sind die Notkredite stetig zurückgegangen und liegen heute etwas über 30 Milliarden Euro.

Im Übrigen deutet das Wort „Selbstbedienung“ auf Eigeninitiative hin. Jedoch waren die Notkredite durchweg Reaktionen auf Schwierigkeiten bei den betreffenden Banken. Bei Dexia, Fortis und Hypo Real Estate (Depfa) ersetzten die Notkredite die Geldmarktkredite, die in den Krisen 2008 und 2011 nicht mehr erneuert wurden, bei den irischen, zypriotischen und griechischen Banken die InterBanken-Kredite und Einlagen, die aus Furcht vor einer Insolvenz der Banken und vor einem Euro-Austritt Griechenlands abgezogen wurden. Die eigentlichen Nutznießer der Notkredite waren die Gläubiger der Banken, denen ein Konkurs und eine Beteiligung an den Verlusten der Banken erspart wurde. In Irland waren die Gläubiger vor allem deutsche Banken, in Zypern russische Oligarchen, in Griechenland private Unternehmen und Haushalte.

Es ist nicht auszuschließen, dass die Mittel, die die Gläubiger erhielten, auch zum Kauf von Gütern, Dienstleistungen und Vermögenswerten in Deutschland dienten.

87 Für die Zeit bis 2012, siehe Hoffmann 2015, für die weiteren Jahre die Bilanzausweise des ESZB.

88 Auch die Entwicklung der Nettofinanzaktiva weist neben dem Maximum 2011 noch ein zweites Maximum 2014 auf. Bemerkenswerterweise liegen beide Maxima jeweils um einige Monate vor den Maxima der Notkredite von 2012 und 2015.

89 In der Spitze 2012 beliefen sich die Notkredite für griechische Banken auf 100 Milliarden Euro, 2015 auf 90 Milliarden Euro.

90 Die Bundesbank hatte 2008 einen Notkredit von 20 Milliarden Euro an Hypo Real Estate zur Finanzierung von deren Tochter Depfa vergeben. Dieser Finanzierungsbedarf entfiel, als Vermögenswerte von 174 Milliarden Euro von Hypo Real Estate an die bundeseigene FMS-Wertmanagement übertragen wurden. $\mathrm{Zu}$ den Kosten für den deutschen Steuerzahler siehe Hellwig 2018b. 
Jedoch ist die Vorstellung, dass die Notkredite mit dieser Zielsetzung vergeben wurden, nicht plausibel. Die irische Regierung hätte es durchaus vorgezogen, die ungesicherten Gläubiger an den Verlusten der irischen Banken zu beteiligen, und stellte 2010, nach dem Auslaufen der 2008 gegebenen Garantien, entsprechende Überlegungen an. Das damals ins Auge gefasste Vorgehen hätte weitere Erhöhungen der Notkredite 2011 und 2012 überflüssig gemacht. Jedoch veranlasste eine Intervention der EZB die irische Regierung, von diesen Überlegungen Abstand zu nehmen. Der Präsident der EZB hatte gedroht, andernfalls die Genehmigung für alle Notkredite, auch die schon vergebenen, zu widerrufen, was das irische Banksystem und die irische Wirtschaft in ein Chaos gestürzt hätte. ${ }^{91}$ Kein Wunder, dass die Mitarbeiter der EZB in Dublin als „The Germans" verschrien waren! Die Vorstellung, dass die Notkredite ein Mittel zur Ausbeutung Deutschlands waren, ist aus irischer Sicht absurd.

\subsection{Geldpolitik und Target-Salden in der Finanzkrise und der Eurokrise}

Sinn $(2018 a, b)$ gebraucht die Formulierung „Selbstbedienung mit der Notenpresse“ nicht nur für eigenständige Aktivitäten der nationalen Zentralbanken nach Art. 14 Abs. 4 der Satzung, sondern auch für Beschlüsse, die der EZB-Rat für die Eurozone als Ganze getroffen hat. Er nennt insbesondere den im Herbst 2008 beschlossenen Übergang zu einem Regime der Vollzuteilung, unter dem alle von Geschäftsbanken zu den vom ESZB vorgegebenen Konditionen (Zinssätze, Sicherheitenstellung) gestellten Kreditanträge gewährt werden, sowie die ebenfalls im Herbst 2008 erfolgte Senkung der Refinanzierungszinssätze und die Senkung der Qualitätsanforderungen an die von den Banken beizubringenden Sicherheiten.

Die durch die Formulierung „Selbstbedienung mit der Notenpresse“ suggerierte Eigenmächtigkeit der nationalen Zentralbanken liegt bei diesen Beschlüssen allerdings nicht vor. Für die Legitimität solcher Maßnahmen macht es einen Unterschied, ob sie von einer oder mehreren nationalen Zentralbanken eigenmächtig durchgeführt werden oder ob sie von dem dafür zuständigen Gremium beschlossen wurden. Dies gilt auch dann, wenn man vermutet, dass das Gremium bestimmte Interessen besonders im Auge hatte.

Die vorgetragenen Behauptungen über die Motive für die Entscheidungen des EZB-Rats beruhen weitgehend auf

91 Whelan 2016. unbelegten Unterstellungen, so etwa, wenn Sinn schreibt, die Beschlüsse von 2008 hätten dazu dienen sollen, die „Finanzierung der (griechischen) Banken mit frisch geschaffenem Geld der griechischen Notenbank zu sichern“ (Sinn 2015d, S. 3). Dass diese Beschlüsse auf dem Höhepunkt der Lehman-Krise gefasst wurden, wird verdrängt, auch dass der Präsident der Deutschen Bundesbank diese Beschlüsse mittrug. Und dass ein guter Teil der Unterstützung mit frisch geschaffenem Geld der Federal Reserve erfolgte, wird nicht wahrgenommen.

Der durch den Lehman-Konkurs ausgelöste Kollaps der Inter-Banken-Märkte hatte die Geldmarktrefinanzierung vieler Banken wegbrechen lassen, mit dramatischen Folgen für das gesamte Finanzsystem. ${ }^{92}$ Die massiven Liquiditätshilfen der Zentralbanken sollten das System stabilisieren, die Refinanzierung der Banken sichern, so dass es nicht zu weiteren Zahlungsausfällen käme und die Banken selbst nicht weiter Vermögenswerte zu verkaufen suchten, nur um zu Bargeld zu kommen. Die Zentralbanken traten als Lender of last resort auf, ganz im Sinne von Bagehot (1873). Mit Hilfe von Währungsswaps gaben sie sich auch die Möglichkeit, die Liquidität der eigenen Banken in anderen Währungen zu unterstützen. ${ }^{93}$ Vor allem die Swap-Operationen, die den Banken des Euroraums mit Dollars aushalfen, trugen zu den hohen Target-Forderungen der EZB in dieser Phase bei. Zu den unmittelbaren Nutznießern gehörten vor allem deutsche Banken, Commerzbank und Hypo Real Estate, in den Vereinigten Staaten auch Deutsche Bank und Dresdner Bank.

Die Formulierung „Selbstbedienung mit der Notenpresse" behandelt die Geldschöpfung im ESZB als exogen, als Ergebnis eigenmächtiger Maßnahmen des EZB-Rats der einzelnen Zentralbanken. Tatsächlich war die Geldschöpfung in doppelter Hinsicht endogen: Zum einen wurde der Vollzuteilungsbeschluss gefasst, weil die Inter-BankenMärkte zusammengebrochen waren. Zum anderen hatte die Vollzuteilungspolitik zur Folge, dass Zentralbankgeld dort geschaffen wurde, wo die Geschäftsbanken es nachfragten.

92 Für eine ausführliche Diskussion der Krisenmechanismen siehe Admati und Hellwig 2013, Kapitel 5.

93 Nach Tooze (2018) gab es zu dieser Zeit einen fatalen Kontrast zwischen dem Verhalten der amerikanischen Federal Reserve und dem Verhalten der EZB. Während die Federal Reserve ausländischen Zentralbanken großzügig Dollars zu Verfügung stellte, war die EZB nicht bereit, Zentralbanken außerhalb des Euroraums auf ähnliche Weise zu unterstützen. Für die baltischen Länder gab es solche Unterstützung durch die schwedische Riksbank, Polen und Ungarn blieben auf sich gestellt. Nach Tooze gingen die Erfolge national-populistischer Parteien bei den folgenden Wahlen in diesen Ländern in hohem Maße auf diese Erfahrung zurück. 
Wenn Sinn und Wollmershäuser (2012) schreiben, mit diesem Beschluss hätte das ESZB den privaten Kapitalverkehr verdrängt, so verwechseln sie Ursache und Wirkung. Die Fiktion, dass ohne die Vollzuteilungspolitik des ESZB die Peripheriebanken weiterhin Kredite von deutschen Banken bekommen hätten, ist nicht vereinbar mit der Tatsache, dass die Inter-Banken-Märkte im Herbst 2008 zusammengebrochen waren. Weil diese Märkte zusammengebrochen waren, war zu befürchten, dass das bisher praktizierte Verfahren der Versteigerung einer vorgegebenen Menge an Refinanzierungskrediten nicht geeignet war, die Liquiditätsklemme etlicher Banken nach dem Lehman-Konkurs zu beheben. Der Verzicht auf eine Mengenvorgabe und ein Versteigerungsverfahren entsprach der Einschätzung, dass bei extremer Unsicherheit über die Situation der Banken und bei Funktionsunfähigkeit der InterBanken-Märkte eine reine Preissteuerung vorzuziehen ist. $^{94}$

In der Eurokrise wirkte sich die Vollzuteilungspolitik asymmetrisch aus, mit einem deutlichen Anstieg der Target-Forderungen der Bundesbank und der Target-Verbindlichkeiten der Krisenländer. Diese Asymmetrie der Wirkungen war teils eine Folge von Asymmetrien in der vorangegangenen Entwicklung, teils eine Folge der Eurokrise selbst. Vor den Krisen hatten deutsche Banken auf den Geldmärkten der Eurozone als Gläubiger fungiert, irische, spanische und griechische Banken als Schuldner. Der Kollaps der Inter-Banken-Märkte bedeutete auch einen Rückzug der deutschen Banken aus diesen Geschäften, teils weil sie um die eigene Refinanzierung fürchteten, teils weil sie das Vertrauen in die Schuldner verloren hatten. Dieser Rückzug war aber nur möglich, weil die Schuldner eine Ersatzrefinanzierung von ihren jeweiligen Zentralbanken bekamen. Ohne die Liquiditätshilfen des ESZB wären die Geldmarktschuldner zahlungsunfähig geworden, und die Geldmarktgläubiger wären selbst in Schwierigkeiten gekommen.

\subsection{Refinanzierungskredite in der Krise - cui bono?}

Sinn (2018a und b, S. 29) schreibt zu dieser Entwicklung: „Nach dem Lehman-Crash verweigerten sich die Kapitalmärkte einer Fortsetzung der Finanzierung der Leistungsbilanzdefizite der südeuropäischen Länder und Irlands. Die ausländischen Anleger wollten zudem das bereits verliehene Geld sobald wie möglich zurückhaben und weiger-

94 Dazu siehe Poole 1970 sowie Weitzman 1974. ten sich, Ersatzkredite zu gewähren. [...] Die oben beschriebene Selbsthilfe mit der Druckerpresse ermöglichte es den Volkswirtschaften, die öffentlichen Überziehungskredite in Anspruch zu nehmen, die durch die Target-Salden gemessen werden.“

Diese Interpretation weist verschiedene Probleme auf: Zum einen sind Volkswirtschaften keine Akteure, und die Kapitalmarktinvestoren finanzieren nicht Leistungsbilanzdefizite, sondern die Aktivitäten der jeweiligen Kapitalnehmer, mit denen sie Verträge abschließen. Zum anderen betraf der Vorgang in der Lehman-Krise nicht nur die südeuropäischen Länder und Irland, sondern die Banken in aller Welt, auch in Ländern wie Deutschland, die einen Leistungsbilanzüberschuss aufwiesen. Zum dritten lenkt die Betonung der Strömungsgröße Leistungsbilanz davon ab, dass es in der Krise nach dem Lehman-Konkurs um Bestandsgrößen ging, da die Banken in hohem Maße Geldmarktkredite zur Finanzierung langfristiger und illiquider Anlagen verwandt hatten, die sie bei Wegbrechen der Refinanzierung nicht ohne größere Verluste kurzfristig realisieren konnten. Die Betonung der Leistungsbilanzdefizite passt allerdings zur Geschichte von der Währungsunion als Instrument zur Ausbeutung „Deutschlands“ durch die Peripherieländer.

Bei näherem Zusehen merkt man aber, dass es hier nicht eine, sondern zwei Geschichten gibt - die Geschichte, dass die Peripherieländer jahrelang Leistungsbilanzdefizite aufwiesen, auf Pump lebten, und die Geschichte, dass die Selbstbedienung mit der Notenpresse dieses Leben auf Pump ermöglichte. Die beiden Geschichten passen insofern nicht gut zusammen, als die Leistungsbilanzdefizite der Peripherieländer schon in den Jahren vor 2008 und dem Aktionismus der Zentralbanken sehr hoch waren. Damals gab es hohe Kapitalexporte privater Investoren aus Deutschland in die Peripherieländer. Die Interventionen der Zentralbanken gaben diesen Investoren in der Krise die Möglichkeit, sich ohne größeren Schaden von ihren Engagements in den Peripherieländern zu lösen.

Die rhetorischen Figuren von den „Target-Krediten“ und von „Deutschland“ als Kreditgeber und „Italien“ oder „Griechenland“ als Kreditnehmer übertünchen die Diskrepanz zwischen den beiden Geschichten. Da werden die privaten Investoren der früheren Phase und die Bundesbank unter dem Etikett „Deutschland“ zusammengefasst, und die mit einer Rückzahlung von Krediten deutscher Geschäftsbanken durch griechische Banken verbundene Erhöhung der Target-Salden der Bundesbank erscheint als „Umschuldung“. Dass auf deutscher ebenso wie auf griechischer oder italienischer Seite jeweils verschiedene Akteure involviert sind, wird verdrängt. Auch die Interessen- 
konflikte und Anreizprobleme innerhalb der einzelnen Länder geraten aus dem Blickfeld.

Zum Entstehen der Leistungsbilanzdefizite der Peripherieländer hatten Fuest et al. (2010) sowie Sinn (2012, 2014) noch erklärt, dass die Länder der Eurozone in den Jahren vor der Finanzkrise unterschiedliche Realzinsen aufwiesen. Nach Schaffung der Währungsunion hatten die Nominalzinsen sich angeglichen, aber bei fragmentierten Gütermärkten waren die Inflationsraten verschieden und daher auch die Realzinsen. Bei einem Nominalzins von 5 Prozent und bei Inflationsraten von 5 Prozent in Irland oder Spanien und 1,7 Prozent in Deutschland war Anfang der 2000er Jahre die Nachfrage nach Krediten in Irland und Spanien relativ hoch, in Deutschland dagegen relativ niedrig; es kam zu erheblichen Kapitalexporten aus Deutschland in die Peripherieländer. Die Leistungsbilanzsalden spiegelten die Kapitalverkehrssalden.

Das eigentliche Versagen lag demnach im Fehlen von Marktdisziplin bei der anfänglichen Kreditvergabe, in der Vernachlässigung der Schuldnerrisiken durch die privaten Investoren. ${ }^{95}$ Bei angemessener Berücksichtigung der Schuldnerrisiken hätten die Nominalzinsen sich nicht völlig angeglichen, und die Kapitalströme wären kleiner ausgefallen. So nährten die Kapitalströme Immobilienblasen, und diese endeten in Immobilienkrisen, Bankenkrisen und Staatsschuldenkrisen. ${ }^{96}$

Ob die Gläubiger die Risiken nicht erkannten oder ob sie sich einfach darauf verließen, dass der Staat ihnen schon helfen würde - so oder so haben hier zentrale Steuerungsmechanismen des Finanzsystems versagt, dies übrigens nicht nur bezüglich der Inter-Banken-Kredite und Staatsanleihen im Euroraum, sondern auch bezüglich USamerikanischer Verbriefungen und Schiffsfinanzierungen. ${ }^{97}$ Die Fehlentwicklung wurde auch durch die Politik der Regierung gefördert, die anstrebte, aus Deutschland einen „AAA-Hub“ für Pfandbrieffinanzierungen zu machen und aus deutschen Pfandbriefbanken (HRE, Eurohypo, WestImmo) europäische Champions. ${ }^{98}$

95 Für frühzeitige Hinweise siehe Bernoth et al. 2004/2012, Hellwig 2007.

96 Besonders ausgeprägt waren die Immobilienblasen in Irland und Spanien. Aber auch Griechenland und Italien sind hier zu nennen. In Deutschland wird zumeist die Finanzpolitik dieser Länder als Problem ausgemacht. Dabei war der Anstieg der staatlichen Verschuldung relativ zum Bruttosozialprodukt in Griechenland in den Jahren 2000/07 niedriger als in Deutschland, in Italien sogar negativ. In Griechenland nahm vor allem die Verschuldung des Finanzsektors zu, wie in Irland und Spanien. Siehe Tooze 2018, S. 108.

$97 \mathrm{Zu}$ den Mechanismen des Versagens siehe Hellwig 2009.

98 Zum Versagen von Politik und Aufsicht siehe Hellwig 2018 b sowie Thiemann 2018.
Die Stützungsmaßnahmen der Staaten und der Zentralbanken in der Krise bewahrten die Finanzinstitute vor den Folgen ihres Fehlverhaltens. In diesem Ausschalten normaler marktwirtschaftlicher Haftungsmechanismen liegt das eigentliche Problem dieser Maßnahmen. Die Stützungsmaßnahmen waren vermutlich notwendig, um ganz im Sinne von Bagehots Lender of last resort noch größere Schäden von den Finanzsystemen und den Volkswirtschaften insgesamt abzuwenden. Gleichwohl ist es anstößig, dass diejenigen, deren Fehlverhalten maßgeblich zur Krise beigetragen hatte, durch staatliche Hilfe in der Krise vor den Folgen dieses Fehlverhaltens geschützt wurden.

Diese Aussage betrifft gerade auch die deutschen Banken. Von den Banken der Peripherieländer, die in den Jahren vor der Krise allzu leichtsinnig Kredite aufgenommen hatten, sind in den Jahren 2010 bis 2014 viele in Sanierungs- und Abwicklungsverfahren genommen worden, mit erheblichen Folgen für Manager und Aktionäre. In diesen Verfahren bewahrten Staatshilfen die Gläubiger vor Verlusten, darunter auch die deutschen Banken, deren Kredite an irische und spanische Banken die Finanzierung der dortigen Immobilienblasen ermöglicht hatten. Die deutschen Banken profitierten also nicht nur von der direkten Unterstützung durch den deutschen Steuerzahler ab 2008 (mit Kosten für letzteren von über 70 Milliarden Euro), sondern auch von der Unterstützung ihrer Schuldner durch andere Staaten. ${ }^{99}$

Die Geschichte, „Deutschland“ habe den „Volkswirtschaften“ der Peripherieländer ein Leben auf Pump ermöglicht, zunächst durch private Kredite und dann, nach einer „Umschuldung“, durch öffentliche Kredite, verdrängt das Versagen der deutschen Finanzinstitute im Vorfeld der Krise, auch die zugrundeliegenden Interessenkonflikte und Governance-Probleme im Verhältnis zwischen diesen Finanzinstituten und dem Gemeinwesen. Diese Geschichte verdrängt auch den Tatbestand, dass die öffentliche Unterstützung dieser Finanzinstitute zu guten Teilen zu Lasten der Staatsfinanzen in den Peripherieländern ging, insbesondere in Irland und Spanien.

In dieser Geschichte spielt die Figur des „Target-Kredits“ eine zentrale Rolle. Bei den Liquiditätshilfen des ESZB für die Geschäftsbanken findet die eigentliche Kreditvergabe statt, wenn eine Zentralbank einer Geschäftsbank einen Refinanzierungskredit gibt, mit dem diese die bisherige Refinanzierung über den Inter-Banken-Markt ersetzt. Das wäre zum Beispiel ein im Rahmen der Vollzuteilung

99 Ohne die Unterstützung des amerikanischen Versicherungskonzerns AIG durch die Federal Reserve wäre vermutlich auch ein Großteil der Milliarden an Derivatepositionen der Deutschen Bank bei diesem Konzern ausgefallen. 
gewährter Refinanzierungskredit der Banca d'Italia an eine italienische Bank. „Deutschland“ hat mit diesem Kredit eigentlich nichts zu tun. „Deutschland“ hat mit dem Gesamtvorgang nur insofern zu tun, als die Verwendung der Mittel zur Ablösung beispielsweise eines Kredits einer deutschen Bank durch die italienische Bank eine Überweisung nach Deutschland erfordert. Diese Überweisung verändert die Target-Salden, erhöht die Target-Verbindlichkeiten der Banca d'Italia und die Target-Forderungen der Bundesbank. Die Interpretation dieser Veränderung als „Kredit“ bietet die Grundlage für die Geschichte, dass „Deutschland“ „Italien“ ein Leben auf Pump ermögliche. Das Problem des Umgangs des ESZB mit den Geschäftsbanken in der Krise wird umdefiniert als Problem des Umgangs von „Deutschland“ mit „Italien“. Die Geschichte fällt in sich zusammen, sobald man berücksichtigt, dass die Banca d'Italia bei dem Refinanzierungskredit an die italienische Geschäftsbank nicht auf eigene Rechnung handelte, sondern auf Rechnung des ESZB, und dass die Target-Salden keinerlei Ansprüche der beteiligten nationalen Zentralbanken untereinander oder gegen die EZB begründen.

Diese Überlegungen gelten auch für die Re-Fragmentierung der Staatsanleihenmärkte in der Eurokrise. In Abschnitt 4.1 hatte ich erläutert, dass in den Jahren 2010 bis 2012 die Banken der von der Eurokrise nicht betroffenen Länder massive Verkäufe von Staatsanleihen der Krisenländer vornahmen. Die Käufer waren Geschäftsbanken der Krisenländer, das ESZB unter dem 2010 geschaffenen Securities Markets Programme und nationale Zentralbanken mit Wertpapierkäufen auf eigene Rechnung (siehe die Abschnitte 3.3 und 4.4). ${ }^{100}$ Soweit die Staatsanleihen von Geschäftsbanken gekauft wurden, dürfte das ESZB indirekt beteiligt gewesen sein, denn die gekauften Staatsanleihen konnten von den Geschäftsbanken als Sicherheiten für Refinanzierungskredite des ESZB eingesetzt werden.

Auch hier trug das Engagement der Zentralbanken dazu bei, die Geschäftsbanken der Länder, die nicht von der Krise betroffen waren, vor den Folgen vergangener Nachlässigkeiten zu bewahren. In den Jahren vor der Krise hatten sie Staatsanleihen gekauft, obwohl die Ertragsraten keine Prämien für Kreditrisiken enthielten. Dabei war aus den Rechtsnormen völlig klar, dass, anders als bei einer Regierung mit Verfügungsgewalt über die Notenpresse, die Möglichkeit einer Zahlungsunfähigkeit eines Mitgliedstaa-

100 So stiegen die ANFA-Positionen der Banca d'Italia allein im Krisenjahr 2011 um mehr als 6 Milliarden Euro an, nicht ganz das Verkaufsvolumen der Deutschen Bank in diesem Jahr. tes der Eurozone nicht auszuschließen war. Diese Möglichkeit wurde ernsthaft erst bedacht, als das Kommuniqué von Deauville im Oktober 2010 von einer Verlustbeteiligung der privaten Gläubiger („Private sector involvement“) sprach und die Finanzminister der Eurozone im März und Juli 2011 einen Schuldenschnitt für Griechenland ankündigten bzw. beschlossen. Die „Erkenntnis“, dass Staatsschuldtitel in der Eurozone ein Kreditrisiko mit sich bringen, veranlasste Banken und andere Investoren, ihre Positionen in diesen Titeln zu reduzieren. Ohne die Interventionen des ESZB bzw. der nationalen Zentralbanken wären die Preise dieser Titel noch drastischer gesunken, und die Verkäufer hätten noch höhere Verluste verbuchen müssen.

Das eigentliche Problem der Zentralbankinterventionen liegt wieder darin, dass die Finanzakteure vor den Folgen ihrer Fehler bewahrt wurden. Die Interventionen mögen notwendig gewesen sein, um Schlimmeres zu verhüten, aber die Anreizwirkungen eines Systems, in dem die Finanzakteure sich auf die Hilfe der Zentralbanken verlassen können, sind gleichwohl bedenklich. ${ }^{101}$ Die Interpretation des Vorgangs als „Umschuldung“ eines Kredits von „Deutschland“ an zum Beispiel „Italien“ wird dem Sachverhalt nicht gerecht und ist aus denselben Gründen zu kritisieren wie die entsprechende Uminterpretation des Ersatzes von grenzüberschreitenden Inter-Banken-Krediten durch Refinanzierungskredite des ESZB an die Geschäftsbanken.

\section{7 „Kapitalflucht“}

In der Eurokrise kam es, wie oben erwähnt, auch zu erheblichen Abzügen von Einlagen aus den Banken der Krisenländer. So gingen die Einlagen inländischer Kunden bei griechischen Banken zurück von 245 Milliarden Euro Ende 2009 auf 222 Milliarden Euro Ende 2010, 182 Milliarden Ende 2011, zwischen 170 und 180 Milliarden jeweils Ende 2012, 2013 und 2014 und sanken dann 2015 noch einmal weiter auf 129 Milliarden; in dieser Größenordnung sind sie bis Anfang 2018 geblieben. Ein Teil der abgezogenen Mittel ging in Bargeld, der weitaus größere Teil zu Finanzinstituten anderer Länder. In anderen Krisenländern war die Entwicklung weniger dramatisch, aber auch in Spanien und Italien gab es erhebliche Einlagenabzüge. In allen Ländern ersetzten Kredite der Zentralbanken die Einlagenfinanzierung der Geschäftsbanken, zum größeren Teil normale Refinanzierungskredite unter dem Vollzuteilungsbeschluss, zu kleineren Teilen Notkredite als Aktio-

101 Farhi und Tirole 2012. 
nen der nationalen Zentralbanken nach Art. 14 Abs. 4 der Satzung (siehe die Abschnitte 3.3. und 4.4). Soweit die Mittel in andere Länder überwiesen wurden, hatte das entsprechende Auswirkungen auf die Target-Salden.

Bei Sinn (2018a,b) ist diese Entwicklung ein Teil der Geschichte von Deutschland als Selbstbedienungsladen, in dem man nach Belieben anschreiben lassen kann, ermöglicht durch die „Target-Kredite“ Deutschlands an die Krisenländer und die Selbstbedienung dieser Länder mit der Notenpresse. Die Wertpapierankäufe des ESZB seit 2015 hätten die Finanzierungsmöglichkeiten der Krisenländer noch weiter begünstigt und deren Bewohnern und anderen Anlegern - die Möglichkeit gegeben, deutsche Unternehmen und deutsche Immobilien zu Preisen unter ihren tatsächlichen Werten zu kaufen.

Auch hier wird die Gegenüberstellung von „Deutschland“ und den „südeuropäischen Ländern“ dem Sachverhalt nicht gerecht. Wenn ein Investor aus Griechenland eine Immobilie in Frankfurt kauft, so freut sich der Verkäufer. Wenn Sinn schreibt, der Verkäufer bekomme doch nur eine Forderung gegen die Bundesbank und diese habe als Gegenposition nur wertlose Target-Forderungen in ihrer Bilanz, so muss er sich entgegenhalten lassen, dass erstens das Geld, das der Verkäufer bekommt, keine Forderung gegen die Bundesbank ist und zweitens der Verkäufer selbst durch seine Bereitschaft zum Verkauf zu erkennen gibt, dass er das Geld, das er bekommt, als angemessene Bezahlung betrachtet. Viele Beiträge zu dieser Diskussion lassen eine gewisse „Betonillusion“ erkennen: Weil Beton massiver ist als Papier, muss der Realwert einer Immobilie größer sein als der Realwert eines Haufens Banknoten (oder der Realwert der Forderung auf Auszahlung solcher Papierzettel). Für den Gebrauchswert trifft das vermutlich $\mathrm{zu}$, denn dieser ist bei den Banknoten praktisch null. Bei Papiergeld kommt es aber auf den Tauschwert an, und dieser ist positiv. Im gegebenen Zusammenhang gibt es bisher auch kein Indiz dafür, dass die Verkäufer der Immobilien an Geldillusion leiden.

Im Rahmen der Europäischen Union wäre es auch rechtswidrig, wenn man versuchte, den Bewohnern oder Bürgern anderer Mitgliedstaaten den Erwerb von Immobilien oder Unternehmen zu erschweren. ${ }^{102}$ Im europäischen Binnenmarkt hat jeder Grieche und jeder Italiener das Recht, sein Vermögen nach Deutschland zu bringen und hier nach eigenem Gutdünken zu verwenden, auch zum Kauf von Immobilien und anderen Vermögenswerten ein-

102 Die Rechtsprechung des Europäischen Gerichtshofs zu Unternehmenserwerben ist in diesem Punkt außerordentlich streng. Siehe Hellwig 2008. zusetzen. Das Anprangern solcher Aktionen als ein Aufkaufen Deutschlands, das verhindert werden muss, läuft letztlich auf einen Aufruf zur Änderung des europäischen Rechts oder gar zum Rechtsbruch hinaus.

Gewiss gibt es Personen und Institutionen in Deutschland, die durch die hier zur Diskussion stehenden Transaktionen geschädigt werden. $\mathrm{Zu}$ nennen sind vor allem die, die bei der betreffenden Immobilie nicht zum Zuge kommen, weil der ausländische Investor mehr bietet. Auch potentielle Mieter werden möglicherweise schlechter gestellt, weil der Käufer die Immobilie dem Mietmarkt entzieht. Derartige Wirkungen gibt es aber bei allen Marktöffnungen. Sie sind für den Ökonomen kein Grund, von solchen Marktöffnungen Abstand zu nehmen.

An dieser Stelle mag eingewandt werden, aus den Binnenmarktregeln könne man doch nicht den Anspruch ableiten, dass man die Einlagen, die man bei einer griechischen oder italienischen Bank hat, dort abzieht und Eins-zu-Eins in Einlagen bei einer deutschen Bank umwandelt, die man dann zum Kauf einer Immobilie in Frankfurt verwendet. Der Einwand ist richtig, geht aber weniger weit als es zunächst den Anschein haben mag. Wir haben ja nicht nur den Binnenmarkt, sondern auch die Währungsunion. In der Währungsunion gibt es keinen Unterschied zwischen griechischen Euro und deutschen Euro. Es gibt keinen Anspruch auf ein Zahlungssystem, das so reibungslos funktioniert, wie das bei Target der Fall ist, aber, wie ich in Abschnitt 4.3 ausgeführt habe, könnte es Substitute für das Target-System geben, die letztlich dieselben Wirkungen hätten. Anders formuliert: Die Warnung, das Target-System lasse zu, dass deutsche Immobilien zu billig an die Bewohner anderer Mitgliedstaaten der Währungsunion verkauft werden, stellt entweder den Binnenmarkt oder die Währungsunion in Frage, versteckt das aber hinter der Kritik an „Target-Krediten“ und an tatsächlichem oder vermeintlichem Fehlverhalten bestimmter Zentralbanken.

Auch der Ausdruck „Selbstbedienung“ ist wieder problematisch. Die Einleger in den Krisenländern haben ihre Mittel nicht deshalb dort abgezogen, weil sie Deutschland leer kaufen wollten, sondern weil sie ihren Regierungen und ihren Banken nicht trauten. Aufgrund der Budgetprobleme ihrer Regierungen mussten sie mit stärkeren Zugriffen des Fiskus rechnen. In Spanien 2012 und Griechenland 2015 war auch von einem möglichen Austritt aus der Währungsunion die Rede; ein solcher Austritt hätte mit großer Wahrscheinlichkeit zu einer Abwertung der auf heimische Währung lautenden Rechtstitel, einschließlich der Einlagen, geführt. In Zypern 2012 und in Italien seit 2016 stand bzw. steht auch die Befürchtung im Raum, dass große Teile des Banksystems insolvent sein könnten. 
Man könnte die Vorgänge auch so interpretieren, dass Frankfurt als Finanzplatz im Wettbewerb mit Athen, Rom oder Madrid steht und zumindest bei den hier zur Diskussion stehenden Anlegern erfolgreich war. Eigentlich erfreulich! Und eigentlich ein Beispiel für die Disziplinierung von Banken und Staaten durch Wettbewerb im Binnenmarkt!?

Die eigentlichen Probleme liegen nicht im Transfer der Mittel aus den Krisenländern nach Deutschland und den dabei entstehenden Target-Salden, sondern in der Dauerhaftigkeit der Refinanzierung der Geschäftsbanken der Krisenländer durch das ESZB. Das Konzept des Lender of last resort ist für Liquiditätskrisen entwickelt worden, die man sich als relativ schnell vorübergehende Paniken vorstellte. Die „Liquiditätskrisen“ der Geschäftsbanken in den Krisenländern sind aber nicht schnell vorübergegangen. Als die Krisen und die Einlagenabzüge begannen, saßen die Geschäftsbanken auf großen Beständen an Krediten, die weiter finanziert werden mussten, wozu die Refinanzierungskredite des ESZB und der nationalen Notenbanken sorgten. Seither sind Jahre vergangen, in denen die Einlagen nicht wieder zurückgekommen sind und die Kreditportefeuilles nur langsam zurückgefahren wurden, das heißt, wir haben in einigen Ländern Banksysteme, die für erhebliche Teile ihrer Refinanzierung auf das ESZB angewiesen sind. Die letztlich notwendige Anpassung der Banksysteme an die durch die Krise bestimmten neuen Marktbedingungen ist verzögert worden.

Man kann Verständnis für die Verzögerung haben, wenn man bedenkt, wie ungünstig die makroökonomische Entwicklung in den Krisenländern verlaufen ist und wie wichtig die Rolle der Geschäftsbanken im Geldsystem ist. Etwaige Versuche, die Kreditportefeuilles der Geschäftsbanken schneller an die Entwicklung der Einlagen anzupassen, hätten die Beeinträchtigungen der Wirtschaftstätigkeit noch verstärkt. Jedoch ist problematisch, dass die Sanierung der Banksysteme so sehr hintangestellt wurde.

Diese Kritik hat allerdings nur wenig mit der TargetDiskussion und dem „Selbstbedienungsladen“ Deutschland zu tun. Die Verlagerung von Vermögen aus Athen nach Frankfurt würde die Target-Forderungen der Bundesbank und die Fähigkeit griechischer Anleger, Immobilien in Frankfurt zu kaufen, auch dann erhöhen, wenn die griechischen Geschäftsbanken völlig gesund wären. In einem großen Binnenmarkt mit Wettbewerb verschiedener Finanzplätze sind hohe Target-Forderungen der Zentralbanken, in deren Gebiet die erfolgreichen Finanzplätze liegen, eine automatische Begleiterscheinung des Erfolgs.

\section{Exit-Hysterie}

Der neuerliche Anstieg der Target-Salden ab 2015 hat andere Ursachen als der Anstieg der Target-Salden in der Finanzkrise 2008 und in der Eurokrise 2010-12. Die Geschichte von den Leistungsbilanzsalden der Peripherieländer und dem Leben auf Pump passt nicht dazu, denn mit Ausnahme von Zypern weisen die Krisenländer inzwischen positive Leistungsbilanzsalden auf. Auch der Verweis auf ANFA-Positionen und Notkredite passt nicht, denn diese Positionen sind seit 2015 zurückgegangen. Die Refinanzierungskredite für Banken haben seit 2015 weitgehend stagniert. ${ }^{103}$ Der Anstieg der Target-Salden seit 2015 ist, wie oben ausgeführt, weitgehend dem Umstand zuzuschreiben, dass das Ankaufsprogramm des ESZB auf deutsche Initiative hin so organisiert wurde, dass die nationalen Zentralbanken jeweils die Staatsschuldtitel des eigenen Staates kaufen, und dass die Verkäufer teilweise in anderen Ländern sitzen, vor allem in den Finanzzentren Frankfurt, Luxemburg und Amsterdam. Vermutlich finden auch weiterhin Kapitalexporte aus Krisenländern statt, etwa von italienischen Anlegern, die Zweifel an der Solvenz der dortigen Banken haben, aber diese dürften weniger wichtig sein als die Wertpapierkäufe der Zentralbanken. ${ }^{104}$

Da die alten Geschichten nicht mehr passen, konzentriert die Empörung sich jetzt auf die möglichen Risiken durch Zahlungsausfälle bei den Target-Salden, „vor allem, wenn einzelne oder alle Länder das Eurosystem verlassen“ (Sinn 2018c). Bei Sinn (2018a,b) heißt es dazu: „Verluste drohen zum Beispiel, wenn andere Notenbanken aufgrund der Target-Schulden ihre Zahlungsverpflichtungen im Eurosystem nicht mehr erfüllen können. So könnte sich ein italienischer Staatskonkurs nebst seiner Folgewirkungen auf das Bankensystem wegen der hohen Target-Schulden der Banca d'Italia von fast einer halben Billion Euro [...] in Verlusten von mehreren Hunderten von Milliarden Euro für das restliche Eurosystem niederschlagen, wovon Deutschland dann 31 Prozent zu tragen hätte. Ähnlich wäre es, wenn Italien aus dem Euro austreten und seine Target-Schulden nicht mehr bedienen würde." Und weiter: „Sollte das Eurosystem kollabieren, sitzt der deutsche Teil des Währungsgebiets auf einem Riesenhaufen Zentralbankgeld, der für ihn allein viel zu groß ist und gewaltige Inflationsgefahren birgt. Die Bundesbank müsste

103 Die Ausnahme ist ein Anstieg um 200 Milliarden Euro in einer Woche im Frühjahr 2017, als die Banca d'Italia nach einer Gesetzesänderung italienische Banken mit zusätzlichen Krediten stützte. 104 Siehe Eisenschmidt et al. 2017. 
dann einen Währungsschnitt machen und/oder das Geld wieder einsammeln und verbrennen [...]“" (Sinn 2018c).

Diese Warnungen vermengen wieder betriebswirtschaftliche und volkswirtschaftliche Erwägungen, ferner auch Warnungen zur Geldpolitik mit Warnungen vor den Target-Salden. Im folgenden gehe ich im einzelnen darauf ein.

\subsection{Rechtliche und betriebswirtschaftliche Erwägungen}

Die Vorstellung, dass ,andere Notenbanken aufgrund der Target-Schulden ihre Zahlungsverpflichtungen im Eurosystem nicht mehr erfüllen können“, erscheint als abwegig, wenn man berücksichtigt, dass die Target-Salden keine Zahlungsverpflichtungen begründen und dass eine Zahlungsverpflichtung einer nationalen Zentralbank gegenüber dem Eurosystem genau dann entsteht, wenn die monetären Einkünfte dieser Zentralbank ihren Anteil an den monetären Einkünften des Eurosystems übersteigen. Dazu verweise ich auf die Ausführungen in Teil 3 dieses Aufsatzes, vor allem die Abschnitte 3.2 bis 3.5. ${ }^{105}$

Was würde es bedeuten, wenn Italien aus dem Euro austreten würde? Dass die Banca d'Italia ihre „TargetSchulden" nicht mehr bedienen würde? Aber wie bedient sie diese Verbindlichkeiten denn jetzt? Wie ich oben gezeigt habe, gibt es keine Zahlungsströme, die an die Höhe der Target-Verbindlichkeiten gebunden sind. Die rhetorische Figur vom „Bedienen der Verbindlichkeiten“ passt nicht, wenn die Regeln der Gesamtorganisation, d.h. des ESZB, keine Verpflichtungen an diese „Verbindlichkeiten“ knüpfen.

Für den Fall eines Austritts gibt es keine rechtlichen Vorgaben. Ein Austritt aus der Währungsunion ist in den europäischen Verträgen nicht vorgesehen und daher auch nicht geregelt. Es gibt Stimmen, die meinen, ein solcher Austritt setze einen Austritt aus der Europäischen Union insgesamt voraus. Wie dem auch sei, das Ergebnis eines solchen Schritts hängt von politischen Erwägungen in den Austrittsverhandlungen ab.

Man könnte sich vorstellen, dass die EZB in einer solchen Verhandlung die Target-Verbindlichkeiten der Banca d'Italia als echte Verbindlichkeiten behandelt, die aufgrund des Austritts unmittelbar fällig gestellt werden. Sie könnte versuchen, sich dabei auf übergeordnetes Völkerrecht zu berufen („Pacta sunt servanda“). Dem dürfte

105 Auch die Ausführungen von Fuest und Sinn (2018) sind damit hinfällig. ein Austrittskandidat entgegenhalten, dass die Target-Verbindlichkeiten keine Schuldtitel sind, sondern Positionen in ESZB-internen Kontensystemen, die dazu dienen, die Vorgaben des Vertrags zur Ermittlung und Verteilung der monetären Einkünfte im ESZB zu implementieren. Der Austrittskandidat könnte dazu etliche Äußerungen der EZB zitieren. Da die Verhandlung in einem weitgehend rechtsfreien Raum stattfindet, käme es letztlich auf die Verhandlungsmacht der jeweiligen Parteien an.

Auf den ersten Blick mag es als verführerisch erscheinen, im Zuge eines Austritts Target-Verbindlichkeiten in Höhen von einer halben Billion Euro zu verweigern und aus den Büchern zu streichen. Bedenkt man aber, dass dies Verbindlichkeiten sind, die die Banca d'Italia zumindest derzeit zu nichts verpflichten, so ist zu fragen, warum irgend jemand solche Verbindlichkeiten für so wichtig erachten sollte, dass er darüber die Kosten eines Konflikts auf sich nimmt. Ökonomen unterstellen sonst ja auch, dass rationale Entscheidungsträger sich nicht durch Illusionen leiten lassen, sondern jeweils hinter die Fassade blicken und rationale Erwartungen über die tatsächlichen Zusammenhänge bilden.

Letztlich kommt es auf die Bedeutung des Austritts für die Zahlungsströme an. Unterstellen wir, dass der Austretende eine Einlösung von Target-Verbindlichkeiten einfach verweigert. Dann hätte der Austritt zur Folge, dass die nationale Zentralbank Erträge für sich behalten könnte, die bisher als monetäre Einkünfte dem ESZB zugerechnet wurden. Der Austritt hätte auch zur Folge, dass die betreffende Zentralbank von der Gewinnverteilung des ESZB ausgeschlossen würde. Beides hängt nicht von den TargetSalden ab, sondern vom Vergleich der monetären Einkünfte betreffenden Zentralbank mit dem Anteil dieser Zentralbank an den monetären Einkünften des ESZB.

Dazu eine überschlägige Rechnung für die Banca d'Italia: Die Bilanz der Banca d'Italia wies Ende 2017 als relevante Aktiva Refinanzierungskredite an Geschäftsbanken in Höhe von 252 Milliarden Euro und Wertpapiere in Höhe von 358 Milliarden Euro aus, zusammen 610 Milliarden Euro. In der konsolidierten Bilanz des ESZB insgesamt stehen 748 Milliarden Euro an Refinanzierungskrediten und 2.834 Milliarden Euro an Wertpapieren, zusammen 3.583 Milliarden Euro. Im Falle eines Austritts würde die Banca d'Italia den Anspruch auf 17,6 Prozent der monetären Einkünfte verlieren; ${ }^{106}$ in erster Näherung beläuft sich der Wert dieses Anspruchs auf ca. 630 Milliarden Euro

106 Italien hat einen Anteil von 12,3 Prozent am gezeichneten Kapital der EZB und 17,6 Prozent am eingezahlten Kapital der EZB; letzterer ist für die Gewinnverteilung maßgeblich. 
(17,6 Prozent von 3.583 Milliarden Euro), das ist mehr als die 610 Milliarden Euro an eigenen Positionen, deren Erträge sie dem Eurosystem entziehen würden.

Bei dieser Rechnung ist ausgeklammert, dass bei den Wertpapieren im Besitz der nationalen Zentralbanken etliche Titel auf das seit 2015 verfolgte Public Sector Purchase Programme zurückzuführen sind, die als Aktivitäten nach Art. 14 Abs. 4 der Satzung behandelt werden und nicht in die monetären Einkünfte des ESZB eingehen. Dies gilt gleichermaßen für die Banca d'Italia und für das ESZB insgesamt. Bei der Banca d'Italia dürften diese Titel an die 200 Milliarden Euro ausmachen, beim ESZB insgesamt zwischen 1.000 und 2.000 Milliarden Euro. ${ }^{107}$ Allerdings weisen die von der Banca d'Italia gehaltenen italienischen Staatsanleihen überdurchschnittlich hohe Ertragsraten auf, so dass bei vergleichbaren Buchwerten die Erträge auf diese Titel für die Banca d'Italia höher sein dürften als für andere Zentralbanken. Berücksichtigt man diese Effekte, so dürfte ein Austritt noch weniger als attraktiv erscheinen.

Soweit die Banca d'Italia die Titel von Investoren in anderen Ländern gekauft hat, kommt hinzu, dass die Gegenposition dieser Titel in ihrer eigenen Bilanz aus TargetVerbindlichkeiten besteht. Die Gegenposition der entsprechenden Target-Forderungen bei der Deutschen Bundesbank dagegen besteht aus Bankeinlagen. Die Target-Verbindlichkeiten werden zum Hauptrefinanzierungssatz verzinst, derzeit Null, die Bankeinlagen zum Einlagenzinssatz, derzeit minus 0,4 Prozent. Die bei der Banca d'Italia veranschlagten Finanzierungskosten für diese Titel sind Null, ${ }^{108}$ die bei der Deutschen Bundesbank anfallenden Finanzierungskosten sind negativ, das heißt, die Bundesbank erwirtschaftet positive Einkünfte im Einlagengeschäft, die der Banca d'Italia nicht zur Verfügung stehen. Der Einbezug dieser Einkünfte der Deutschen Bundesbank in die Gewinnverteilung des ESZB lässt einen Austritt eines anderen Landes aus der Währungsunion noch weniger attraktiv erscheinen.

Zum Abschluss dieser Diskussion noch eine Bemerkung zu den Wirkungen des Public Sector Purchase Pro-

107 Die Ankäufe im Rahmen des Public Sector Purchase Programme sind auf die nationalen Zentralbanken entsprechend ihren Kapitalanteilen an der EZB aufgeteilt worden. Ein Betrag von 200 Milliarden bei der Banca d'Italia entspräche demnach einer Position von 1.667 Milliarden beim ESZB insgesamt.

108 Und damit auch gleich dem Zinssatz auf die fiktiven Refinanzierungskredite, die bei der Bestimmung der monetären Einkünfte an die Stelle der aus der Vergemeinschaftung herausgenommenen Staatsanleihen treten. Siehe die Diskussion in den Abschnitten 3.2 und 3.3. gramme: Bei diesem Programm ist nicht nur vorgesehen, dass die nationalen Zentralbanken jeweils die Schuldtitel ihres eigenen Staates kaufen, es ist auch vorgesehen, dass das vom EZB-Rat für das ESZB als ganzes vorgesehene Volumen entsprechend den Kapitalanteilen auf die nationalen Zentralbanken verteilt wird. Diese Vorgabe ist in Deutschland kritisiert worden, weil die Kapitalanteile unter anderem von den Bevölkerungszahlen abhängen und somit die Zentralbank eines Landes mit geringem Bruttoinlandsprodukt pro Kopf der Bevölkerung mehr Staatsanleihen kaufen konnte als bei einer Verteilung nach Bruttoinlandsprodukt. ${ }^{109}$

Die Verteilung nach Kapitalanteil hat aber den Vorteil, dass das Programm bezüglich der Austrittsanreize neutral ist. Wenn wir unterstellen, dass alle Staatsanleihen dieselbe Ertragsrate aufweisen und dass die Refinanzierungskosten aller Zentralbanken gleich sind, so bedeutet ein Ankaufvolumen Q auf Ebene des ESZB, dass die Zentralbank des Landes i Titel im Wert von $\alpha_{i} Q$ kauft und darauf monetäre Einkünfte $\Delta \alpha_{i} Q$ erzielt, wobei $\Delta$ die Nettoertragsrate nach Abzug der Refinanzierungskosten ist. Die monetären Einkünfte des ESZB insgesamt auf diese Titel belaufen sich auf $\Delta Q$, der Anteil der betreffenden Zentralbank daran auf $\Delta \alpha_{i} \mathrm{Q}$, d.h. genau den Betrag, den sie auf die selbst gekauften Titel erzielt, und die Austrittsanreize werden durch die Ankäufe nicht verändert. Die vorher genannten Sondereffekte, Appropriation der Risikoprämien auf die Anleihen des eigenen Staates durch die jeweilige nationale Zentralbank und eine Differenz zwischen den Zinssätzen auf Target-Verbindlichkeiten und auf Geschäftsbankeneinlagen, bewirken, dass das Programm die Austrittsanreize sogar senkt und damit auch die eventuellen negativen Folgen eines Austritts für die verbleibenden Zentralbanken.

Die vorstehenden Erwägungen werfen auch Zweifel auf bezüglich des Vorschlags von Sinn (2012, 2014), die Target-Salden jährlich zu bereinigen, indem man „echte“ Vermögenswerte von den Zentralbanken mit Target-Verbindlichkeiten an die Zentralbanken mit Target-Forderungen überträgt. Würden zum Beispiel die von der Banca d'Italia gehaltenen Staatsanleihen an die Bundesbank übertragen, so erhielte der italienische Fiskus verstärkte Anreize, mit einem Staatskonkurs zu liebäugeln. Unter dem derzeitigen Arrangement ist ein Staatskonkurs unattraktiv, denn die Staatsanleihen werden ganz überwiegend von der Banca d'Italia und von Investoren in Italien, Banken und Wählern, gehalten. Soweit die Staatsanleihen aufgrund des Public Sector Purchase Programme erwor-

109 Heinemann 2017. 
ben wurden, gehen die Zinsen nicht in die monetären Einkünfte des ESZB ein, sondern verbleiben bei der Banca d'Italia und gehen im Zuge der Gewinnausschüttung zurück an den italienischen Fiskus. Eine Kürzung bei diesem Teil des Schuldendienstes würde dem italienischen Staat nichts bringen. Kämen diese Anleihen aber im Zuge der von Sinn vorgeschlagenen Bereinigung der Target-Salden an die Deutsche Bundesbank, so gäbe es für den italienischen Staat einen Anreiz, die Zahlungen zu kürzen, denn von den Zinszahlungen an die Bundesbank kämen im Zuge der Gewinnausschüttung nur zu einem kleinen Teil zurück an den italienischen Staat.

\subsection{Volkswirtschaftliche Erwägungen}

Und die Inflationsrisiken? Sinn (2018c) warnt, dass bei einem Zerfall der Währungsunion die in Deutschland gehaltene Menge an Zentralbankgeld viel zu groß wäre, so dass es „gewaltige Inflationsrisiken“ gäbe. Um dem vorzubeugen, müsste die Bundesbank in erheblichem Umfang Zentralbankgeld vernichten! Und dazu bräuchte sie die Hilfe des Steuerzahlers!

Auch bei dieser Warnung ist es angebracht, genauer hinzusehen. Natürlich birgt die außergewöhnliche Expansion der Zentralbankgeldmenge Inflationsrisiken. Aber die hängen nicht davon ab, ob Italien aus der Währungsunion austritt oder ob es gar zu einem Zerfall der Währungsunion kommt. Die Zentralbankgeldmenge ist seit 2015 im gesamten Euroraum dramatisch gewachsen. In normalen Zeiten hätte man erwartet, dass dadurch eine hohe Inflation entstände, aber die Zeiten sind nicht normal. Ein erheblicher Teil des neu geschaffenen Zentralbankgeldes wird von den Geschäftsbanken als Liquiditätsreserve gehalten und hat keinen Einfluss auf die gesamtwirtschaftliche Nachfrage nach Gütern und Dienstleistungen. Die Inflationsraten sind entgegen allen Warnungen niedrig geblieben.

Die in Deutschland gehaltene Menge an Zentralbankgeld ist jetzt schon außergewöhnlich groß. Ein Austritt Italiens aus der Währungsunion würde diese Geldmenge nicht unmittelbar beeinflussen. Insofern wären die Inflationsrisiken nach dem Austritt eines großen Mitgliedstaates oder gar dem Zerfall der Währungsunion kaum höher als sie es jetzt schon sind. Im übrigen hat Sinn immer wieder betont, die Schöpfung von Geld in den Peripherieländern und der Transfer dieses Geldes nach Deutschland habe die Bundesbank gezwungen, sich bei der eigenen Geldschöpfung zurückzuhalten. Ich bin nicht überzeugt, dass Sinns Konzept der länderspezifischen Geldaggregate in einer Währungsunion wirklich sinnvoll ist, merke aber an, dass nach der Logik dieses Arguments die in Deutschland ge- haltene Menge an Zentralbankgeld schon auf die deutsche Situation zugeschnitten sein müsste.

Im Vorfeld des Austritts eines Landes könnte es zu einer „Kapitalflucht“ aus diesem Land in andere Länder kommen, einer Variante früherer Spekulationen auf Aufoder Abwertungen von Währungen. Dadurch könnte die Zentralbankgeldmenge in Deutschland noch einmal erhöht werden. Die mit einer solchen Spekulationswelle verbundenen Inflationsrisiken wären allerdings gering, denn die Spekulanten würden ihre Mittel repatriieren, sobald das neue Währungsregime etabliert wurde. Die eigentlichen Kosten einer solchen Spekulation dürften darin liegen, dass die Spekulanten im Nachhinein mehr von der neuen Währung bekommen als bei dem von dem betreffenden Staat vorgeschriebenen Konversionskurs. Diese Kosten treffen in erster Linie die Zentralbank und den Fiskus des betreffenden Staates, denn der Schnitt, den sie bei der Konversion von Euro auf eine neue Währung machen, wird verringert.

Und die Verluste der Bundesbank? Sollte ein Land mit hohen Target-Verbindlichkeiten aus der Währungsunion austreten, so erleidet die EZB einen Buchverlust auf diese Bilanzposition; man kann sich vorstellen, dass dieser Buchverlust in Form eines Schnitts auf Target-Forderungen an die nationalen Zentralbanken weitergegeben wird, mithin die Bundesbank auch einen Buchverlust auf ihre Target-Forderungen erleidet.

Was aber ist die ökonomische Bedeutung eines Buchverlusts auf eine Forderung, aus der man keinerlei Erträge zieht? Nach den in Abschnitt 2.3 angestellten Überlegungen ist dieser Buchverlust letztlich irrelevant. Auch eine aus bilanzrechtlichen Erwägungen notwendige Minderung von Ausschüttungen oder sogar Rekapitalisierung hätte aus den oben ausgeführten Gründen keine weiteren Wirkungen. Allerdings könnte man sich auch vorstellen, dass dieser Buchverlust entsprechend der in Abschnitt 2.1 beschriebenen früheren Praxis als „Ausgleichsposten wegen Verlust aus Neubewertung der Target-Position“" in der Bilanz geführt würde, ohne dass das ausgewiesene Eigenkapital herabgesetzt würde. Materiell wäre das nicht von Bedeutung.

Materiell von Bedeutung ist es, wenn ein Austritt eines Landes aus der Währungsunion dazu führt, dass die zu erwartenden Erträge aus den monetären Einkünften des ESZB zurückgehen. Die dabei zur Diskussion stehenden Beträge sind aber nach den Ausführungen im vorstehenden Abschnitt gering.

Materiell von Bedeutung wäre es ebenfalls, wenn das mit der Erhöhung der Zentralbankgeldmenge seit 2015 verbundene Inflationspotential sich irgendwann doch realisieren sollte. Dann müsste das ESZB die Wertpapierkäufe 
rückgängig machen, wenn es das Ziel der Preisstabilität nicht verletzen will. Und dann wäre es durchaus möglich, dass die Verluste aus negativer Geldschöpfung den früheren Geldschöpfungsgewinn übersteigen; wie in Kapitel 2 beschrieben, wäre dies dann der Fall, wenn die Verkaufspreise unter den früheren Kaufpreisen lägen. Dieses Risiko ist aber unabhängig von der Diskussion um die Folgen eines möglichen Austritts eines Landes oder gar eines Zerfalls der Währungsunion. Es hat auch nichts mit den Target-Salden zu tun. Letztlich kommen wir hier wieder zurück zur Grundsatzdiskussion über die Rolle der Geldpolitik in einem Umfeld, in dem eine passive Geldpolitik, zum Beispiel eine Politik konstanten Wachstums der Zentralbankgeldmenge, aufgrund von Verhaltensänderungen bei den Banken und den anderen Teilnehmern der Wirtschaft Risiken für die Preisstabilität birgt.

Es wäre wünschenswert, dass wir diese Diskussion als solche führen, das heißt, dass wir uns dem FriedmanSchwartz-Paradox stellen. Es wäre auch wünschenswert, dass wir über den angemessenen Umgang der Zentralbank mit den Geschäftsbanken und über das Verhältnis von Preisstabilität und Finanzstabilität diskutieren. Die Empörung über die Ausbeutung Deutschlands durch „TargetKredite“ und eine behauptete „Selbstbedienung mit der Notenpresse" verhindert diese Diskussion.

Danksagung: Ich danke den Teilnehmern der Makrorunde von Carl Christian von Weizsäcker für kontroverse Diskussionen sowie Jens Eisenschmidt, Christoph Engel, HansJürgen Hellwig, Klaus-Peter Hellwig und Adalbert Winkler für detaillierte Kommentare.

\section{Literaturverzeichnis}

Acharya, V.V. und S. Steffen (2015), The greatest carry trade ever? Understanding European bank risk, Journal of Financial Economics 115, S. 215-36.

Admati, A. R. und M. Hellwig (2013), The Bankers ‘New Clothes: What's Wrong with Banking and What to Do about It, Princeton, N. J., Princeton University Press,

Bagehot, W. (1873), Lombard Street: A Description of the Money Market, London, Henry S. King \& Co.

Bernoth, K., J. von Hagen und L. Schuknecht (2004/2012), Sovereign risk premia in the European government bond market, $E C B$ Discussion Paper Nr. 369, European Central Bank, Frankfurt, veröffentlicht in: Journal of International Money and Finance 31 (5), S. 975-95.

Bofinger, P. (2018), Sind Target-Salden eine „Druckerpresse“ für Kredite?, Handelsblatt vom 19. August 2018.

Born, K. E. (1967), Die deutsche Bankenkrise 1931, München, Piper.

Brunnermeier, M. K., H. James und J.-P. Landau (2016), The Euro and the Battle of Ideas, Princeton, N. J., Princeton University Press.
Capitelli, R. und P. Buomberger (1990), Zur Geldpolitik der achtziger Jahre: Einige grundsätzliche Überlegungen, Schweizerische Zeitschrift für Volkswirtschaft und Statistik 126 (4), S. 535-51.

Caprio, G. und D. Klingebiel (1996), Bank insolvencies: Cross-country experiences, Policy Research Working Paper 1620, World Bank, Washington, D.C.

Caprio, G. und D. Klingebiel (1997), Bank insolvency: Bad luck, bad policy, or bad banking?, Paper für die Annual World Bank Conference on Development Economics, 25.-26. April 1996.

Coase, R. C. (1972), Durability and Monopoly, Journal of Law and Economics 15, 143-49.

Deutsche Bundesbank (2016), Zur Bedeutung und Wirkung des Agreement on Net Financial Assets (ANFA) für die Implementierung der Geldpolitik, Monatsberichte der Deutschen Bundesbank, März 2016, S. 87-97.

Eichengreen, B. J. (1992), Golden Fetters: The Gold Standard and the Great Depression, 1919-1939. Oxford, Oxford University Press.

Eisenschmidt, J., D. Kedan, M. Schmitz, R. Adalid und P. Papsdorf (2017), The Eurosystem's Asset Purchase Programme and Target balances, ECB Occasional Paper Nr. 196, European Central Bank, Frankfurt.

ESRB (2015), Report on the Regulatory Treatment of Sovereign Exposures, European Systemic Risk Board, Frankfurt.

Farhi, E. und J. Tirole (2012), Collective moral hazard, maturity mismatch, and systemic bailouts, American Economic Review 102, S. 60-93.

Fratzscher, M. (2018), Das Target-System ist für Deutschland und Europa ein Anker der Stabilität, Handelsblatt vom 2. August 2018.

Frenkel, J. A. und Johnson, H. G. (1976), The Monetary Approach to the Balance of Payments, Toronto, University of Toronto Press.

Freytag, A. und G. Schnabl (2017), Monetary policy crisis management as a threat to economic order, Credit and Capital Markets-Kredit und Kapital 50(2), S. 151-69.

Friedman, M. und Schwartz, A. J. (1963), A Monetary History of the United States 1867-1960, Princeton, N. J., Princeton University Press.

Fubini, G. (2018), Salva banche a la tedesca: che pasticcioni!, Corriere della Sera vom 2. Juli 2018.

Franz, W., C. Fuest, M. Hellwig und H.-W. Sinn (2010), Zehn Regeln zur Rettung des Euro, Frankfurter Allgemeine Zeitung vom 18. Juni 2010.

Fuest, C. und H.-W. Sinn (2015), Die Risiken der Notkredite, Handelsblatt vom 10. Juli 2015 und Ökonomenstimme, 13. November 2015.

Fuest, C. und H.-W. Sinn (2016), Non tacemus, Ökonomenstimme, 18. Januar 2016.

Fuest, C. und H.-W. Sinn (2018), Target-Risiken ohne Euro-Austritte, ifo-Schnelldienst 71 (24).

Goldfeld, S. M. (1976), The case of the missing money, Brookings Papers on Economic Activity 3, S. 683-739.

Goodhart, C. A. G. (1988), The evolution of central banks, Cambridge, MA, MIT Press.

Gurley, J. G. und E. S. Shaw (1960), Money in a Theory of Finance, Washington D. C., Brookings.

Hahn, F. H. (1965), On some problems of proving the existence of an equilibrium in a monetary economy, in: The Theory of Interest Rates: Proceedings of a Conference Held by the International Economic Association, London, Macmillan, S. 126-35. 
Hakenes, H. und I. Schnabel (2010), Banks without parachutes: Competitive effects of government bail-out policies, Journal of Financial Stability 6(3), S. 156-68.

Hall, R. E. und R. Reis (2015), Maintaining central-bank solvency under new-style central banking, NBER Working Paper 21173, CEPR Discussion Paper 10741.

Hayek, F. A. (1931), Prices and Production, London, Routledge.

Hayek, F. A. (1976), Denationalization of Money - The Argument Refined, The Institute of Economic Affairs, London.

Heinemann, F. (2017), Die Bedeutung der EZB-Anleihekäufe für die Schuldenfinanzierung der Euro-Staaten, Gutachten, Zentrum für Europäische Wirtschaftsforschung, Mannheim, online verfügbar unter http://ftp.zew.de/pub/zew-docs/gutachten/PSPP_Analyse_Heinemann_2017.pdf

Hellwig, M. F. (1985), What do we know about currency competition?, Zeitschrift für Wirtschafts- und Sozialwissenschaften 105, S. 565-89.

Hellwig, M. F. (1993), The challenge of monetary theory, European Economic Review 37, S. 215-42.

Hellwig, M. F. (2007), Switzerland and Euroland: European Monetary Union, monetary stability and financial stability, in: SNB (Hrsg.), The Swiss National Bank 1907-2007, Zürich, Verlag Neue Zürcher Zeitung, S. 741-80.

Hellwig, M. F. (2008), Zur Problematik staatlicher Beschränkungen der Beteiligung und der Einflussnahme von Investoren bei großen Unternehmen, Zeitschrift für das gesamte Handelsrecht und Wirtschaftsrecht 172, S. 768-87.

Hellwig, M. F. (2009), Systemic risk in the financial sector: An analysis of the subprime-mortgage financial crisis, De Economist 157, S. $129-208$.

Hellwig, M. F. (2014), Yes Virginia, there is a European Banking Union! But it may not make your wishes come true, in: Österreichische Nationalbank (Hrsg.), Towards a European Banking Union: Taking Stock, $42^{\text {nd }}$ Economics Conference 2014, S. $156-81$.

Hellwig, M. F. (2015a), Financial stability, monetary policy, banking supervision, and central banking, in: Monetary Policy in a Changing Landscape: Proceedings of the First ECB Forum on Central Banking, S. 21-54.

Hellwig, M. F. (2015b), Die Zentralbank braucht keinen Gewinn, Der Tagesspiegel vom 21. Februar 2015.

Hellwig, M. F. (2015c), Der Vergleich hinkt, Süddeutsche Zeitung vom 23. Januar 2015.

Hellwig, M. F. (2015d), Richtige und falsche Ängste vor einer expansiven Geldpolitik, Frankfurter Allgemeine Sonntagszeitung vom 8. März 2015.

Hellwig, M. F. (2015e), Financial Stability and Monetary Policy, Preprint 10/2015, Max-Planck-Institut zur Erforschung von Gemeinschaftsgütern, Bonn.

Hellwig, M. F. (2015f), Notstand oder Erpressung?, Handelsblatt vom 3. Juli 2015 und Ökonomenstimme, 7. Juli 2015.

Hellwig, M. F. (2015g), Si tacuissent, Oekonomenstimme, 8. Dezember 2015.

Hellwig, M. F. (2018a), Bargeld, Giralgeld, Vollgeld, Zur Diskussion um das Geldwesen nach der Finanzkrise, in: Deutsche Bundesbank (Hrsg.), 4. Bargeldsymposium der Deutschen Bundesbank, Frankfurt 2018, S. 94-147.

Hellwig, M. F. (2018b), Germany and the Financial Crises since 2007, Vortrag auf der 4. Macroprudential conference der Sveriges Riksbank, Stockholm, online verfügbar unter https://www.riksbank. se/globalassets/media/konferenser/2018/germany-and-financial-crises-2007-2017.pdf.

Hellwig, M. F. (2018c), Wider die deutsche Target-Hysterie, Frankfurter Allgemeine Sonntagszeitung vom 29. Juli 2018.

Herlt, R. (1973), Ist die Bundesbank pleite?, Die Zeit vom 20. Juli 1973. Hoffmann, D. (2015), Die EZB in der Krise: Eine Analyse der wesentlichen Sondermaßnahmen von 2007 bis 2012, Nr. 1 der Schriftenreihe zur Erforschung des Geldwesens, Berlin, Pro BUSINESS GmbH.

Hoffmann, A. und G. Schnabl (2016), The adverse effects of unconventional monetary policy, Cato Journal 36(3), S. 449-84.

Jensen, U. (2017), Zornpolitik, Berlin, Suhrkamp Verlag.

Johnson, H. G. (1969), Inside money, outside money, income, wealth, and welfare in monetary theory, Journal of Money, Credit and Banking 1, S. 30-45.

Krahnen, J. P. (2018), Über Scheinriesen: Was TARGET-Salden tatsächlich bedeuten, unveröffentlichtes Manuskript, Center for Financial Studies, Frankfurt.

Mayer, T. (2018), Ein Wahnsinn namens Target 2, Frankfurter Allgemeine Sonntagszeitung vom 10. Juli 2018.

Mises, L.v. (1912/1924), Theorie des Geldes und der Umlaufmittel, München und Leipzig, Duncker und Humblot, erste Auflage 1912, zweite erweiterte Auflage 1924.

Modigliani, F. und M. H. Miller (1961), Dividend policy, growth and the valuation of shares, Journal of Business 34, S. 411-33.

Myrdal, G. (1932), Das politische Element in der nationalökonomischen Doktrinbildung, Halle, Junker und Dünnhaupt.

Patinkin, D. (1956/1965), Money, Interest and Prices, erste Auflage Englewood Cliffs, N. J., Prentice-Hall, 1956, zweite Auflage New York, Harper and Row, 1965.

Papadia, F. (2015), ANFA or a perfect storm in a cup of tea, Money Matters - Perspectives on Monetary Policy, 17. Dezember 2015, online verfügbar unter http://moneymatters-monetarypolicy. eu/anfa-or-a-perfect-storm-in-a-cup-of-tea/?utm_campaign=twitter\&utm_medium=twitter\&utm_source $=$ twitter.

Pesek, B. P. und T. R. Saving (1967), Money, Wealth and Economic Theory, New York, Macmillan.

Plickert, P. (2015), Heimliches Gelddrucken in Rom und Paris, Frankfurter Allgemeine Zeitung vom 7. Dezember 2015.

Poole, W. (1970), Optimal choice of monetary policy instruments in a simple stochastic macro model, Quarterly Journal of Economics 84, S. 197-216.

Reis, R. (2015), Different types of central bank insolvency and the central role of seignorage, Journal of Monetary Economics 73, S. 20-25.

Rich, G. (1990), Capitelli und Buomberger zur schweizerischen Geldpolitik: Der Wechselkurs als Deus ex machina?, Schweizerische Zeitschrift für Volkswirtschaft und Statistik 126(4), S. 553-65.

Savona, P. (2012), Letter to German and Italian friends: How the European Economic Mechanism works, international Konferenz "Crisi economica e nuovi nazionalismi: la percezione della politica economica tedesca percepita dai partners europei" in Florenz, online verfügbar unter https://cesifin.it/wp-content/ uploads/2017/01/Savona_21_11_15ed.pdf.

Schnabel, I. (2004), The German twin crisis of 1931, Journal of Economic History 64, S. 822-71.

Schnabel, I. (2009), The role of liquidity and implicit guarantees in the German twin crisis of 1931, Journal of International Money and Finance 28, S. 1-25. 
Schnabl, G. (2017), Die EZB unterhöhlt die Grundpfeiler unserer Wirtschaftsordnung, Focus Money vom 4. September 2017.

Sinn, H.-W. (2009), Deflation oder Inflation?, Project Syndicate, 26. Februar 2009, online verfügbar unter https://www.projectsyndicate.org/commentary/forget-inflation/german?barrier=accesspaylog.

Sinn, H.-W. (2012), Die Target-Falle: Gefahren für unser Geld und unsere Kinder, München, Hanser Verlag.

Sinn, H.-W. (2013), Verantwortung der Staaten und Notenbanken in der Eurokrise, ifo-Schnelldienst 66 (Sonderausgabe 12. Juni 2013), ifo-Institut, München.

Sinn, H.-W. (2014), The Euro Trap. On Bursting Bubbles, Budgets, and Beliefs, Oxford, Oxford University Press.

Sinn, H.-W. (2015a), Die Krise in Griechenland - Immer mehr Anleger ziehen Kapital ab - und schaffen es auch nach Deutschland, Süddeutsche Zeitung vom 10. Februar 2015.

Sinn, H.-W. (2015b), Das Eurosystem ist wie eine Aktiengesellschaft, Der Tagesspiegel vom 11. Februar 2015.

Sinn, H.-W. (2015c), Das Geld der EZB fällt nicht wie Manna vom Himmel, Frankfurter Allgemeine Sonntagszeitung vom 16. März 2015.

Sinn, H.-W. (2015d), Die griechische Tragödie, ifo-Schnelldienst 68 (Sonderheft 29. Mai), ifo-Institut, München.

Sinn, H.-W. (2018a), Fast tausend Milliarden Euro, Frankfurter Allgemeine Zeitung vom 17. Juli 2018.

Sinn, H.-W. (2018b), Fast 1000 Milliarden Target-Forderungen der Bundesbank: Was steckt dahinter?, ifo-Schnelldienst 71(14), ifoInstitut, München.

Sinn, H.-W. (2018c), Irreführende Verharmlosung, Frankfurter Allgemeine Sonntagszeitung vom 5. August 2018

Sinn, H.-W. und T. Wollmershäuser (2012), Target loans, current account balances and capital flows: The ECB's rescue facility, International Tax and Public Finance 19, S. 468-508.

Thiemann, M. (2018), The Growth of Shadow Banking: A Comparative Institutional Analysis, Cambridge, U. K., Cambridge University Press.

Tilly, R. H. (1989), Banking institutions in historical and comparative perspective: Germany, Great Britain and the United States in the nineteenth and early twentieth century, Journal of Institutional and Theoretical Economics 145, S. 189-209.

Tobin, J. (1967), Commercial banks as creators of 'money', in: D. Hester and J. Tobin (Hrsg.), Financial Markets and Economic
Activity, Cowles Foundation Monograph 21, New Haven, CT, Yale University Press.

Tooze, A. (2018), Crashed: How a Decade of Financial Crises Changed the World, New York, Viking.

Vaubel, R. (1985), Competing currencies: The case for free entry, Zeitschrift für Wirtschafts- und Sozialwissenschaften 105, S. 54765.

Weidmann, J. (2014), Für die Verluste haften die Steuerzahler, Frankfurter Allgemeine Sonntagszeitung vom 28. Dezember 2014.

Weitzman, M. L. (1974), Prices vs. quantities, Review of Economic Studies 41, S. 477-91.

Whelan, K. (2014), TARGET2 and central bank balance sheets, Economic Policy 29(77), S. 79-137.

Whelan, K. (2016), Banking Union and the ECB as lender of last resort, in: F. Allen, E. Carletti, J. Gray und M. Gulati (Hrsg.), Filling the Gaps in Governance: The Case of Europe, Robert Schuman Centre for Advanced Studies, European University Institute, Florenz.

Whelan, K. (2017), Should we be concerned about Target balances?, Europäisches Parlament, Directorate General for Internal Policies, Policy Department A: Economic and Scientific Policy, Economic and Monetary Affairs, Monetary Dialogue, November 2017, online verfügbar unter http://www.europarl.europa.eu/ cmsdata/131947/MD \%20WHELAN \%20f.rmatted_FINAL \% 20publication.pdf.

Winkler, A. (2015), Argumentation gegen EZB-Staatsanleihenkäufe, Wirtschaftsdienst 95, S. 178-85.

Winkler, A. (2018a), Zehn Jahre nach dem Konkurs von Lehman Brothers. Ordnungspolitische Irrtümer in der Bewertung der EZB-Geldpolitik seit der globalen Finanzkrise, Perspektiven der Wirtschaftspolitik 19, S. 141-72.

Winkler, A. (2018b), Große Summe - großes Problem? Warum die Debatte um die Target-Salden so hitzig ist, Wirtschaftsdienst 98 (10), S. 744-51.

Wissenschaftlicher Beirat (2017), Zur Diskussion um Bargeld und die Null-Zins-Politik der Zentralbank: Gutachten des Wissenschaftlichen Beirats beim Bundesministerium für Wirtschaft und Energie, online verfügbar unter http://www.bmwi.de/Redaktion/DE/ Publikationen/Ministerium/Veroeffentlichung-Wissenschaftlich er-Beirat/gutachten-wissenschaftlicher-beirat-gutachten-dis kussion-um-bargeld.pdf?_blob=publicationFile \&v=8 .

Woodford, M. (2003), Interest and Prices: Foundations of a Theory of Monetary Policy, Princeton, N. J., Princeton University Press. 